\title{
Competitiveness by Design: An Institutionalist Perspective on the Resurgence of a 'Mature' Industry in a High Wage Economy
}

by

\section{Carolyn J. Hatch}

A thesis submitted in conformity with the requirements for the degree of Doctor of Philosophy

Department of Geography and Planning University of Toronto 2013

(C) Copyright by Carolyn J. Hatch 2013 


\title{
Competitiveness by design: an institutionalist perspective on the resurgence of a 'mature' industry in a high wage economy
}

\author{
Doctor of Philosophy 2013 \\ Carolyn J. Hatch \\ Department of Geography and Planning \\ University of Toronto
}

\begin{abstract}
This thesis examines the learning dynamics underpinning the resurgence of Canada's office furniture manufacturing sector, which underwent dramatic growth following its near collapse in the wake of the North American trade liberalization beginning in the late 1980s. It investigates the role that design and quality have played in prompting a move up-market and enhancing the sector's competitiveness. It also focuses on other leaning processes that drive economic growth, looking at attempts to transfer workplace practices from Continental Europe to Canada, as well as the institutional obstacles that shape and constrain these processes. Finally, it examines how furniture firms learn from their customers, and the key role played by market intermediaries such as sales agents, dealers, interior designers, and architects in linking producers with consumers as well as influencing the final furniture product.

The learned behaviour hypothesis that is central to this thesis suggests that globally competitive firms operating in a Canadian institutional context prosper by learning how to produce (i.e. industrial practices and processes) and what to produce (i.e. design-intensive, high quality products) from the above sources that are both internal and external to the manufacturing firm. The scope of research considers the social and
\end{abstract}


organizational practices through which manufacturing knowledge is integrated into innovation processes, as well as their dynamics, spatiality and temporality, the institutional forces that shape the skills, training, tenure and design dimensions of a high performance workplace, and the mechanisms and conditions that mediate the transfer of manufacturing knowledge at a distance. The empirical analysis entails a mixed-methods approach including a survey questionnaire and in-depth interviews with industry experts. The analysis contributes to core debates in economic geography and the social sciences concerning the role of proximity and distance in innovative production, and the structure / agency debate. In summary, it finds that economic growth in the office furniture sector in Canada is dependent upon not only local knowledge networks and flows but also global sources of innovation and competitive advantage. It also advances an agency-centered institutionalist economic geography by showing that institutions interact in complex ways with the decision-making of economic actors to shape local labour dynamics and the behaviour of firms. 


\section{Acknowledgements}

A project of this magnitude is simply not possible without the invaluable support and assistance from institutions and many remarkable individuals. First and foremost, I have benefitted tremendously from the guidance and advice I have received along the way from Meric Gertler, who recognized that a museum curator and specialist in 20th century decorative arts could bring something to the field of economic geography. His encouragement, critical eye, and insightful feedback over the past five years have greatly shaped these pages, the questions I have asked, and the economic geographer I have become.

The financial support of the research undertaken here has come from the Social Sciences and Humanities Research Council of Canada (SSHRC), the Ontario Graduate Scholarship (OGS), the Program on Globalization and Regional Innovation Systems (PROGRIS), and the University of Toronto Department of Geography and Planning, and is gratefully acknowledged. I am especially indebted to Kim Derrick (Office of the Dean), Jessica Finlayson (Geography), Deborah Huntley (PROGRIS) and Marika Maslej (Geography) for their helpful assistance in matters of administration every step of the way.

In addition to the mentoring and support of my advisor, I owe a great deal of gratitude to the members of my dissertation committee: Richard DiFrancesco, Jason Hackworth, Deborah Leslie, Kathi Wilson and David Wolfe, for their careful reading of my work, provocative questions, and insightful comments at critical moments during the process. A special thanks to Debby for her infectious enthusiasm for furniture and design, her many ideas, and thoughtful advice. I would also like to thank the external member of my committee, Susan Christopherson (Cornell), for her valuable suggestions and comments. Her review of my thesis and perspective of its contributions allowed me to see my work with fresh eyes.

I feel exceptionally fortunate to have been a part of a vibrant intellectual community of colleagues and friends at the University of Toronto, particularly early on in my PhD. Thanks to the members of the Cultural Economy Lab and others in the Department of Geography and Planning, in particular Patrick Adler, Josh Akers, Jason Burke, John Paul Catungal, Amy Cervenan, Heather Dorries, Emily Eaton, Kate Geddie, Atle Hague, Brian Hracs, Mia Hunt, Dieter Kogler, Jason Kovacs, Angela Loder, Andrey Petrov, Josee Rekers, Matti Siemiatycki, Greg Spencer, Ben Spigel, Matt Talsma and Tara Vinodrai for the many conversations, formal and informal discussions about our work and that of others, reading groups, and sense of community. I will never forget the vibrant discussions of key debates with Josee, Kate and Atle during our Economic Geography Reading Group 'meetings' on my rooftop patio. I am also grateful for close friendships with Kate and Josee, who have taught me much about my own way of thinking, as I have learned from theirs. We have shared many moments of struggle and celebration, and more recently have ventured into collaborative work together.

I also appreciate the assistance of Angela Loder and Tara Vinodrai who helped me to develop the survey instrument and its online interface, Jennifer Shiller for all her hard work in assisting me to administer the survey, and Sango Otieno at the Statistical Consulting Center (Grand Valley State University) for the many hours he generously devoted to helping me with the statistical analysis. 
A week at the Summer Institute in Economic Geography (SIEG) in June 2010 at the University of British Columbia, hosted by Jamie Peck and Trevor Barnes, has profoundly shaped my understanding of the exciting subfield of economic geography, its core debates, methods, and practices, and my own place in it. The exceptional scholars that I was privileged to encounter, as well as the relationships I have since developed, have been an invaluable asset to my intellectual development. SIEG remains a vital community with whom I continue to engage, especially Christine Benna Skytt-Larsen, Tim Heinemann, Pedro Marques, and Heather Simard.

I would be remiss if I did not acknowledge the many senior managers who consented to being interviewed and / or surveyed for this research, several of whom on more than one occasion, and who gave generously of their time touring me around their factories. A special thanks to Frank Delfino (Teknion) whose ongoing support of my project has resulted in many networking opportunities in the industry, as well as an essay contribution to the corporation's book, Design Does Matter, which seeks to advance awareness of the skills that designers bring to business. Much gratitude also goes to the shopfloor workers who shared their many insights, and the brilliant designers with whom I had the privilege to engage.

The ideas in these pages have been strongly shaped by provocative discussions with and feedback from colleagues at conferences in Boston, Las Vegas, Washington D.C., and New York City (American Association of Geographers), Montreal, Halifax, and Toronto (Innovation Systems Research Network), Cambridge, England (Danish Research Unit for Industrial Dynamics), and Ottawa and Waterloo (Canadian Association of Geographers / International Congress of the Social Sciences and Humanities). The Program on Globalization and Regional Innovation Systems at the Munk Center for Global Affairs and the Innovation Systems Research Network (ISRN) provided me the opportunity to engage with an exceptional community of scholars across Canada, to conduct research on questions of vital public policy significance, and to present my work and receive feedback at an early stage of the PhD. My involvement in the ISRN has influenced my understanding of the intersection between the research we conduct in academia, policy, and economic development practice.

My pathway to the $\mathrm{PhD}$ was very much shaped by my previous career in curatorial practice at Toronto's Royal Ontario Museum (ROM), where I was fortunate to work with many amazing individuals and 'museum geeks' who have become lifelong friends. Special thanks to Stephanie Allen, Peter Kaellgren, Karla Livingston, Angela Raljic, Susan Sivric, Alexandra Palmer and many others for believing in my abilities and encouraging me to take the next step.

I am especially indebted to my family: to Mum, Dad, Mary, Janice, Michael and Alex, for their ongoing support; to Nicolas, for the joy and perspective he brings to my life everyday; and most of all, to Stéphane, for the immeasurable love, support and encouragement he has shown throughout the many ups and downs of this journey, and for his positive outlook that has kept me grounded.

Carolyn J. Hatch

February 13th, 2013 


\section{Table of Contents}

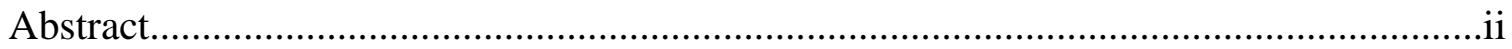

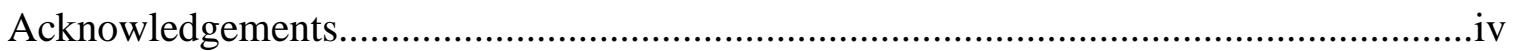

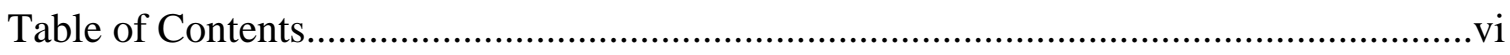

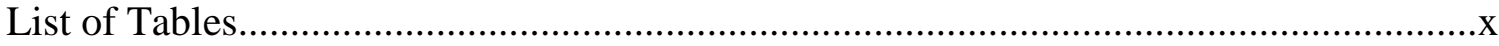

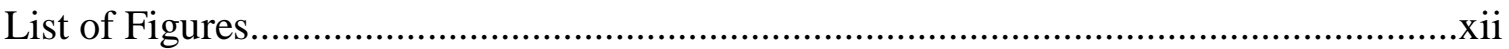

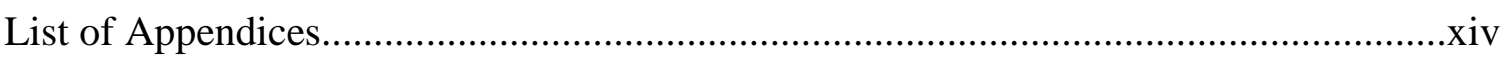

Chapter I: Advanced manufacturing strategies in a global economy......................1

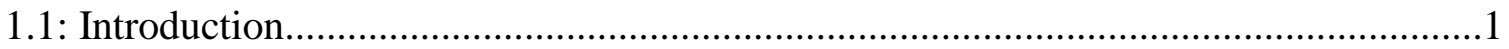

1.2: Learned behaviour: research scope and questions............................................

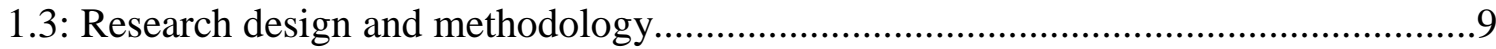

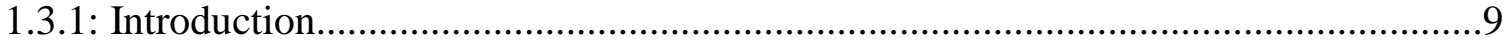

1.3.2: Case study: the Canadian contract furniture manufacturing sector.......................11

1.3.2.1: Introduction and industry performance.................................................... 11

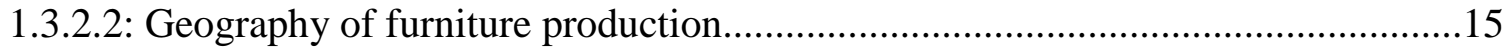

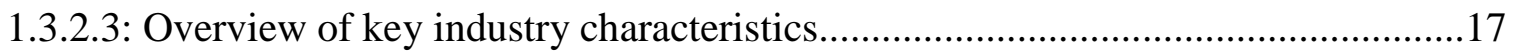

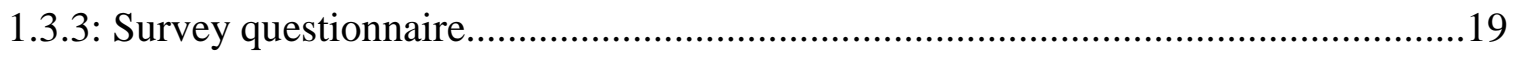

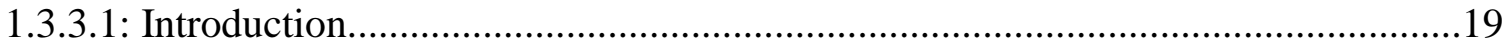

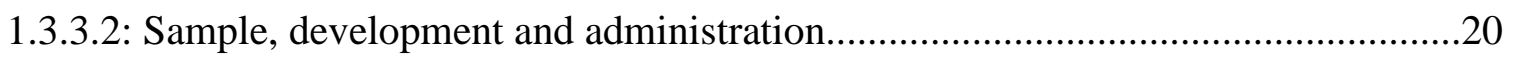

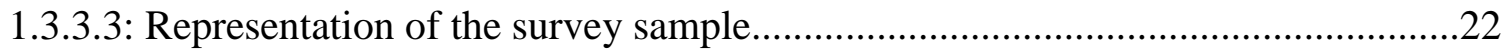

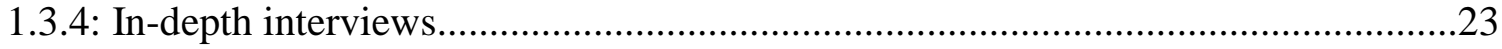

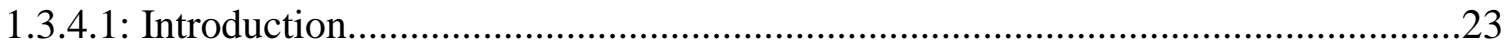

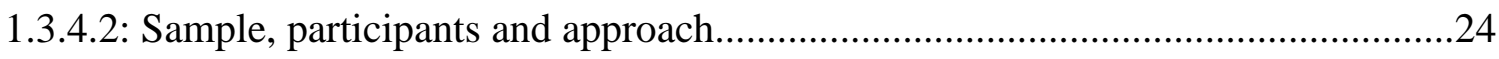

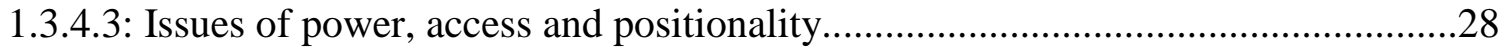

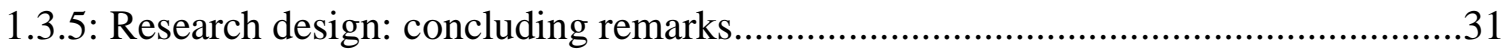

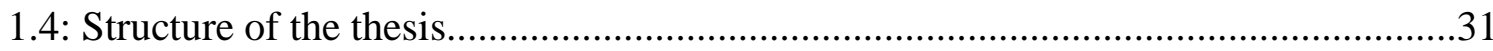




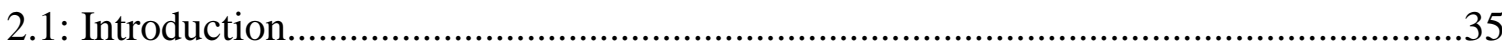

2.2.1: The international mobility of manufacturing talent...........................................38

2.2.2: The institutional foundations of competitive advantage: a disjunction

at the national scale?

2.2.3: Bridging the skills gap: knowledge flows and industrial practices from

Continental Europe to Canada.... .43

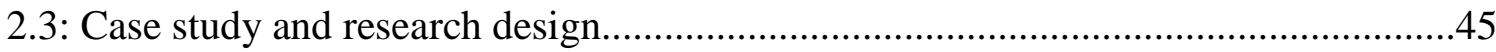

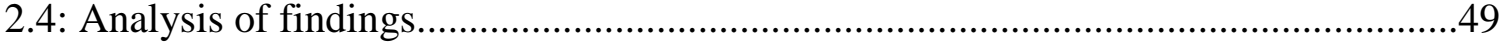

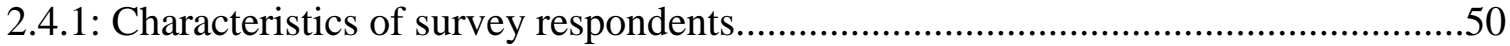

2.4.2: Workplace practices in Canadian contract furniture manufacturing firms.............53

2.4.2.1: Use of training and technology investments.................................................53

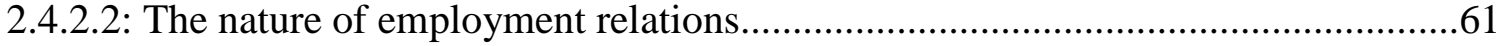

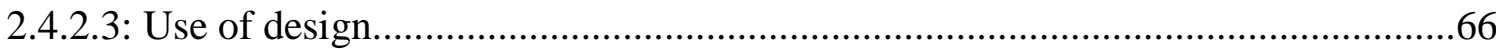

2.5: Implications for institutional economic geography..........................................69

Chapter III: Learning from designers: a time-spatial analysis of knowledge creation

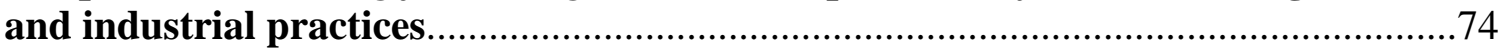

3.1: Introduction. .74

3.2.1: The rise in importance of design to the contemporary production of goods

3.2.2: Understanding the complex knowledge base of design.....................................78

3.2.3: The economic geography of innovation: local and global knowledge networks and flows .81

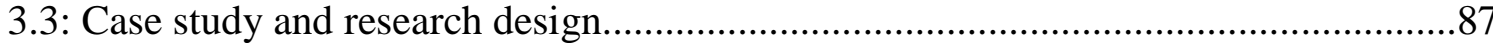

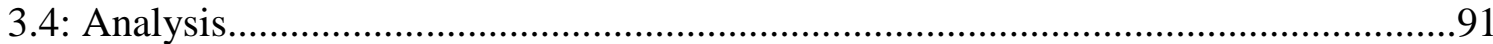

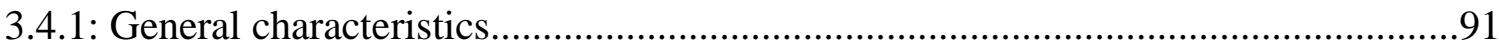

3.4.2: Design-intensity of manufacturing operations................................................94

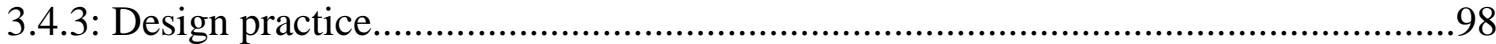




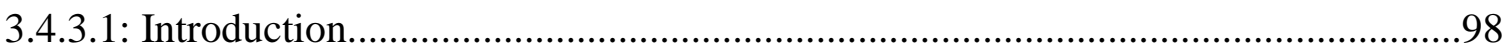

3.4.3.2: Long-term employment structures: the internal design team...............................99

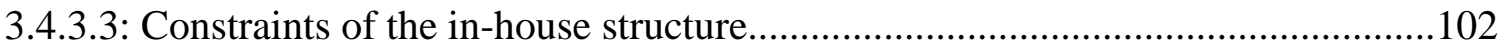

3.4.3.4: Short-term employment structures: temporary project designers.......................103

3.4.3.5: Design at a distance.........................................................................................107

3.5: Summary and conclusions.......................................................................112

Chapter IV: Learning from customers: the social and spatial dynamics of userproducer interaction in the innovation process......................................................116

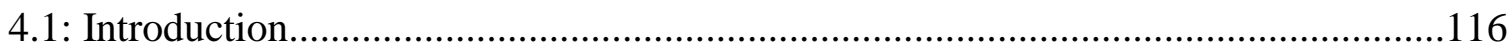

4.2.1: Complex goods production and the value of learning from users.........................120

4.2.2: Characteristics of products and markets that rely on learning-by-using...............121

4.2.3: Understanding the multiple ways of learning from users: deduction and inductive

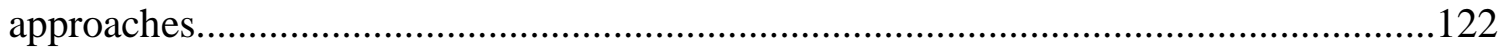

4.2.4: Lundvall's framework: user-producer interaction and the sharing of knowledge. 124

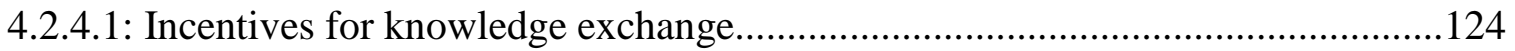

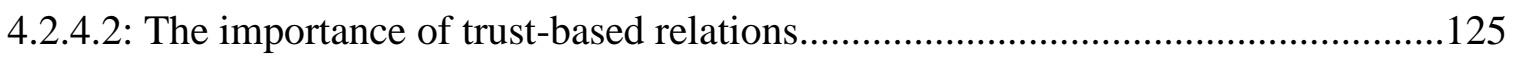

4.2.4.3: The implications of proximity and distance......................................................126

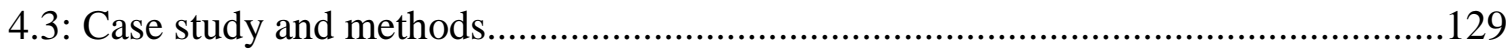

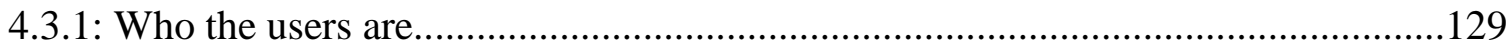

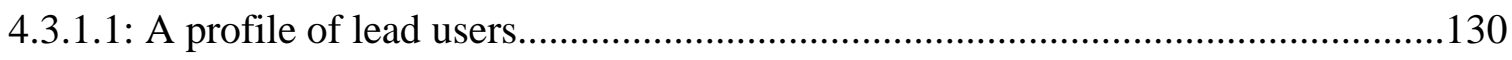

4.3.1.2: The furniture dealer: the structure of distribution and the role of dealers..........133

4.3.1.3: The role of the art and design community......................................................134

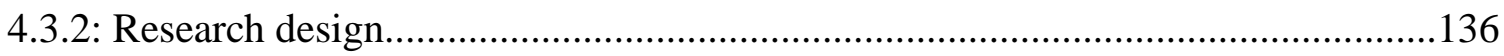

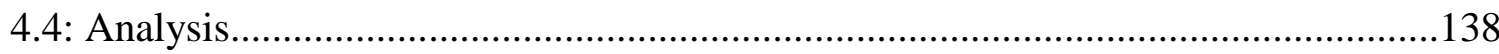

4.4.1: The importance of user knowledge..................................................................138

4.4.2: Co-development practices in the Canadian contract furniture manufacturing

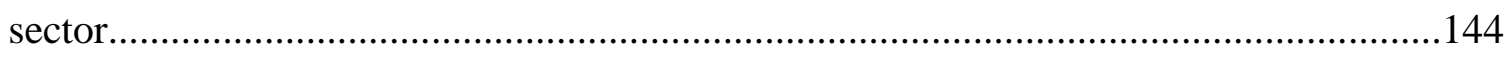

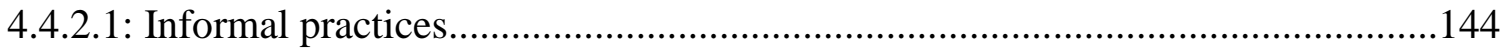

4.4.2.1.1: The furniture dealer: acquiring and sharing market knowledge......................144 
4.4.2.1.2: Identifying trends through customization...................................................146

4.4.2.2: Formal practices........................................................................................147

4.4.2.2.1: The art and design community: acquiring and sharing design

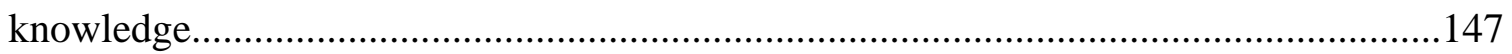

4.4.2.2.2: Advanced research practices.........................................................................149

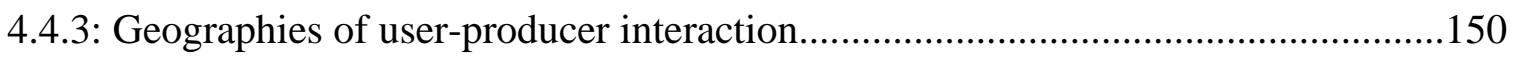

4.4.3.1: The importance of trust-based relations...........................................................150

4.4.3.2: Permanent and temporary forms of co-location...............................................153

4.5: Learning from furniture users? Lessons for theory, policy and firm practice...........156

Chapter V: Competitiveness by design: reflections on theory and policy..................162

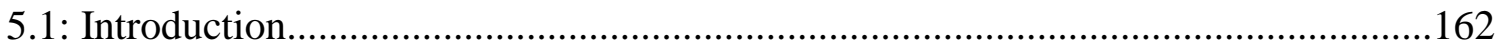

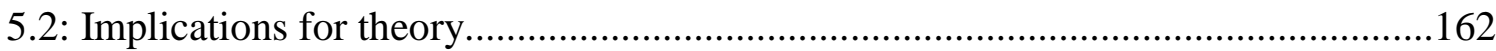

5.2.1: Geography of knowledge flows: the role of proximity and distance in innovative

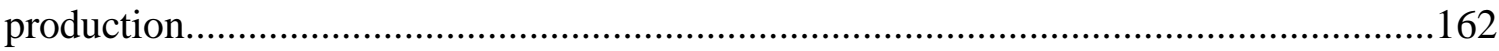

5.2.2: Structure, agency and the institutional embeddedness of manufacturing

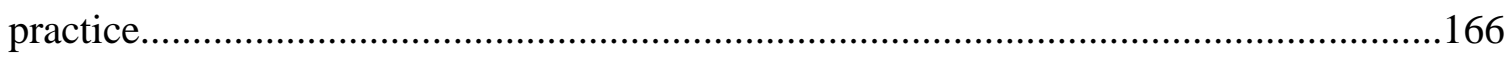

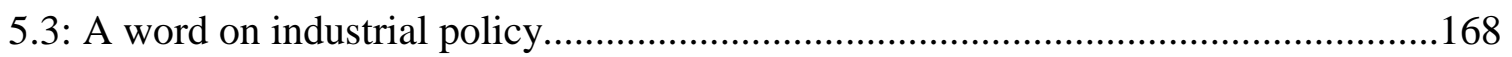

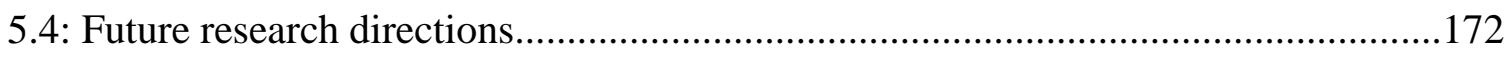

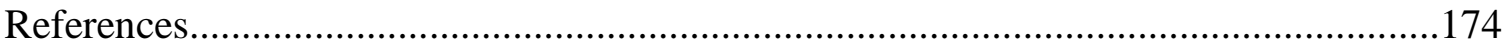

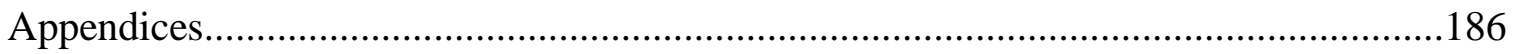




\section{List of Tables}

Table 1.1: Comparison of industry and survey sample by geography. .23

Table 2.1: $\quad$ Breakdown of interview participants

Table 2.2: Breakdown of representatives from intermediary organizations and government agencies.............................................................. 48

Table 2.3: Characteristics of survey respondents................................................49

Table 2.4: Mean scores to describe characteristics of production............................50

Table 2.5: Percentage of firms rating factors as 'highly important' to success...........50

Table 2.6: Characteristics of sample groups.....................................................52

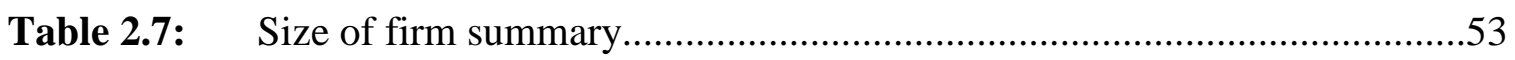

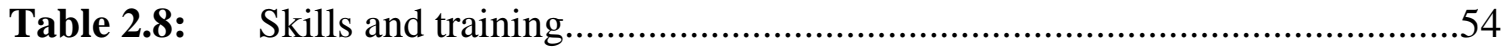

Table 2.9: Mean score to describe characteristics of production.............................58

Table 2.10: Nature of employment relations.......................................................61

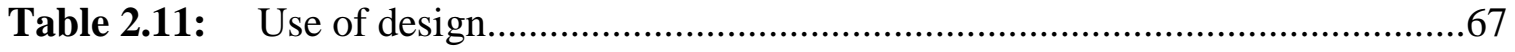

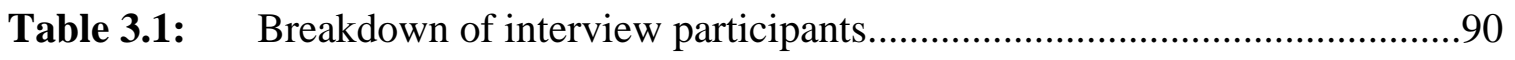

Table 3.2: $\quad$ Breakdown of representatives from trade associations and government agencies

Table 3.3: Comparison of key firm characteristics and performance levels, grouped by firm size / number of employees.

Table 3.4: Comparison of key firm characteristics and performance levels, grouped by geographic region.

Table 3.5: Comparison of firm characteristics and performance levels, grouped by firms who 'carry out design' (YES) and firms who 'do not carry out design' (NO)

Table 3.6: Mean score for production strategies, grouped by YES (carry out design) and NO (do not carry out design).

Table 3.7: Characteristics of firms that carry out design......................................98 
Table 4.1: $\quad$ Breakdown of interview research participants.....................................137

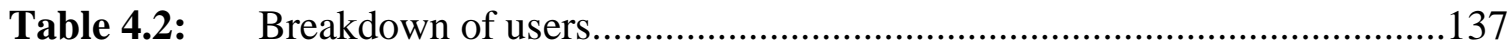

Table 4.3: Breakdown of industry organizations and government agencies............138

Table 4.4: Comparison of firm characteristics grouped by YES (close relations with lead customers highly important to firm success) and NO (close relations with lead customers not highly important to success).........................141

Table 4.5: Comparison of production strategies grouped by YES (information from clients and users highly important to success) and NO (information from clients and users not highly important)........................................143

Table 4.6: User producer interaction in the Canadian contract furniture manufacturing sector 


\section{List of Figures}

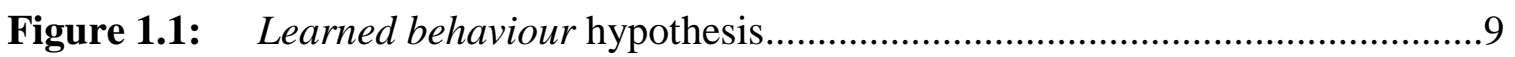

Figure 1.2: Location of contract furniture manufacturers in Canada............................10

Figure 1.3: $\quad$ Major North American contract furniture markets......................................14

Figure 1.4: Location of contract furniture manufacturers in Southern Ontario............16

Figure 1.5: Location of contract furniture manufacturers in Southern Quebec...........16

Figure 1.6: Location of firms in Toronto region.......................................................17

Figure 2.1: Breakdown of interview participants by occupation,

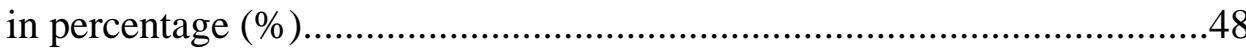

Figure 2.2: Breakdown of interview participants, by geography,

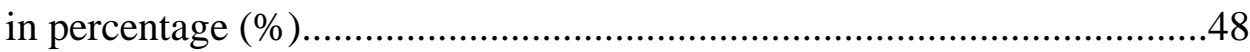

Figure 2.3: Percentage of respondents rating the following sources of information as

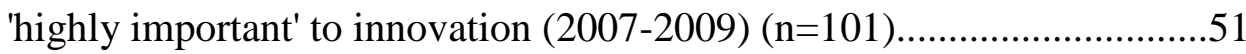

Figure 3.1: Product design and development investment intensity in Canadian manufacturing industries 2008 , in percentage $(\%)$..................................... 88

Figure 3.2: Breakdown of interview participants by occupation,

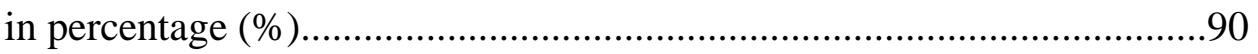

Figure 3.3: Breakdown of interview participants by geography,

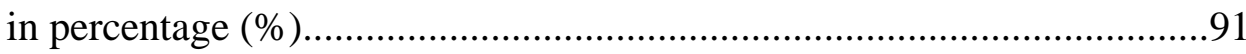

Figure 3.4: Correlation between size of firm and annual sales performance (2008)..

Figure 3.5: Comparison of firm size and annual sales performance (2008), grouped by geographic region.

Figure 3.6: Percentage of respondents rating factors as 'highly important' to success of firm $(\mathrm{n}=101)$

Figure 3.7: Comparison of firm size, percentage of skilled employment, annual sales performance and productivity (2008), grouped by YES (carry out design) and NO (do not carry out design). 
Figure 4.1: Multiple channels of learning in the Canadian contract furniture

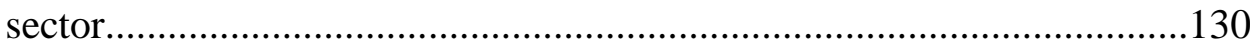

Figure 4.2: Percentage of respondents rating factors as 'highly important' to innovation

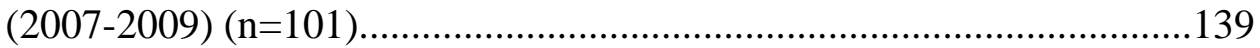

Figure 4.3: Percentage of respondents rating factors as 'highly important' to success of

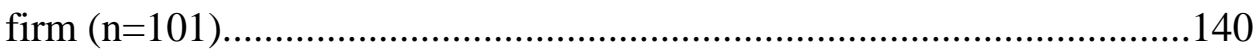

Figure 4.4: Comparison of YES and NO groups, firm size and annual sales performance (2008)...... 


\section{List of Appendices}

Appendix I: $\quad$ Survey invitation letter (English) / survey invitation letter

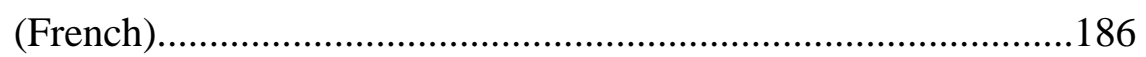

Appendix II: $\quad$ Survey cover page (English) / survey cover page

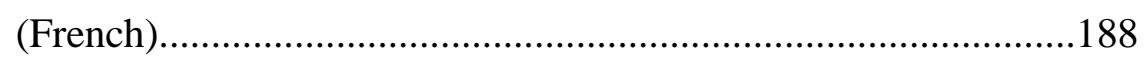

Appendix III: $\quad$ Survey consent form (English) / survey consent form

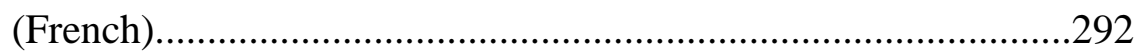

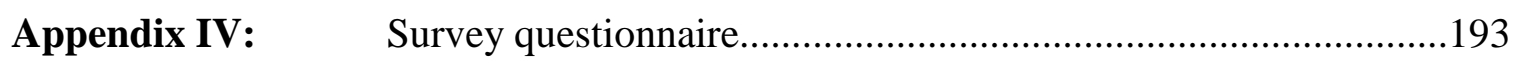

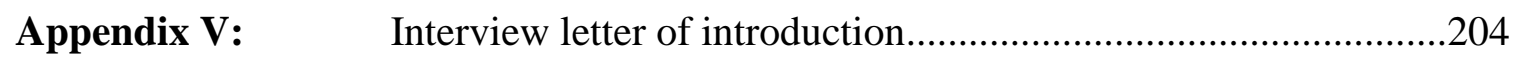

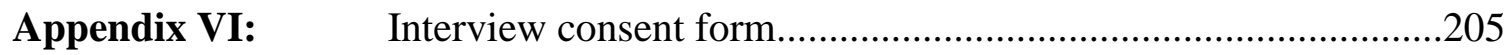

Appendix VII: Interview guide (generic senior manager / designer)...................206

Appendix VIII: $\quad$ Interview guide (contract designer).............................................209

Appendix IX: $\quad$ Interview guide (production)..................................................211 


\section{Chapter I}

\section{Advanced manufacturing strategy in a global economy}

\section{1: Introduction}

There is widespread agreement in academic and policy circles that the nature of contemporary capitalism has undergone profound changes in structure and organization in recent decades. The precise contours of these shifts, and the forces producing such change, have been the subject of a flurry of discussion and debate within geography and across the social sciences. It is said that Fordist systems of mass production have been beset by a range of problems, and considerable attention has since been drawn to the development of new production and innovation practices in a period characterized variously as 'post-Fordism', after-Fordism', the 'new economy', the 'creative economy', the 'knowledge-based economy' or the 'learning economy'. Differences in terminology aside, it has become clear within the contemporary period of capitalism and intensified globalization that knowledge, learning and innovation are vital elements for economic development and growth, and the capability to create and diffuse knowledge (also referred to as innovation) is a key economic process that strongly influences national and regional economic performance.

One of the central tenets of the influential 'learning economy' thesis (Lundvall and Johnson 1994) is that knowledge has become the most important resource underpinning 
the viability of the modern firm, and interactive learning, by extension, the most fundamental process. The present era of capitalist activity, this perspective argues, has ushered in new constellations of knowledge and learning, a shift that has been propelled by three interrelated phenomena: the development of advanced information and communications technologies, the move towards greater flexibility in work practices, and changes to the process of innovation itself. Within this competitive context, a firm's ability to combine new and existing types of economic knowledge, at a greater number of interfaces, both within and outside the firm, is a much more fundamental and strategic process than it was before, and central to economic change and growth. In order to access an increasingly complex and variegated knowledge base, it has become imperative for firms to open horizontal communications at all levels of the organization, as well as develop cooperative relations and alliances with external actors. This has entailed a growing need for a much broader participation in the learning process, and the development and multi-skilling of individual workers, which has become of paramount importance.

With the rise of the knowledge-based economy, there is a growing consensus that the primary purpose of the modern firm is to produce, absorb, share, disseminate, and apply knowledge, its most crucial economic resource, with the ultimate goal of enhancing the competitiveness of its products. Implicit in this view is the idea that the process of learning (i.e. knowledge production and / or acquisition) can be managed by a firm, in other words, economic value can be deliberately created through the effective accumulation, exploitation and use of knowledge assets. As indicated, firms are confronted with an ever-increasing diversity and complexity of knowledge resources, 
which must be effectively mobilized in any successful innovation process. This means that the development of organizational forms and industrial practices that increase the learning capability of the modern firm have become crucially significant (Lundvall and Johnson 1994).

Transformations in the nature of capitalist competition have placed a premium on the role of creativity and culture in contemporary (urban) economic development, and the growing importance of creative, symbolic and aesthetic inputs into the production of goods (Scott 2000, 2001, 2004; Florida 2002). The rapid growth and spread of cultural product industries occurring in modern society is said to reflect the increasing convergence between the economic order, on the one hand, and cultural expression, on the other (Lash and Urry 1994). Creativity has assumed a heightened stature in the discourses of academic, policy, business and economic development communities of late, and is understood as key to competitiveness and regional economic success. Creative, high-skilled knowledge workers (or the oft used term 'talent'), are seen to be the generators of new ideas important to innovation and knowledge-intensive production (Saxenian 2000; Florida 2002; Markusen 2004). Such skilled workers are viewed as being highly mobile between firms and places, thereby facilitating the flow of (tacit and codified) knowledge across firm boundaries, as well as regional, national and institutional divides (Saxenian 1994; Gertler and Vinodrai 2005). They are recognized as agents of innovation and key actors in the circulation of knowledge and industrial practice.

Broader shifts in the terms of competition have resulted in fundamental changes in the supply side of the economy, as manufacturing firms have sought new ways to gain market share by tailoring their products towards qualitatively distinctive market niches, 
and pursuing a competitive strategy based on design, quality and distinctiveness, rather than cost alone (Scott 1988; Scott 2001; Power and Scott 2004). Moreover, the onus on firms to achieve successful innovations in product and process has become paramount. In pursuing smaller, more fragmented and quickly changing niche markets, firms have recognized that responsiveness to changing market conditions, time to market, and ontime delivery are critical determinants of success in many industries. In response to these competitive pressures, manufacturers have been compelled to adopt radically new sets of practices and forms of organization in the workplace. This has entailed not only investments in the development of a skilled, multi-tasked workforce, as already described, but also the implementation of sophisticated machinery and advanced manufacturing technologies (AMT), and novel approaches to workplace organization that enable flexibility, responsiveness, and quality improvements to be identified and implemented on an ongoing basis (Gertler 2004).

Closely related to these internal changes has been a restructuring in the wider social division of labour between firms, in effect, an expansion of the locus of innovation from the internal resources of the firm towards external networks and knowledge pools (Powell 1990; Sayer and Walker 1992; Cooke and Morgan 1993; Saxenian 1994). Under the new competitive conditions, it has proven far more efficient for a producer to draw upon the specialized inputs of external suppliers in order to achieve its competitive goals more effectively. In fact, one of the central features of intensified globalization and integration of world markets has been the redefining of the core competencies of the firm to focus on the highest value-added segments of manufacturing and service, while reducing direct ownership over non-core functions. This has laid the groundwork for 
changes in the governance structure of firms in sectors producing for global markets towards vertical disintegration - as producers find it advantageous to outsource an increasing share of their non-core activities (Gereffi et al. 2005). Thus, discrete elements of the production process that were once provided within the boundaries of the legal entity of the firm are increasingly being acquired through market transactions between firms and external suppliers. Thus the same principles of specialization and division of labour operating inside the firm are now being exploited at a social scale of organization between firms, which has enhanced the overall flexibility of producers, both individually and collectively (Gertler 2003).

The strong consensus in the literature is that the above phenomena have rendered geographic proximity between firms and their innovation partners increasingly significant, for three complementary reasons. First, the increased transaction-intensity between organizations resulting from the new social division of labour puts a premium on spatial proximity and geographical concentration as a means to reduce transaction costs (Scott and Storper 1987; Scott 1988). Second, the process of learning-through-interacting is said to be underpinned by the frequent sharing of proprietary kinds of technical and market information, and is best supported by closeness. This is because continuous and repeated face-to-face interaction serves to build up trust and 'social capital' (Putnam 1993) between transacting parties, which facilitates the flow of confidential production knowledge that is crucial to competitive success (Lundvall 1988). Third, the 'know how', tacit dimension of production knowledge defies easy articulation, is best acquired experientially, and is particularly difficult to exchange over long distances, it is argued. Thus it must be done so locally, since it cannot be readily removed from its human and 
social context and transferred into codes understandable by others, which makes it spatially sticky (Maskell and Malmberg 1999; Lundvall and Maskell 2000; Storper and Venables 2004).

These ideas are at the heart of contemporary debate in economic geography, yet much recent discussion has centered around unpacking the concept of proximity, suggesting that it is wrong to associate the term solely with its geographical meaning (Boschma 2005). The crux of this argument is that 'relational' forms of proximity, in other words certain cognitive, social, cultural, organizational, professional or institutional affinities shared between innovating actors (Gertler 2008), may matter more than (or at least as much as) simple geographical closeness in determining the ease with which tacit forms of knowledge can transfer between parties. These types of commonalities, it is said, may transcend spatial distance separating actors, suggesting that spaces of knowledge creation, learning and innovation are not merely local, but truly global in scale (see also Lave and Wenger 1991; Brown and Duguid 1996; Bathelt et al. 2004; Amin and Roberts 2008).

While debates on proximity and distance are at the very foundation of the contemporary literature in economic geography, the institutional characteristics of an economy that shape a firm's ability to learn and innovate remain a crucial question. Different countries and national institutional systems are not equally successful in coping with the challenges associated with these broader shifts in the nature of competition, and in producing (and reproducing) local labour market dynamics that underpin the circulation of knowledge and practice crucial to competitive advantage. In Canada, for example, a number of the most fundamental features of the high performance 
manufacturing workplace, in particular the extensive training and long-term development of labour, as well as the establishment of trust-based network relations with specialist suppliers, are said to be significantly constrained by the way in which economic processes are structured and governed at the national and provincial scales. The prevailing approach in Canada is typical of the experience in other Anglo-American industrialized economies, whereby corporate governance regimes, labour market and industrial relations institutions engender instability in employment relations and undermine a sense of trust that is crucial to collaborative engagement between innovating partners (Hall and Soskice 2001; Christopherson 2002; Gertler and Wolfe 2004; Gertler 2004).

\subsection{Learned behaviour: research scope and questions}

These ideas, issues and debates constitute the theoretical framework for the empirical analysis that is presented in this dissertation, in which the sources, mechanisms, processes and channels of learning (as manifested in the transmission, propagation and diffusion of industrial practices) are the object of analytical scrutiny. My approach involves a detailed investigation of the workplace practices employed by firms in Canada's 'contract' (or office) furniture manufacturing sector, which has a strong designand quality-oriented focus and has undergone dramatic growth following the advent of North American trade liberalization during the 1990s.

My 'learned behaviour hypothesis' (Figure 1.1) suggests that globally competitive contract furniture firms operating in a Canadian institutional context learn how to produce (i.e. the development of specific industrial practices and processes) and what to 
produce (i.e. design-oriented, customized, high-quality products) from a variety of internal and external sources. As an example, firms learn the 'how' of production from an understanding of alternative national institutional configurations and associated labour practices that derive from the embodied knowledge of their founders (and other mobile managers), who have lived, studied and worked within the coordinated market economies and high-skilled manufacturing regimes of Continental Europe. In addition, firms learn what to produce through the cultural and market knowledge embodied by these entrepreneurs, as well as from designers and other specialist suppliers, clients and customers, and competitor firms in the sector. The specific questions addressed in this dissertation are these: What are the critical sources of knowledge and processes of learning that support innovative production in a sector that is dependent upon a high level of design-intensity, quality, and customization / specialization? What are the social and organizational practices through which manufacturing knowledge is integrated into innovation processes, as well as their temporality and spatiality? What forces determine or influence firms' practices? In particular, how does the Canadian institutional environment and industrial workplace mediate the creation and circulation of manufacturing knowledge, and what is the role of individual and firm-level agency in shaping competitive outcomes? How do individual agents such as owners, managers and workers successfully develop high-quality, design-intensive products within an institutional environment that is allegedly antithetical to such a strategy? What are the mechanisms and conditions that facilitate the transfer of manufacturing knowledge over long distances? 


\section{Figure 1.1: Learned behaviour hypothesis}

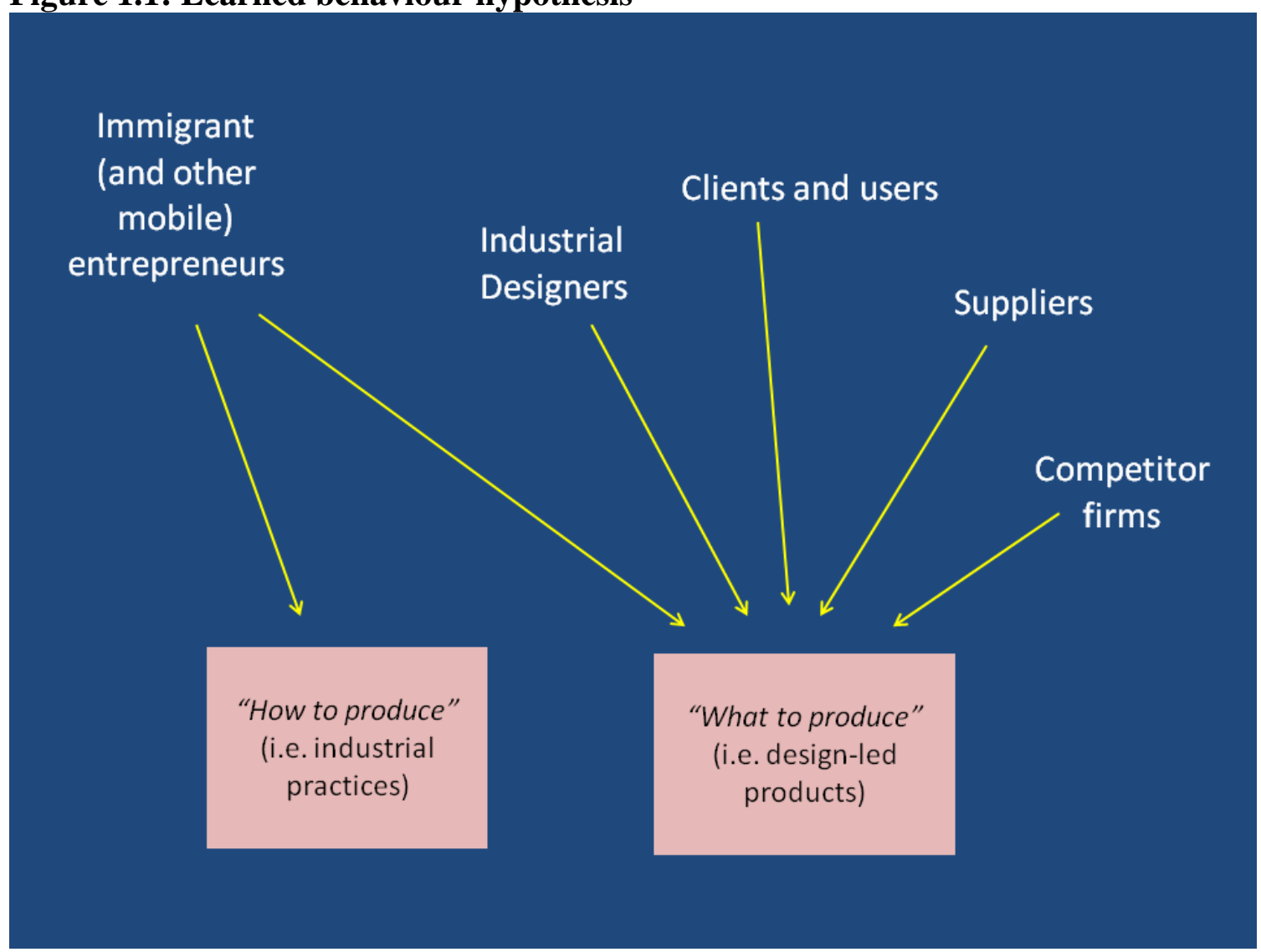

\subsection{Research design and methodology}

\subsubsection{Introduction}

The empirical analysis presented in this dissertation investigates the industrial and design practices of Canadian contract furniture manufacturing firms located in three geographic regions in Canada: Ontario, Quebec and the western provinces, which together constitute nearly $98 \%$ of the Canadian industry (Statistics Canada 2011) (Figure 1.2). The research design is based on a mixed-methods approach and is drawn from two primary modes of inquiry, namely a bilingual (English and French) online industry survey questionnaire to the full population of firms and a series of in-depth, semi-structured interviews with 
industry experts. Both methods were carried out concurrently, and will be elaborated on in detail in the coming discussion.

\section{Figure 1.2: Location of contract furniture manufacturers in Canada}

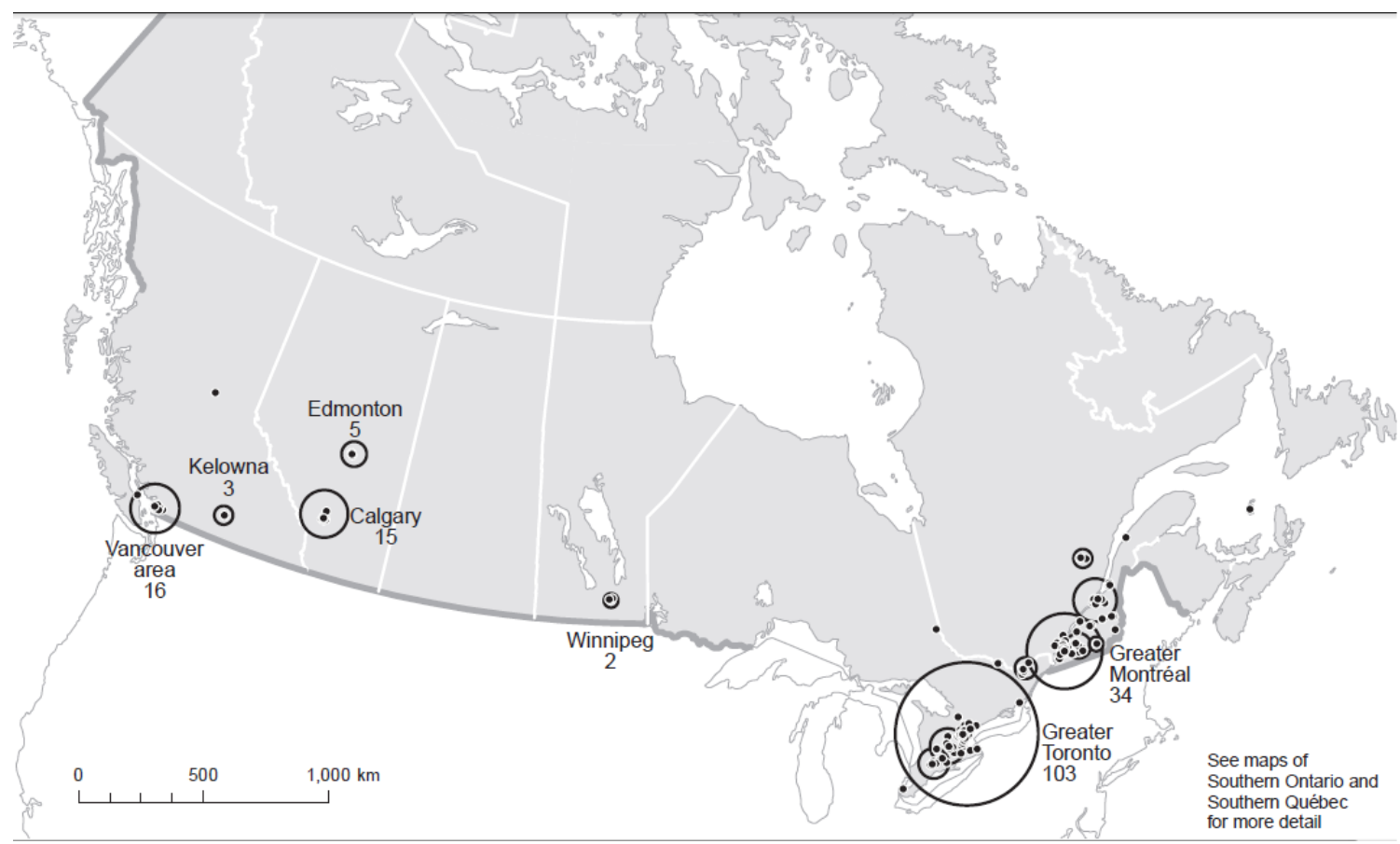

Source: Cartography Office, University of Toronto

There are considerable benefits derived from mixing quantitative and qualitative elements within this project and my rationale for such an approach stems from several methodological considerations. For one, this combination of techniques has enabled me to address a broader range of issues than would otherwise be possible through either the questionnaire or interviews on their own (Philip 1997). Second, it has allowed me to approach my research questions from different vantage points and to triangulate methods through the cross-checking of results (Valentine 2001; Winchester 2000; Cook and Crang 
1995). Third, these complementary techniques have, as anticipated, resulted in a generalizable and broad perspective of this manufacturing sector in Canada through my survey, and an individual, in-depth exploration of key issues through my interviews. According to McLafferty (1995), this couples the 'power of the general' with the 'insight and nuance of the particular'. Fourth, I have been motivated by consideration of future potential audiences for my work, as Philip (1997) states that research resulting from strictly qualitative techniques is often 'not understood' or may be 'deemed inappropriate' by many outside the academy. Therefore, a substantial quantitative element in my project, I hope, would greatly enhance the policy relevance and applicability of my work.

\subsubsection{Case study: the Canadian contract furniture manufacturing sector}

\subsubsection{Introduction and industry performance}

Case studies have long been recognized in geography as a meaningful approach for developing a detailed understanding of the relationships between the behaviours of individual agents and their causal context. Particularly when focusing on the individual actions and decisions of economic agents, Clark $(2007,195)$ writes that case studies are able to "handle the complex interplay between culture, institutions, and the nature of everyday decision-making." In the words of Gertler (2004, x), "I am convinced that the only way to gain a proper understanding of the practices and strategies of firms, and the impact of relationships, structures and geographical context on their actions is to engage in the hard work of detailed, finely textured case studies: there really is no substitute for 'being there"'. 
This dissertation has sought to build theory and develop insight on the factors and processes shaping firm behaviour by way of case study research. As indicated, it draws on a case of the Canadian contract furniture manufacturing sector, and my rationale to use this particular case is driven by several methodological considerations. First, it constitutes what Peck (2007) has referred to as a 'critical case' for this research in that it has enabled me to generate new explanatory insights into the multiple ways in which firms learn 'how to produce' and 'what to produce', rather than merely enriching the catalogue of existing cases and illustrating extant theoretical claims. Second, given that one of this project's objectives is to understand how national institutions influence employment practices and competitive outcomes, I suggest that the national scale is the appropriate scale from which to approach this project.

This sector provides a compelling case study in which to investigate questions about industrial and design practices due to its strong growth since the advent of the Free Trade Agreement with the US in 1989, and later the North American Free Trade Agreement (NAFTA). In the midst of widespread, long-term economic downturn throughout the Canadian manufacturing landscape, the Canadian furniture industry has demonstrated resilience and vibrancy. It is emblematic of key dimensions of economic change in the Canadian manufacturing industry following NAFTA. Traditionally dominated by small scale, craft-based factories catering to regional markets, the Canadian furniture industry was expected to be more vulnerable than most sectors in responding to the influence of trade liberalization. Not surprisingly, it underwent a major shake-out between 1989 and 1991 that led to a decrease in the number of establishments by nearly one half and a reduction in employment by just under 30\% (Pau et al. 1998). Faced with 
the realities of new domestic markets and competitive pressures, firms had no choice but to become more competitive, or risk extinction. By the mid-1990s, the industry had undergone a renewal as firms upgraded the quality, responsiveness and timeliness of production, enabling them to achieve tremendous success in export markets (Gotlieb 2002). Between 1980 and 2001, global exports increased by $10.5 \%$ each year on average (compared to an $8.8 \%$ increase for all manufactured exports) and between 1993 and 2002 it was the fastest growing manufacturing industry in Canada, increasing exports by $250 \%$ (Industry Canada 2007). Moreover, from 1999 to 2005, the total value of exports climbed from $\$ 54$ to $\$ 94$ billion USD and presently Canada is the $5^{\text {th }}$ largest exporter of this product to the world. It ships $53 \%$ of its production goods beyond its borders, primarily to the US, and has enjoyed an impressive trade surplus with the US which peaked at $\$ 5.8$ billion in 2002 and was $\$ 4.0$ billion in 2006 (Industry Canada 2008) (see map of major North American markets in Figure 1.3). Manufacturing value-added per employee increased steadily at $1.8 \%$ from 2001 to 2010 , which is a key indicator of the industry's productivity performance (Industry Canada 2012).

Within the broader Canadian furniture industry, this research focuses on the contract segment which encompasses the production of office (rather than household) furniture, as per the North American Industrial Classification System (NAICS) coding category 3372 . The above performance trends have been particularly pronounced in the contract furniture segment of the market, which has undergone exceptionally high growth, especially throughout the 1990s and up to 2009. Statistics reveal that while the share of household furniture experienced significant decline during the period 1988-97, from 45 to $26 \%$, the 'office' and 'other' sectors rose from 54 to 64\% (Pau et al. 1998). 
Data on the Canada / US trade balance further illustrates the divergent trajectories of these two primary furniture subsectors and shows that by 1997 , contract furniture had a significantly higher surplus as compared to the household manufacturing segment, at more than three times the value (US \$722 versus US \$229 million).

Figure 1.3: Major North American contract furniture markets

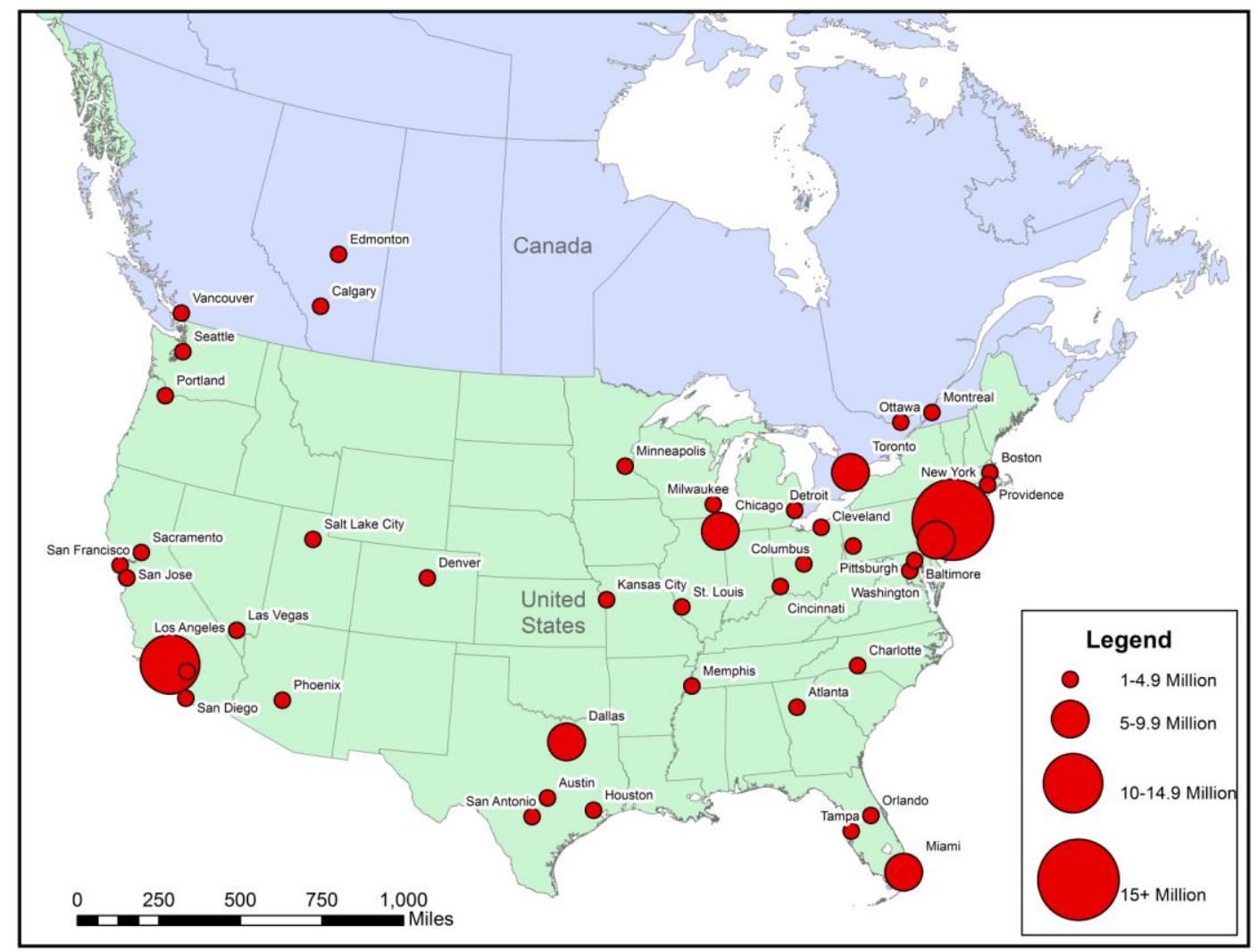

Source: Author's calculation based on data from www.citypopulation.de

The contract segment also showed considerable growth during the subsequent period. For instance, from 1997 to 2006, manufacturing revenues increased from \$3 to $\$ 4.6$ billion for this sector, and manufacturing value-added expanded from $\$ 1.6$ to $\$ 2.4$ billion (Industry Canada 2010). Comparison of performance, productivity and revenue 
indicators between the contract and household furniture segments during this period shows that the former sector continued on its trajectory of growth, and the latter persisted on a path of economic stagnation or decline. Between 1997 and 2009, for example, manufacturing revenue per employee for the contract sector increased from $\$ 150,000$ to $\$ 160,000$, whereas its domestic furniture counterpart remained the same at a considerably lower 120,000. Likewise, during this very same period, manufacturing value-added per employee grew from $\$ 74,000$ to $\$ 84,000$ for the contract furniture segment, yet it declined somewhat from 61,000 to 60,000 for the household segment. By 2008, average SME revenue (for profitable firms) for contract furniture was $\$ 1.2$ million, yet the household industry showed a much lower revenue of \$603,000 (Industry Canada 2011).

\subsubsection{Geography of furniture production}

Many innovative, design-oriented furniture firms are located in major urban areas such as Toronto, Montreal, and Calgary (see Figures 1.4-1.5), which correspond to key domestic markets and the presence of large and vibrant design workforces. In fact, research by Gertler and Vinodrai (2004) shows that Canada's design labour force is primarily urbanbased, and that Toronto in particular has a critical mass of designers - the third largest design workforce in North America behind New York and Boston. Thus it is not surprising that the majority of innovative manufacturing firms are located in the Toronto region (Figure 1.6), which suggests that the co-location of producers alongside other actors in the furniture value chain is an important source of competitive advantage. Within these cities, most firms cluster in industrial areas surrounding the urban core, 
allowing them access to lower cost production sites, yet still within close proximity to the diverse urban environments and the creative milieu that downtown neighbourhoods have to offer.

Figure 1.4: Location of contract furniture manufacturers in Southern Ontario

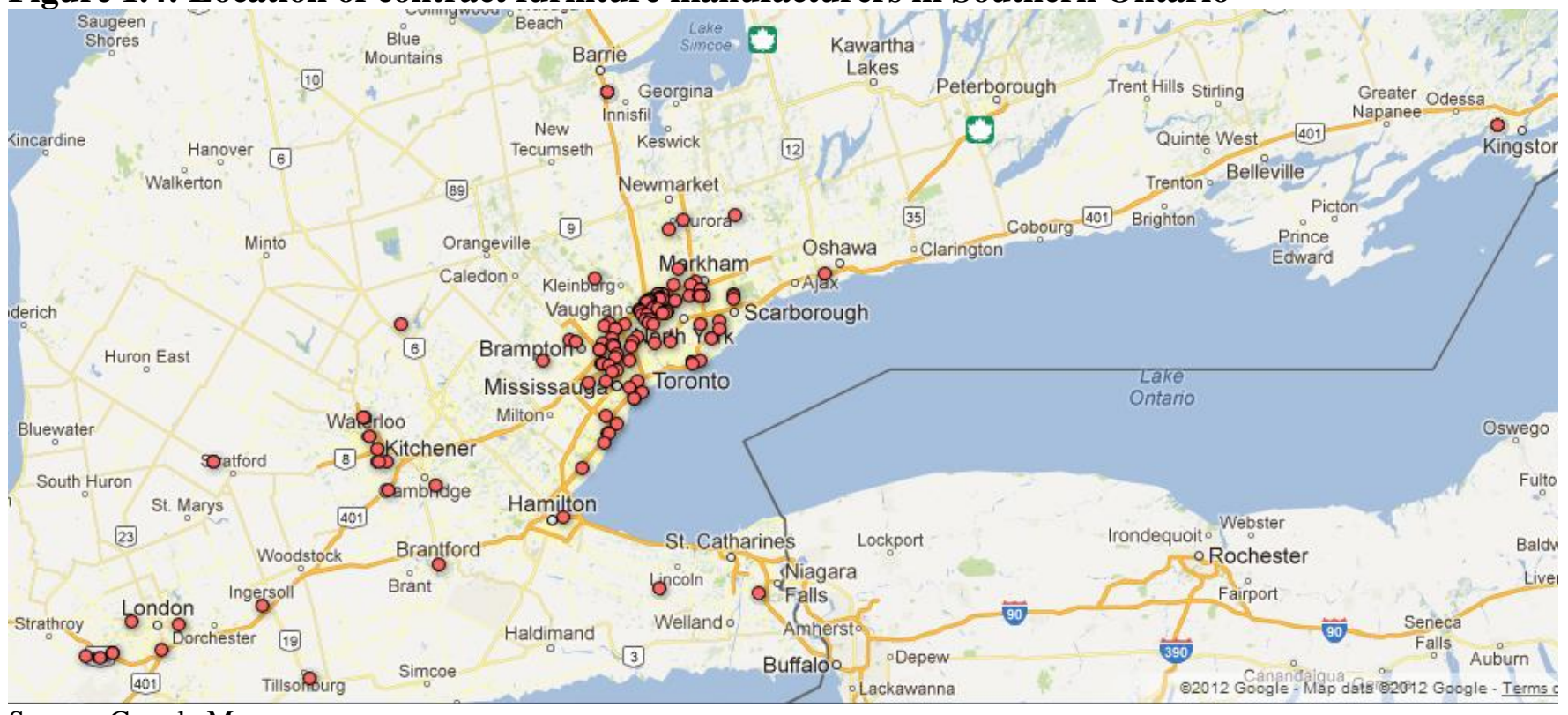

Source: Google Maps

Figure 1.5: Location of contract furniture manufacturers in Southern Quebec

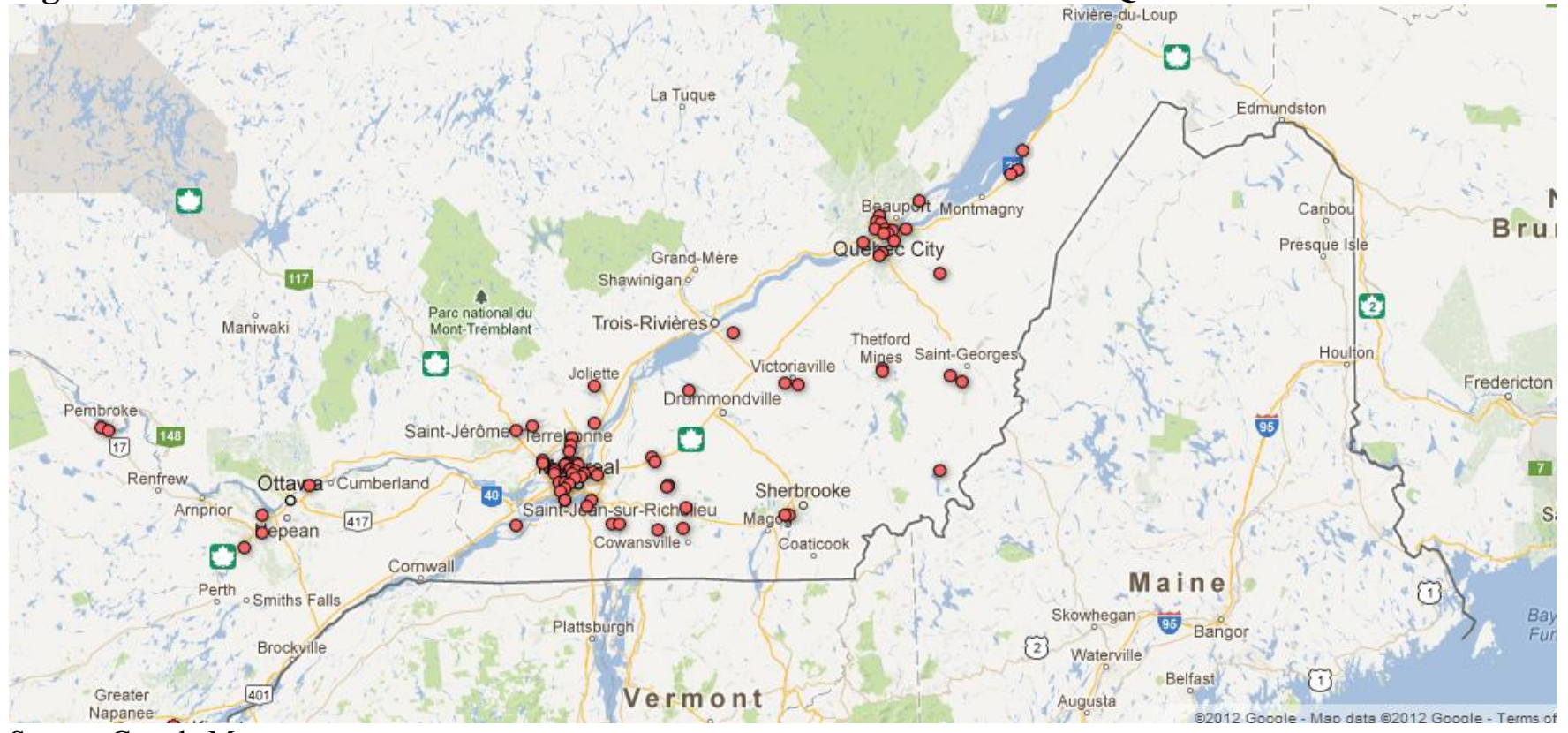

Source: Google Maps 


\subsubsection{Overview of key industry characteristics}

The industry is coined 'contract' because the furniture is made-to-order, in other words, it is not produced until the contract between producer and client is signed. As a result, the contract furniture segment is more design-driven than other furniture subsectors, for four main reasons. First, it is a capital good rather than a consumer good, which means that contract furniture is an asset intended to improve productivity in the workplace; as such, quality is critical because product use can be harsh. Second, the market is often strongly shaped by architects and interior designers. Therefore, furniture manufacturers emphasize quality, customization and design in order to be attractive to these decision makers and influencers who mediate one of the industry's most critical market segments. Third, corporate customers want to project a progressive image by having modern, contemporary furniture in their offices. Fourth, because contract furniture is produced to order, it is essentially customized for every customer.

\section{Figure 1.6: Location of firms in Toronto region}

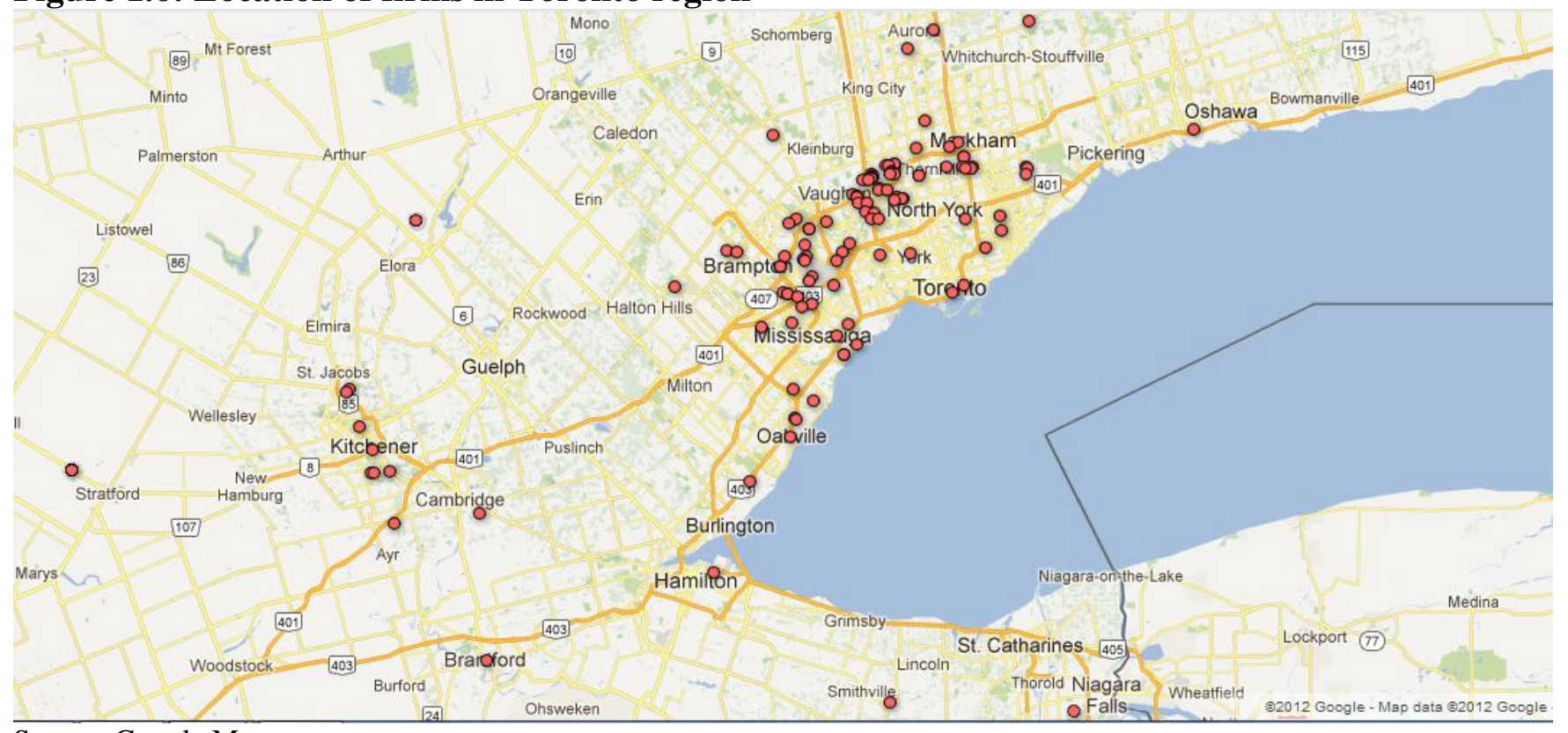

Source: Google Maps 
Due to the style of product and the high level of customization, contract furniture manufacturers increasingly source their supplies from local, domestic and continental suppliers, suggesting that the industry is insulated from (although not immune to) the detrimental effects of offshoring. The favouring of local, national and North American upstream suppliers can be explained by a variety of factors. First, innovative producers employ a just-in-time (JIT) production strategy which reduces in-process inventories and associated carrying costs, and focuses on continuous improvement to enhance quality, efficiency and return on investment. Such a system is reliant upon a complex web of logistics and pools of localized suppliers that can deliver materials and other physical inputs on a frequent, and often daily, basis. Moreover, a propensity to 'reshore' supply chains is shaped by the very nature of the capital goods market itself and the desire to keep production close to the North American consumer base. Quality control issues or delayed / missed shipments could have a debilitating impact on the business performance of the end user, in which case the cost advantages of sourcing from China, Brazil or elsewhere can immediately be lost. Furthermore, an increased awareness in recent years of the importance of environmentalism and sustainability by the end user community has exerted pressure on producers to reduce carbon footprints by minimizing the offshoring of production. Finally, lower energy costs in North America and rising wages in developing countries have significantly reduced the cost advantages of offshoring and compelled companies to work increasingly with suppliers that are closer to home.

Another notable feature of this segment of the furniture industry is its close tracking of the ebbs and flows of the business cycle. It is not surprising that during 
periods of economic decline and high unemployment, corporations, government agencies, and other private and public sector actors do not generate strong demand for business and institutional furniture. The tremendous influence of broader economic conditions upon the furniture market became immediately apparent as I began my fieldwork during the fall of 2009, directly following the financial crisis of 2007-2008. As I administered the survey, conducted the interviews and participated in plant tours from November 2009 to July 2010, I observed factories that were operating at much diminished capacities, managers who were strategizing to remain afloat, and employers capitalizing on government assistance programs ${ }^{1}$ to avoid layoffs while they waited for economic conditions to improve. As expected, these conditions were particularly pronounced for producers whose main markets were finance and other corporate sectors, given the recent collapse of major financial institutions, the bailout of banks by national governments, and the downturn in stock markets across the world.

\subsubsection{Survey questionnaire}

\subsubsection{Introduction}

The exploratory survey instrument was designed to solicit a broad array of information about firm performance and industrial practices in this sector through basic closed-ended questions (see Appendix IV). In particular, it focused on the following areas: firm history and ownership, foundations of success, competitive strategy, sources of knowledge,

\footnotetext{
${ }^{1}$ Work-Sharing is an adjustment program of the Government of Canada designed to help employers and employees avoid layoffs when there is a temporary reduction in the normal level of business activity that is beyond the control of the employer. The measure provides income support to employees eligible for Employment Insurance benefits who work a temporarily reduced work week while their employer recovers.
} 
performance, and the presence of design activity, if any. In addition, information was collected about practices related to worker recruitment, training and development, retention, and labour management techniques during periods of economic downturn.

\subsubsection{Sample, development and administration}

The survey sample was drawn from an initial industry list of NAICS 3372 made publicly available online by Industry Canada (IC), which was then cross-referenced with Scott's Industrial Directory of Canadian Manufacturers. The initial list yielded a total of 450 firms in the industry, which was then stratified by firm size to exclude all firms with less than five employees, for a total of 302 firms. Further research uncovered that 84 of these firms had either gone out of business or were not relevant, and were thus eliminated. In order to learn about relevant firms that did not appear on my original cross-referenced list, I conducted research in market research reports and trade journals, I attended two trade shows, and I conducted key informant interviews. This information revealed an additional two firms that were not on the original IC/Scott's lists. In the end, the list was refined to a final industry sample of 220 firms.

I elected to administer the questionnaire as an online internet survey rather than a postal survey, in order to reduce costs and expedite access to the sample of research participants (who presumably spend considerable time at their desks). I designed it such that coded responses became automatically downloaded into an SPSS database, thus greatly facilitating the processing of data. Although time consuming at the front end, this 
approached saved considerable time at later stages of the project when I was busy coding interview data. $^{2}$

The questionnaire was administered initially to a small number of pilot participants $(n=5)$, senior managers in the industry whom I had previous personal contact with, having either interviewed them or met them at trade fairs. The pilot questionnaire enabled me to refine the terminology, list of questions, and scope of analysis, from which I made revisions and subsequently launched it to firms across Canada. The survey was administered between January and September 2010 and targeted senior managers, in particular plant, production or human resources managers or firm founders, as these individuals were deemed most closely involved with and knowledgeable about the survey content.

At the outset, I struggled greatly with a low response rate, likely due to the fact that it was sent out en masse to the full list of industry contacts I had compiled, and not tailored specifically to the individual recipient. Based on advice from my committee, I revamped my approach to take the extra time at the front end to customize each email to the individual participant. In addition, I enlisted the assistance of a student to help me follow-up with individual firms via telephone in order to get a commitment from the respondent to complete the survey, and to determine if they would prefer to do so online or in hard copy. In the end, these strategies were successful and resulted in a response rate of $46 \%$, based on 101 useable returns.

\footnotetext{
${ }^{2}$ Using software by Survey Monkey®, I designed and developed an online questionnaire that was made available from a bilingual email invitation (Appendix I) via a webpage titled 'Manufacturing

Competitiveness' / ' Compétitivité industrie manufacturière', which summarized the key goals and scope of the research, information about project funding, and incentives for participating (Appendix II). As per the guidelines stipulated by the Office of Research Ethics (ORE), the survey included a consent sign-off statement just prior to the start of the questionnaire (Appendix III).
} 


\subsubsection{Representativeness of the survey sample}

Data shows that there is not a significant bias in the response sample of firms in comparison to the larger industry in terms of geography, firm size, and firm age, the three variables for which I have data for the non-respondent firms. For geography, Industry Canada (2011) indicates that of the $98 \%$ of Canadian firms in the case study, $57 \%$ are based in Ontario, 26\% in Quebec, and the remaining balance of 17\% are located in the West. My sample is fairly consistent: 60\% of firms are in Ontario, $18 \%$ are in Quebec, and $22 \%$ are located in the western provinces (Table 1.1). The region showing the most significant underrepresentation in comparison with the 2011 data is Quebec, as I expected $26 \%$ of firms in the larger industry and my sample reflects only $18 \%$. One might assume it was a language issue since the majority of firms are French speaking. However, as discussed, I developed a French survey specifically for this market, and all correspondence and follow-up calls were conducted in French. In fact, much time and resources were invested in upping the response rate for this region, but unfortunately, these firms proved far more challenging to engage than those in the other regions.

Statistical tests reveal that there is no significant difference between the respondent and non-respondent samples in terms of firm size and firm age. Mean firm size (number of employees) for the sample is 90 , and the median firm size is 18 . This can be compared to the mean size of firm for those that did not respond which is 76 , and the median size of firm, which is 25 . Based on a p-value of .201, Mann-Whitney U tests show that there is no significant difference between the respondent sample and the nonrespondent sample in terms of firm size. Likewise, the mean age of firm for the sample is 
33 years and the median age of firm is 29 years. The mean and median age of firm for those that did not respond is 31 and 27 years, respectively. Based on a p-value of .687, Mann-Whitney U tests reveal that the respondent firms are not significantly older than the non-respondent firms.

Table 1.1: Comparison of industry and survey sample by geography

\begin{tabular}{|c|c|c|}
\hline & $\begin{array}{c}\text { Number of office furniture } \\
\text { establishments (NAIC 3372) by } \\
\text { region, in percentage (\%) }\end{array}$ & $\begin{array}{c}\text { Author's survey response rate by } \\
\text { region, in percentage (\%) }\end{array}$ \\
\hline ON & 57 & 60 \\
\hline QC & 26 & 18 \\
\hline West & 17 & 22 \\
\hline
\end{tabular}

Source: Industry Canada, 2011.

\subsubsection{In-depth interviews}

\subsubsection{Introduction}

The primary method for gathering information for the in-depth qualitative component of this research was semi-structured, face-to-face interviews, which allowed for a more detailed probing and insight into what are presumably learned behaviors (or not), one of the central ideas of this research. As Schoenberger (1991) discusses, although interviews can involve complex relationships between interviewer and interviewee, if carefully used they can provide a qualitative context that amplifies and enriches the meanings derived from quantitative methods. Clark (1998) adds that this research technique, or what he calls 'close dialogue', can play an important role in promoting theoretical innovation by enabling a researcher to build a picture from below, from the details gleaned from dialogue and the knowledge of others. This produces a fine-grained, substantive 
appreciation of diversity and is a means of better understanding the actual practice of decision-making in firms.

\subsubsection{Sample, participants and approach}

For the interview component of my research, I used a 'purposeful' sampling technique identified by Patton as suitable for qualitative analysis because it enables one to select 'information-rich cases for study in greater depth so as to learn a great deal about matters of central importance to the research' (Patton 2002). To this end, I identified a subset of leading Canadian firms that fit the following pre-determined criteria: globally competitive, design-led, and high-quality. This exemplifies what Patton refers to as 'criteria' sampling and I identified this sample through several means. First, I reviewed government statistics, market research reports, commentaries on the industry found in trade journals and newspapers, participation at trade shows, as well as preliminary results from both the survey and key informant interviews. ${ }^{3}$

Five groups formed the basis of my in-depth research interviews. These included 1: senior managers (and where possible, firm founders), 2: designers (both in-house designers and external industrial design consultants), 3: production staff, 4: professional users, and 5: representatives from trade / professional organizations and government agencies. In total, 70 personal interviews were conducted between November 2009 and July 2010 with intermediaries and individuals representing 20 leading firms throughout

\footnotetext{
${ }^{3}$ Recognition of the central role played by foreign-born (and other mobile) entrepreneurs informed the basis on which results were disaggregated and analyzed: by national origin of firm founder, as categorized by Continental Europe (CE) and Anglo-America (AA). In subsequent analyses, the sample was also grouped and analyzed by geographic region (Ontario, Quebec, West), firm size (1-50, 51-100, 101$500,>500$ ), and by firms who carry out design versus those that do not.
} 
Ontario, Quebec and the western provinces. In addition to these primary methods, I also participated in two international trade fairs in Toronto, as well as lengthy tours of eight plants representing all three regions: four facilities in Ontario, two in the West, and two in Quebec (for a complete breakdown of interview participants by geography, occupation and organization, see Tables 2.1 and 2.2, and Figures 2.1 and 2.2).

The purpose of the interviews with the first group, senior managers, was to elicit information about their personal background and career history, the history of the firm in which they work, the culture and primary markets of the firm, practices in the area of design (if applicable), production, and human resources, questions pertaining to their key competitors, suppliers and users, and foundations of competitive success (Appendix VII). Several of the same types of questions were posed to senior in-house designers, but I placed greater emphasis on design practices (Appendix VII). For external, freelance design consultants, my questions were geared towards understanding the nature of their temporary engagement with firms in the industry, the way in which design is organized in this sector, and the geography of design activity (Appendix VIII). Interviews with shop floor employees were directed at understanding the educational and career history of interview participants, practices of recruitment, training and development, degree of flexibility and autonomy in the workplace, the nature of management / employee relations, and finally, the importance of teamwork and collaborative relations (Appendix IX). The interviews with professional users were focused on the nature of their engagement with the producer firm, and the means by which they garner end user knowledge, pull producers into the innovation process, and integrate user knowledge into product development. The interviews with representatives from intermediary 
organizations varied in large part according to their position, the organization for which they work, and their area of expertise. I sought to glean perspectives on specific occupations within the sector, the Canadian and / or North American contract furniture market, and/or the broader Canadian manufacturing industry. In sum, by organizing the interview component of the research in this manner and drawing on complementary groups of industry experts, both inside and outside the manufacturing firm, I was able to acquire an in-depth understanding of strategies, practices and outcomes that have shaped the Canadian industry, and to triangulate findings across individuals and groups.

Minichiello et al. (1995) advises that the most important consideration in question order during the interview process is in preserving rapport between the interviewer and informant, as the relationship established between the two is often critical to the collection of opinions and insights. Taking this into account, I began with some factual, easy-to-answer questions on general issues, followed by a gradual move towards more personal or sensitive matters specific to the informant (Hay 2000). I used an interview guide to direct discussion and to ensure consistent coverage of key issues across the different groups of interviewees. However to explore unanticipated topics related to my core research questions, I did allow participants to diverge from the guide and raise additional issues. The cultural nuances of the study groups necessitated variations in my intended interaction and it was thus imperative to acquaint myself with the cultural context of each informant prior to the interview. My approach quickly became easier and more fluent with experience. The interview questions were designed to be open-ended with the format as fluid and conversational as possible, and I attempted to prompt areas of interest and importance to the interviewee. As the research progressed, I made changes 
to the order and wording of questions and topics if I found that it was needed, as new information and experiences were fed back into my research design. Adelman (1981, in Hay 2000) advised that I maintain a 'critical inner dialogue' during interviews. This required that I constantly analyze what was being said and simultaneously formulate the next question or prompt, asking myself whether I understood what the informant was saying or not. This meant that in my approach, I attempted to prevent comments that I did not understand from sliding by, with the expectation that I would be able to make sense of them afterwards.

I contacted potential participants by phone or email, as appropriate, to introduce the project and to request an in-person interview. Participants were provided with a brief description of the project, as well as assurances of anonymity and confidentiality prior to gaining their consent for the interview. For the most part, consent was gained in writing. Ten out of the 70 interviews were conducted over the telephone, in which cases consent was recorded on tape. The interviews lasted between roughly 45 minutes and 2 hours and were taped with the permission of the participants and notes taken throughout the duration. The majority of interviews were carried out at the manufacturing firm or place of work, yet in a small number of cases, they were conducted at a cafe or the interviewee's home.

All interviews were transcribed verbatim to ensure that the richness and texture of comments, the style of speech, and the subtle nuances of the commentary were retained. Together, the interviews, along with my hand-written notes of personal observations, as well as the survey results, formed the data from which I conducted my analysis. Through reading over these texts, and building on ideas developed during the fieldwork, I 
determined codes for reoccurring themes, and looked for repetition, relationships, and patterns, and I also related these themes to the theoretical literature that I was reading before, during, and after the fieldwork period. In other words, data collection and analysis were not discrete processes, but rather processes that constantly overlapped. Thus themes emerged from the data in an iterative manner, much like how Clark $(2007,191)$ describes, as he tends to "work backwards and forwards between theory and the empirical world in a reflexive manner." I began the process of data management, coding and interpretation using NVivo qualitative data software. However while this proved invaluable at the outset as an initial means by which to organize large amounts of qualitative information, in the end, I found that reading and re-reading the texts myself was a preferable format. This is because I discovered that it was often difficult to predict the precise degree of coding detail that was required until it came time to write.

\subsubsection{Issues of access, power and positionality}

As anticipated, there were distinct issues of access, power and positionality across the various groups of interview participants. Surprisingly, access to senior managers did not pose much of a challenge, as most individuals quite willingly agreed to be interviewed after being informed of my research goals and intentions. Likewise, there were no significant difficulties in setting up interviews with either designers or representatives from intermediary organizations. By contrast, however, production workers proved to be quite inaccessible, for two main reasons. First access to shop floor staff necessitated permission from, and coordination by, their supervisors. Their temporary absence from the production floor is not an altogether straightforward process, given the hands-on, fast- 
paced, team-dependent nature of their work. Second, because contact information for hourly employees is rarely made publically available (i.e. via company websites, etc.), I had no choice but to rely on senior individuals to carry out the candidate selection process on my behalf.

The inaccessibility of this group results in two potential weaknesses in this research. First, the sample is limited by geography, representing workers at Ontario plants only. This is because my access to these individuals was dependent upon my ability to build relations and trust with their superiors beforehand. This took time, a luxury that I did not have while conducting fieldwork during brief stints in Quebec and western Canada. Second, having been chosen by their supervisors, the sample may be biased towards employees with a certain disposition, perhaps more likely to sing a company's praises than to reflect critically on the nature of management / employee relations and industrial practices on the shop floor.

Given that a fundamental component of my dissertation research involved corporate interviews with senior executives, most of whom were male, it was important to be aware of what Clark (1998) has identified as the intimacy of close dialogue. There are reasons to be concerned that interviews of this nature may deliver information that is 'tainted by suspect motives', in other words, vulnerable to systematic and random errors because they rely on respondents telling the truth about themselves and their industry. In these circumstances, methodological rigour has demanded a sustained level of reflexivity on my part and a critical awareness in the sense of not necessarily trusting everything I was told. In short, I sought to be wary of simply recording and reporting. 
Moreover, as a young female interviewer, there were also obvious and inherent issues of power and identity at play. As Hay $(2000,193)$ points out, "A researcher has a social, locational and ideological placement relative to the research project or to other participants and it may be influenced by biographical characteristics such as class, race, and gender, as well as various formative experiences." Prior to entering the field and at various stages of contacting and interviewing informants, I tried to be aware of my own positionality as a researcher. This meant that throughout the research process, I sought to be critically self-reflexive and transparent about the possible influence of interpersonal factors on the information that I subsequently used in my analysis.

In a related vein, according to Valentine $(1997,113)$,

Sharing the same background or similar identity to your informant can have a positive effect, facilitating the development of a rapport between interviewer and interviewee and thus producing a rich detailed conversation based on empathy and mutual respect and understanding.

In fact, one influential factor in choosing this research topic in the first place was my curatorial expertise and background in design. ${ }^{4}$ Thus my strong knowledge of the principles of contemporary design and my comfort with the cultural nuances of the design community was an asset in the field, which ultimately helped me to mitigate the problems a complete outsider might have faced. This knowledge also enabled me to assert authority during interviews, particularly with corporate elites, so that I could push participants to give a greater degree of detail.

\footnotetext{
${ }^{4}$ Prior to my PhD, I worked in curatorial practice and collections management at Toronto's Royal Ontario Museum (ROM). During my tenure at ROM, I managed one of the museum's largest collections of artifacts and works of art in the Anthropology Department, authored a book titled DECO LALIQUE: Creator to Consumer, which explores the consumption of Art Déco in Canada, and curated a major exhibition of the same name.
} 


\subsubsection{Research design: concluding remarks}

In summary, my goal during the survey, interviews and my overall research design was to purposely seek out a diversity of opinion and experience. When multiple methods are used in the way that I have described, the material generated by each technique does not always reinforce or validate that produced by the other; but rather different techniques may throw up apparently very contradictory findings. Valentine (2001) says that such findings are not a problem but rather show how successful one can be at capturing the complexities, contradictions, ambiguities and messiness of human behavior and everyday life. The secret of a good research design, therefore, is not to produce a nice linear, consistent story but rather to be able to recognize why the accounts generated by a mixed methods approach can be so different from one another. I have found that these differences, contradictions and complexities have produced a fuller and richer understanding of my research questions.

\section{4: Structure of the thesis}

This thesis is organized into five chapters, starting with the introductory chapter. The following three empirical chapters comprise the substantive contribution of this thesis, with each individual chapter taking a unique focus within the broader topic of learned behaviour, and engaging with complementary bodies of theory and literature throughout. Each paper seeks to advance our understanding of the various research questions that have been identified above.

Chapter Two investigates how firms 'learn' what to produce and how to produce from immigrant (and other mobile) entrepreneurs, and explores the institutional 
foundations of innovation and competitive advantage in Canada's contract furniture manufacturing sector. This chapter connects to ongoing work in economic geography and the social sciences to enhance our understanding of the role of institutions in shaping firm practice and competitive outcomes, and seeks to advance a more agency-centered institutionalist economic geography. The chapter focuses on three dimensions of industrial practices: the use of training and investments in technology, the nature of employment relations, and the use of design. The analysis reveals that the most globally competitive firms operating in a Canadian institutional context prosper by learning a set of production practices and the value of design-intensive products from the embodied knowledge of their founders (and other senior managers), who, as indicated above, have lived, studied and worked within the high-wage, coordinated market economies of Continental Europe. The ability of these entrepreneurs to transfer corporate knowledge from Continental Europe to Canada has had direct benefits for learning and innovation processes critical to the synthetic knowledge base of this sector. This critical flow of embodied knowledge, I suggest, has been instrumental in the ability of leading Canadian firms to overcome regulatory obstacles that run counter to the development of a highskilled manufacturing strategy, and, ultimately, in propelling the Canadian industry to international success.

In Chapter Three, I analyze the way in which firms in the case study 'learn' what to produce from industrial designers. I draw on the knowledge base approach that has emerged within the geography of innovation literature to identify a two-fold industrial knowledge base that predominates in design-oriented manufacturing - synthetic knowledge and symbolic knowledge - with each said to rest on dramatically different 
labour market dynamics. I then investigate the specific design practices that support each sphere of knowledge in the case study, and the various geographies of these practices. The analysis reveals that stable employment relations (in the form of an in-house design team) foster a work organization that supports the creation of synthetic knowledge by facilitating spatial proximity between economic actors, and contributes to incremental innovation. By contrast, short-term structures (namely the employment of temporary, project designers) promote symbolic knowledge formation, creativity, and a more radical innovation process. A firm's temporary engagement with internationally recognized designers who are located in geographically distant markets is mediated within communities of design practice, and supported by the development of relational proximity, which is further enhanced by the establishment of temporary co-presence between distanciated designers and their counterparts in the Canadian firms.

Chapter Four also investigates how firms 'learn' what to produce, yet in this case the source is clients and users. Drawing on Lundvall's theory of user-producer interaction $(1985,1988)$ as well as related literatures in innovation and industrial organization theory, Chapter Four examines the importance of user involvement in the innovation process in a manufacturing sector that is dependent upon a high degree of design-intensity, quality and customization. It also explores the social and organizational practices through which (professional) user knowledge (professional user segments including both the furniture dealer and interior designer / architect) is integrated into development processes, both informal and formal practices, as well as their dynamics, spatiality and temporality. Research from the case study shows that the development of trust-based user-producer relations are dependent upon spatial proximity between 
economic actors, a condition that encourages face-to-face interaction. These conditions are critical to the dealer - producer partnership, in which permanent forms of co-presence in the same locality / region are established. They are also important to the success of the interior designer - producer venture, which must often rely instead on temporary forms of proximity. These conditions, though not optimal, are found to be both effective and sufficient to support interactive learning between this professional user segment and the furniture producer.

The final chapter in this thesis presents concluding remarks concerning the overall theoretical implications of this dissertation, with a focus on the role of proximity and distance in the processes of knowledge creation, learning and innovation, and key contributions to the structure / agency debate. It also addresses the question of the policyrelevance of this research, and areas of future research. 


\section{Chapter II}

\section{Learning from Europe: the institutional foundations of industrial dynamics}

\subsection{Introduction}

One of the central ideas that has emerged within contemporary economic development theory is that intangible assets such as knowledge and creativity are critical determinants in shaping the innovative trajectory of firms and regions (Maskell and Malmberg 1999). For that reason, a place's ability to attract and retain mobile knowledge workers, or the oft-used term 'talent', is of paramount importance to local and regional growth (Florida 2002). Implicit in these debates is the importance of the process of mobility, or the migration of skilled and talented individuals from one country to another, as a vehicle through which human capital and knowledge are imported to a host country. Such processes are said to play a decisive role in the creation, diffusion, and international dissemination of knowledge (OECD 2002, 2008; Saxenian 2006).

The successful diffusion of corporate knowledge and organizational practices across national, cultural, and linguistic divides, is a topic that has garnered significant attention in the management literature (i.e. Kostova 1999; Bjorkman and Lu 2001; Kostova and Roth 2002; Guler, Guillen and Macpherson 2002; Aguilera and Jackson 2003; Saka 2004). A central proposition within this research is that mobile executives 
who circulate among international subsidiaries of the multi-national corporation (MNC) bring ideas and knowledge with them in embodied form. The literature on 'Japanization' is a case in point, and illustrates the viability of exporting industrial methods and modes of work organization to subsidiary operations in other countries (Womack, Jones and Roos 1990; Kenney and Florida 1993; Abo 1994, 1996). A more critical body of work and counterargument in economic geography contends that there is likely to be significant variation in the practices that have actually been implemented in institutionally diverse host environments, and that the most faithful reproductions are in settings whose dominant institutions of corporate governance, labour markets, industrial relations and capital investments most closely resemble the host environment (Gertler 2001). One area of research shows that the net result is a new 'hybrid' industrial model combining various features of both home- and host-country practices (Gertler and Vinodrai 2005).

Be it hybrid model or precise reproduction, the transfer of knowledge and industrial practices via corporate actors, and from one institutional regime to another in order to enhance innovation in new regional bases, represents a central idea in this chapter. Drawing on a case study of the Canadian contract (or office) furniture manufacturing sector, I analyze the ways in which key executives in the industry, who either hail from or have gained substantial manufacturing experience in other countries (notably the high-skill production regimes of Northern Europe), can make important contributions to manufacturing in Canada. In so doing, I draw on literatures of the geography of innovation, the more recent project ecologies research, and theory of institutional economic geography. I investigate the local labour dynamics that underpin 
innovation in contract furniture manufacturing, which combines both synthetic and symbolic knowledge, as well as the broader Canadian institutional framework that produces (and reproduces) local labour market practices.

I argue that the national regulatory environment in Canada may not be conducive to an advanced manufacturing strategy because it does not support a high-skilled model of innovation. Such a model is dependent upon an emphasis on workforce development and stable labour markets that provide the optimal conditions for employers' investments in training. Yet market governance regimes and labour market institutions in Canada are said to engender a very different set of conditions: unstable employment practices and a disincentive on the part of firms to train their employees. The complex embedding of the strategic behaviour of firms and other actors in their socio-institutional environment is a concept that is widely recognized in the institutional economic geography literature. This chapter moves beyond such an approach to consider how institutions interact with the agency of individuals and firms to shape industrial practices and competitive outcomes. Specifically, it investigates the degree to which a number of immigrant entrepreneurs who are prominent in the industry have used their knowledge of the importance of training and workforce development to bring an understanding of high performance manufacturing to Canada. This critical flow of embodied knowledge, I suggest, has been instrumental in the ability of Canadian firms to overcome regulatory obstacles that run counter to a high-skilled regime, and, ultimately, in propelling the Canadian industry to international success.

The empirical analysis investigates workplace practices in these Canadian firms according to three specific dimensions: the use of training and investments in technology, 
the nature of employment relations, and the use of design. I provide evidence to demonstrate that the transfer of manufacturing knowledge from Continental Europe to Canada has indeed taken place in the Canadian industry. Yet the interaction between the imported practices and the host institutional setting, as well as the ways in which these coalesce in a hybrid industrial model to combine both synthetic and symbolic knowledge, is both multifaceted and complex. By way of conclusion, I offer summary comments and identify implications for theory.

\subsubsection{The international mobility of manufacturing talent}

As we enter an intensified phase of globalization in the present period of capitalist activity, transnational entrepreneurship and the mobility of the highly skilled are increasingly widespread phenomena. Likewise, foreign-born, skilled entrepreneurs represent an ever-more powerful force in 21st century economic development, both directly as entrepreneurs, and indirectly as facilitators of trade with and investment in their countries of origin (Saxenian 2002; see also Waldinger, Aldrich and Ward 1990; Kloosterman and Rath 2003). One vein of research finds that immigrants start new businesses, generate jobs, exports and wealth, as fast as their native counterparts; yet they also foster a region's integration into the global economy (Borjas 1994, 1995; Friedberg \& Hunt 1995; Smith \& Edmonston 1997). Dalziel (2008) and Portes and Sensenbrenner (1993) find that amongst highly successful entrepreneurs, immigrants outperform nonimmigrants on the basis that they may be more likely to have certain personality traits and social networks that are conducive to business success. 
Research in both policy and academic circles shows that skilled immigrants can be a vital source of innovation and high-tech entrepreneurship, and that the inflow of talent can have a positive impact on science and technology assets in receiving countries (OECD 2002; Saxenian 2006). For example, Saxenian (2006) demonstrates how foreignborn talent transfers institutional know-how from one country to another in order to establish technology operations to new regional bases. The key agents and actors in this study are a set of immigrant entrepreneurs who bring their know-how to bear on the development of overseas operations. Their migration to the US, and subsequent return migration from Silicon Valley back to their countries of origin, constitute a vehicle through which human capital and institutions are imported.

The successful transfer and implementation of institutional know-how from one industrial regime to another is particularly crucial in the case of the Canadian industrial workplace, given that the dominant institutions of corporate governance, labour markets, and industrial relations may run counter to an advanced manufacturing strategy. Moreover, research from the case study has revealed that a disproportionate number of senior managers and entrepreneurs have accumulated extensive international experience, having immigrated to Canada from Northern Europe, where they would have acquired valuable design and manufacturing knowledge working within diversified quality production regimes. Foreign-born or not, a significant proportion of the industry's key corporate actors have either acquired their education, training or professional experience in countries such as Germany, Denmark or Italy, regularly attended major trade shows in these countries, visited manufacturing plants there, or experienced a similar kind of exposure to Continental European manufacturing practice. During initial key informant 
interviews, for example, one firm founder of German descent said that 'there was a community of people here in Toronto during the 1960s that were the seeds of the contract industry in Canada, many of them of German background.' Likewise, the history of the flourishing Calgary industry can be traced to the immigration of a number of skilled Danish craftsmen and their families, many of whom had undergone apprenticeship training in upholstery, furniture and the skilled trades prior to their arrival in Canada. The knowledge that these individuals have acquired during their experiences abroad may have played a role to propel the Canadian industry to international success, and the purpose of this chapter is to explore evidence supporting this claim.

\subsubsection{The institutional foundations of competitive advantage: a disjunction at the national scale?}

Scholars who draw upon the literature of the geography of innovation suggest that different industries rely on different knowledge bases for activities that are most central to their competitiveness (Asheim and Gertler 2005; Gertler 2008). Within each knowledge base, the precise roles of tacit and codified knowledge, and the labour needs for innovation, are said to differ accordingly. While the lead proponents of this view acknowledge that knowledge involved in innovation is increasingly complex and multidimensional (see also Sunley et al. 2008 for a thorough discussion of design knowledge), they nonetheless imply that there are two predominant kinds of industrial knowledge that underpin innovation in design-led, complex manufacturing: synthetic knowledge and symbolic knowledge.

Inherent in this view is that synthetic knowledge prevails in industrial settings where innovation takes place mainly through the application or novel combination of 
existing knowledge, and involves incremental developments (Asheim and Gertler 2005).

The formation of this type of industrial knowledge rests on the capacity of an organization to build a wealth of skill and problem-solving capability among its workforce through many years of training and learning-by-doing. Of fundamental importance is the ability of workers to develop a high level of expertise through consensus-based working relations that are cultivated in the workplace over the long-term (Gertler 2004).

Innovation in furniture production is also dependent upon creative and design inputs, for which symbolic knowledge is crucial. Symbolic knowledge is said to underpin economic activity that is focused on creating aesthetic meaning and symbolic value, and involves the creative process (Asheim, Coenen, and Vang 2007; Gertler 2008). Unlike analytical- or synthetic-based industries that compete primarily on the use-value of their products, the economic value of symbolic-based industries tends to arise through intangible assets, namely their aesthetic character or 'sign-value' (Lash and Urry 1994; Scott 2000). The growing literature on project ecologies contends that the creative process (and symbolic knowledge formation) is facilitated by short term employment structures, open labour markets, and the rapid movement of skilled workers between firms and projects (Grabher 2002; Christopherson 2002a).

Industrial practices that underpin design-intensive furniture manufacturing, both the long-term, high-skill conditions conducive to synthetic knowledge formation, as well as short-term, flexible systems more consistent with symbolic knowledge creation, are shaped by a set of nationally-anchored institutions that define the fundamental incentive structure guiding firm behavior. This insight constitutes one of the core ideas that has 
emerged from the institutional economic geography literature, in particular national business systems and 'varieties of capitalism' (i.e. Maurice et al. 1986; Aoki 1988; Albert 1993; Gertler 1995; Wever 1995; Streeck 1996; Pauly and Reich 1997; Lam 2000; Gertler 2001; Hall and Soskice 2001; Christopherson 2002b; Lam 2002; Gertler 2004; Dunford 2005; Clark and Wojcik 2007). As Lam (2000, 2002) argues, specific macro level institutional configurations and organizational forms promote different micro level labour market practices and paths of career development. For example, capital market institutions are said to shape time horizons and expectations concerning paybacks from investment. Likewise, labour market and industrial relations institutions determine the strength of incentives for firms to provide training, rates of labour force turnover, and other complementary practices such as the degree of participation of shop floor workers in firm decision-making.

Yet the prevailing structure in Canada, this theory contends, is one typical of other Anglo-American, liberal market economies (LME), whereby short-term investment regimes and labour market institutions engender unstable employment relations (Hall and Soskice 2001; Christopherson 2002b; Gertler 2004). Despite the obvious links between labour force development and firm performance, the importance of training in Canada and other LMEs tends to be undervalued, and firms maintain much shorter-term relations with their workers. The situation in Canada can be contrasted with the coordinated market economy (CME) in countries such as Germany, the Nordic countries, and Japan. Here, market governance regimes and industrial relations institutions are said to produce more long-term, stable employment relations beneficial to synthetic knowledge creation, a flattening of organizational hierarchies to enhance the empowerment of shop floor 
workers and the internal flow of information, and a strong propensity for firms to invest in the development of their workers (Hall and Soskice 2001; Christopherson 2002b; Bathelt and Gertler 2005). This theory claims the establishment of institutionally mediated forms of comparative advantage, as is evident in the global dominance of certain Continental European and Asian countries in engineering and complex manufacturing, Germany and Japan being the iconic examples.

The nature of labour market institutions and corporate governance regimes that are inherent in Canada provide the appropriate institutional conditions in which design inputs into the product development process may thrive (Hall and Soskice 2001; Christopherson 2002a; Vinodrai 2006). However, the ease with which the necessary labour needs are met for the industrial manufacturing and synthetic knowledge aspect is less clear. This literature review would seem to suggest that the Canadian industrial workplace presents regulatory obstacles towards the achievement of high performance manufacturing practice due to unstable employment conditions and endemically low levels of skill development by firms in the Canadian economy. In other words, there is a gap in manufacturing practice in Canada that may be understood as an incompatibility between the need for a high-skill, long-term strategy, on the one hand, and a national regulatory framework that does not support this strategy, on the other.

\subsubsection{Bridging the skills gap: knowledge flows and industrial practices from Continental Europe to Canada}

Yet despite these apparent institutional obstacles, and in the midst of widespread, longterm economic downturn throughout the Canadian manufacturing landscape, the Canadian furniture industry has demonstrated resilience and vibrancy. It is emblematic of 
key dimensions of economic change in the Canadian manufacturing industry since the advent of trade liberalization with the US in 1989, and later NAFTA. As discussed at length in Chapter One, the contract furniture subsector was the engine behind the strong performance observed in the broader furniture industry, which was the fastest growing manufacturing industry in Canada from 1999 to 2002, almost doubling its exports to the US between 1999 and 2005 from \$54 to \$94 billion USD (Industry Canada 2007, 2008). The contract sector substantially outperformed other furniture segments during the immediate post-NAFTA era, with an annual trade surplus in 1997 of $\$ 722$ billion versus $\$ 229$ billion for the household segment, and a growth in its share of total furniture production (1989 to 1997) from 54 to $64 \%$ compared to decline in the household sector from 45 to $26 \%$. It continued to see higher performance levels compared to its household counterpart in the following period as well, with manufacturing revenues per employee in 2009 at $\$ 160,000$ versus $\$ 120,000$ for the household segment, and manufacturing valueadded per employee in the same year at $\$ 84,000$ compared to $\$ 60,000$ for the domestic sector.

Given the strong performance of this subsector of the furniture industry, this chapter tests the proposition that the industry's key executives who have garnered strong manufacturing knowledge from experience in other countries have acted as conduits of knowledge transfer, bringing an understanding of alternative practices to Canada. There are obvious benefits derived from the ability of Canadian firms to borrow employment practices that prevail, in this case, in the coordinated market economies and high-skill manufacturing regimes of Northern Europe. The ability to do so has direct impact on 
knowledge creation and innovation processes critical to the synthetic knowledge base of this sector.

This chapter therefore hypothesizes that the most competitive firms operating in a Canadian institutional context prosper by learning a set of production practices and the value of design-intensive products from the embodied knowledge of their founders and / or other senior managers, who have lived, studied and worked within high-wage, coordinated market economies of Continental Europe. The research questions are these: to what extent have the distinctive features of manufacturing systems and practices originating in Continental Europe been transferred to and replicated in Canadian firms? What is the role of the embodied knowledge of immigrant (and other mobile) entrepreneurs in propelling the Canadian industry to success? To what extent do incompatible institutional features of the host Canadian economy limit or shape the manner in which such imported practices can be implemented?

\subsection{Case study and research design}

The empirical analysis in this chapter has been designed to address these research questions directly. It focuses on the industrial and design practices of Canadian contract furniture manufacturing firms located in Ontario, Quebec and the western provinces, which together represent $98 \%$ of the total industry (Industry Canada 2011). This sector provides a compelling case study due to its strong growth since the 1990s, at which time firms operated in a context of a strong US economy, a weak Canadian dollar, ${ }^{5}$ and

\footnotetext{
${ }^{5}$ A decline in value of the Canadian dollar (CAD) relative to the currencies of major competitive countries such as the US following NAFTA and up to 2002 is undoubtedly a crucial factor underpinning economic growth in the contract furniture subsector during this period, driving both domestic manufacturing costs and revenue from exports in Canada's favour. However, this does not explain the industry's continued
} 
intensified economic openness on continental and global scales. Despite heightened competition from low-cost manufacturers in China as well as high-cost, design-oriented producers in the US and Europe, these favorable economic conditions enhanced opportunities for Canadian firms to expand sales into US markets, and globally. The research design presented here involves a multiple-methods research approach entailing an on-line industry survey to the full population of firms in the industry $(\mathrm{N}=220 ; 46 \%$ response rate; $\mathrm{n}=101$ useful returns $)$, as well as a series of semistructured, in-depth interviews with industry experts, both inside and outside the firm, with twenty leading firms represented in the interview sample. In order to investigate questions about industrial and design practices in the subsector, I spoke to manufacturing firm senior managers, (several of whom are also firm founders), as well as senior designers and shop floor employees. Because of the common practice in the industry of bringing in external design consultants on a temporary, project basis, a topic that is explored in detail in Chapter Three, I included a number of external contract designers in the sample too. Another vital component of the qualitative analysis also came from sources external to the firm, that of representatives from intermediary organizations including professional and trade organizations and government agencies (see Table 2.2).

pattern of growth in the subsequent period, in particular a $2.1 \%$ annual increase in manufacturing revenues per production worker that is documented from 2000 to 2009 (Industry Canada 2011a), given the steady rise of the CAD against the US greenback and other major currencies from 2002 to the present day. These conditions would have rendered domestic costs (i.e. labour) relatively higher, yet at the same time incentivized investments in capital equipment, machinery and technology outside Canada. Technological advancements from capital investments often result in a lower demand for production workers along with a rise in demand for administrative and managerial staff, which is precisely the shift that has taken place between 2000 and 2009, when shopfloor staff declined by $4.5 \%$ and administrative positions increased by $0.9 \%$ (Industry Canada 2011b). Together, this evidence points to the intensified investment by Canadian firms in capital and technology during the period, as well as other crucial factors such as the development of labour, and design. 
These individuals provided an invaluable outside expert perspective on questions about practices within the subsector, and more broadly.

The breakdown of interview participants is provided in the following tables and graphs. In total, 70 interviews were carried out, 60 of which were conducted in person at the manufacturing operation or place of work, and the remaining balance of ten were carried out over the telephone. As indicated in Chapter One, the interview sample was based on a purposeful sampling technique (Patton 2002) used to identify a subset of "leading" Canadian firms that fit the following pre-determined criteria: globally competitive, design-led, and high-quality. The breakdown of the interviewees is: 43 senior managers (including 6 senior designers), 10 production workers, 9 representatives from intermediary organizations or government agencies, and 8 external designers. The geographical representation of the research participants is: $61 \%$ of individuals are from firms based in Ontario, 23\% represent companies in the West, and 16\% are from Quebecbased manufacturers. In addition to these primary methods, I also participated in two international trade fairs, as well as lengthy tours of eight plants representing all three regions: four facilities in Ontario, two in the West, and two in Quebec.

\section{Table 2.1: Breakdown of interview participants}

\begin{tabular}{|c|c|c|c|c|}
\cline { 2 - 5 } & Ontario & West & Quebec & Total \\
\hline Senior Managers & 23 & 12 & 8 & 43 \\
\hline Internal Senior Designers* & 4 & 1 & 1 & 6 \\
\hline Production Workers & 10 & 0 & 0 & 10 \\
\hline Representatives from Intermediary Organizations & n/a & n/a & n/a & 9 \\
\hline External Designers & 4 & 2 & 2 & 8 \\
\hline Total Interviews & 37 & 14 & 10 & 70 \\
\hline
\end{tabular}

* this group overlaps with senior managers, and is thus not included in the count 
Table 2.2: Breakdown of representatives from intermediary organizations and government agencies

\begin{tabular}{|l|c|}
\hline Canadian Manufacturers and Exporters & 2 \\
\hline Industry Canada Service Industry and Consumer Product Branch/ State of Design Project & 2 \\
\hline Business and Institutional Furniture Manufacturing Association & 2 \\
\hline Association of Registered Interior Designers of Ontario & 1 \\
\hline Ontario Furniture Manufacturer's Association & 1 \\
\hline
\end{tabular}

Figure 2.1: Breakdown of interview participants by occupation, in percentage (\%)

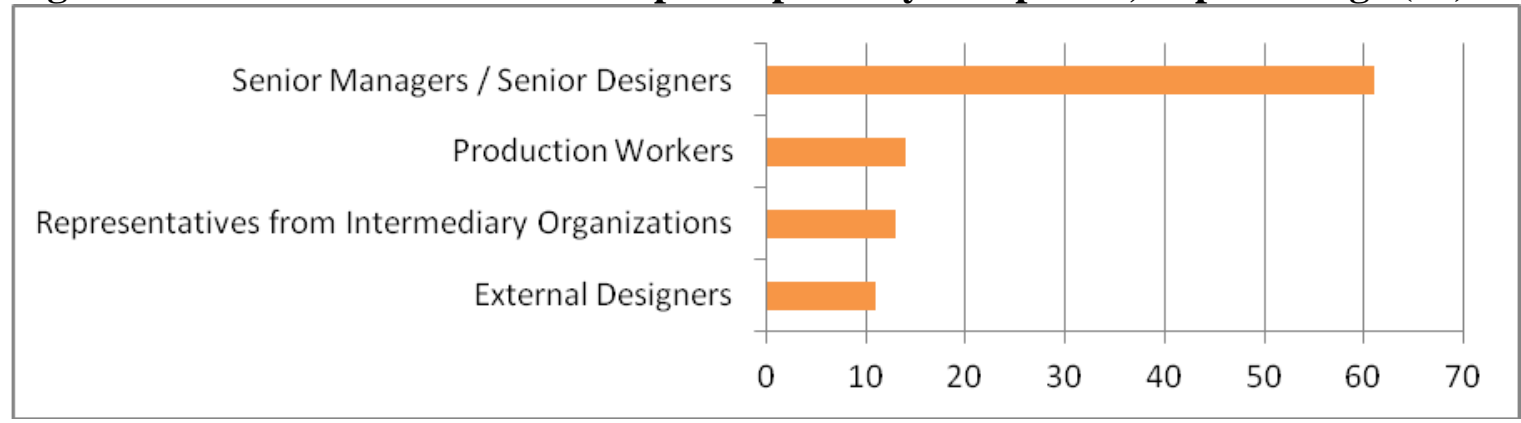

Figure 2.2: Breakdown of interview participants by geography, in percentage (\%)

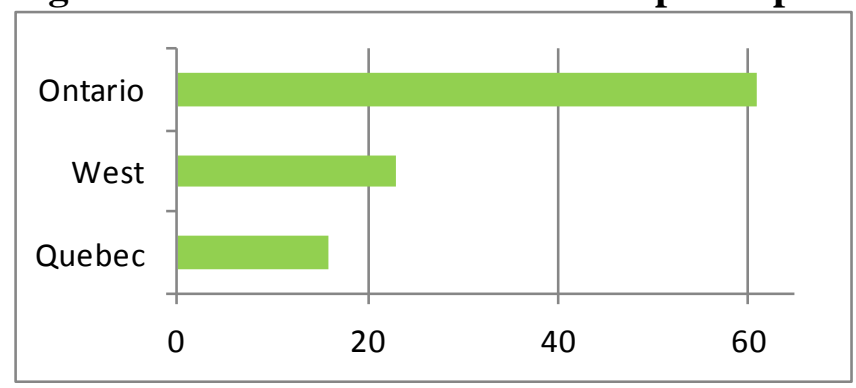

Recognition of the central role played by foreign-born (and other mobile)

entrepreneurs informed the basis on which results were disaggregated and analyzed: by national origin of firm founder, as categorized by Continental Europe (CE) and AngloAmerica (AA). ${ }^{6}$ In the following discussion, information from the survey is presented in tabular format. As will become apparent, however, its interpretation is frequently assisted by use of qualitative information gleaned from the interviews with senior managers,

\footnotetext{
${ }^{6}$ The CE sample includes not only all firms whose founders originated in CE countries, but also those who were educated or trained in these countries. The decision to organize the sample in this way is based on the hypothesis that those who studied and / or worked in Continental Europe, while not having necessarily originated there, have nevertheless had the opportunity to assimilate similar tacit (and explicit) knowledge of the manufacturing practices that predominate in such countries.
} 
designers and shop floor workers. I begin by providing a summary of overall survey findings, then I analyze workplace practices according to three specific dimensions: 1 the use of training and investments in technology, 2 - the nature of employment relations, and 3 - the use of design. I address each of these dimensions and the findings from the study.

\subsection{Analysis of findings}

Table 2.3: Characteristics of survey respondents

\begin{tabular}{|c|c|}
\hline \multirow[b]{3}{*}{ Percentage distribution of firms by region } & $60 \%$ Ontario \\
\hline & $22 \%$ Western Canada \\
\hline & $18 \%$ Quebec \\
\hline Mean size of firm (employment), range & $90,5-2000$ \\
\hline Mean age of firm (years) & 33.3 \\
\hline $\begin{array}{l}\text { Skilled employment as percentage of overall employment } \\
\text { (education) }\end{array}$ & 34 \\
\hline $\begin{array}{l}\text { Skilled employment as percentage of overall employment } \\
\text { (occupation) }\end{array}$ & 69 \\
\hline Percentage of firms Canadian-owned & 97 \\
\hline Percentage of firms privately held & 98 \\
\hline Percentage of family firms & 66 \\
\hline Percentage of firm founders born outside Canada & 42 \\
\hline \multirow[b]{7}{*}{$\begin{array}{l}\text { Geography of origin country of firm founders born outside Canada, } \\
\text { in percentage }\end{array}$} & $2 \% \mathrm{US}$ \\
\hline & $17 \% \mathrm{UK}$ \\
\hline & $17 \%$ Germany \\
\hline & $17 \%$ Nordic countries \\
\hline & $17 \%$ Italy \\
\hline & $\begin{array}{l}19 \% \text { Other European } \\
\text { Continental countries }\end{array}$ \\
\hline & $\begin{array}{l}11 \% \text { Non Anglo-American, Non } \\
\text { Continental European countries }\end{array}$ \\
\hline Percentage of firm founders educated or trained outside Canada & 29 \\
\hline \multirow{4}{*}{$\begin{array}{l}\text { Geography of country in which firm founder was educated or } \\
\text { trained, in percentage }\end{array}$} & $10 \%$ US \\
\hline & $37 \%$ Germany \\
\hline & $16 \%$ Nordic countries \\
\hline & $37 \%$ Italy \\
\hline
\end{tabular}

Source: Author's survey of Canadian contract furniture sector, 2010 
Table 2.4: Mean score to describe characteristics of production based upon the following scales

\begin{tabular}{|c|c|c|}
\hline Quality & 1 (low quality) and 7 (high quality) & 6.4 \\
\hline Design-Intensity & 1 (generic) and 7 (deign driven) & 6.0 \\
\hline Degree of Customization & $\begin{array}{l}1 \text { (high volume production for mass markets) and } 7 \\
\text { (small batch production for niche markets) }\end{array}$ & 5.7 \\
\hline Flexibility of Operations & $\begin{array}{l}1 \text { (infrequent changes to product line) and } 7 \text { (highly } \\
\text { flexible, adaptive to markets) }\end{array}$ & 6.0 \\
\hline
\end{tabular}

Source: Author's survey of Canadian contract furniture sector, 2010

Table 2.5: Percentage of firms rating factors as 'Highly Important' to success

\begin{tabular}{|c|c|}
\hline Quality of Design & 78 \\
\hline Supply of workers with particular skills & 59 \\
\hline Close relations with lead customers & 70 \\
\hline Close relations with key suppliers & 74 \\
\hline
\end{tabular}

Source: Author's survey of Canadian contract furniture sector, 2010

\subsubsection{Characteristics of survey respondents}

Results from the survey show that most of the companies (87\%) are single-plant, relatively small operations. While the mean firm size in terms of employment is 90 , there is a considerable range (5-2000), and the majority of firms cluster within the 5-50 employee range. The small-scale, entrepreneurial nature of the industry is evident in the survey sample, as $98 \%$ of respondent firms are privately held and $66 \%$ are family-owned and operated. Given that innovation in the contract furniture sector is a relatively recent phenomenon that came into effect primarily following the North American Free Trade Agreement in 1989, the average age of firms is quite high, at thirty-three years. Although 97\% of companies are Canadian-owned, a considerable $42 \%$ of firm founders were born 
outside Canada, in countries such as the US, UK, Germany, the Nordic Countries and Italy. A total of $29 \%$ of founders were also educated or trained outside the country (some of whom overlap with those originating outside Canada), in the US, Germany, the Nordic countries or Italy (Table 2.3). Whether Canadian- or foreign-born, Figure 2.3 illustrates the vital role that firm founders in the case study play as sources of knowledge for innovation. Survey respondents were asked to rate the importance of nineteen sources of information to their innovation during the period 2007-2009 and results show that knowledge from firm founder(s) is the second most highly rated factor, just behind clients and customers.

Figure 2.3: Percentage of respondents rating the following sources of information as 'highly important' to innovation (2007-2009) $(n=101)$

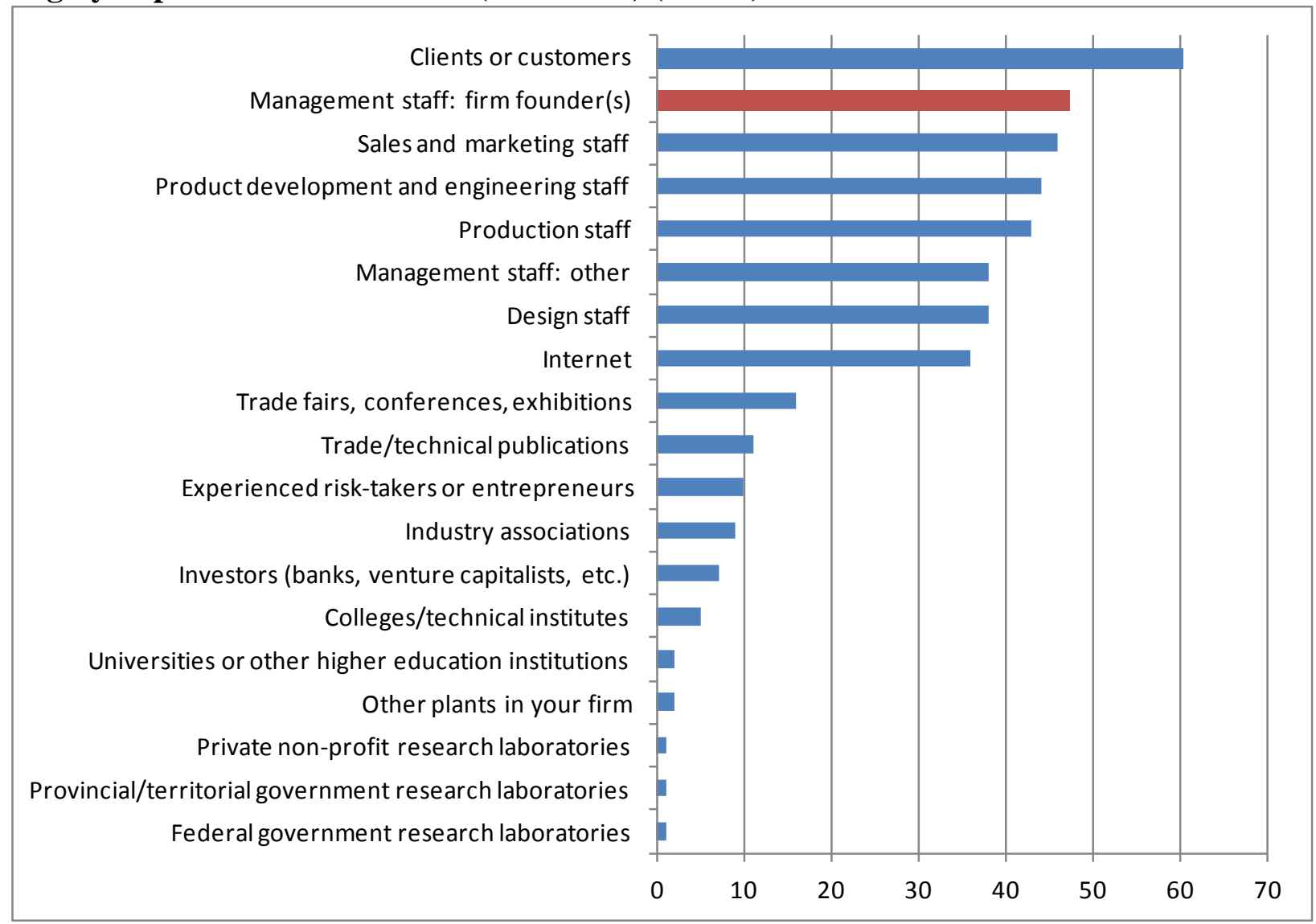


On a one- to seven-point Likert scale, firms were asked to rate their competitive strategy based upon the following dimensions: between 1 (low quality) and 7 (high quality), and between 1 (generic) and 7 (design driven) (Table 2.4). Results indicate that firms are competing in the high end of the market, with a score of 6.4 for high quality and 6.0 for design-driven. This resonates with the $78 \%$ of firms who rate 'quality of design' as 'Highly Important' to competitive success (Table 2.5).

Two indicators reveal the presence of a highly skilled manufacturing labour force in the case study. The first is a measure of worker occupation which suggests that $69 \%$ of workers in the industry hold positions that require a substantial level of expertise. The second is an indicator of educational attainment and reveals that $34 \%$ of workers are considered skilled, as defined by the proportion of individuals who hold a university degree and/or college or technical institute diploma. The fact that on average, just over one third of the workforce is skilled upon entry into the organization, yet over two thirds hold high-skill positions, indicates that a significant amount of training and development occurs in the workplace following recruitment (Table 2.3).

\begin{tabular}{|c|c|c|c|}
\hline \multirow[t]{2}{*}{ Table 2.6: Characteristics of sample groups } & & Anglo America & $\begin{array}{c}\text { Continental } \\
\text { Europe }\end{array}$ \\
\hline & $\mathrm{n}$ & 67 & 25 \\
\hline \multirow[t]{4}{*}{ Annual Sales (dollar value) } & mean & $8,524,600$ & $61,161,000$ \\
\hline & median & $2,200,000$ & $5,600,000$ \\
\hline & st. dev & $15,375,600$ & $151,882,000$ \\
\hline & $\mathrm{p}$ & \multicolumn{2}{|c|}{.105} \\
\hline \multirow[t]{4}{*}{ Productivity } & mean & 157,363 & 290,291 \\
\hline & median & 125,000 & 133,333 \\
\hline & st. dev & 134,742 & 535,250 \\
\hline & $\mathrm{p}$ & \multicolumn{2}{|c|}{.470} \\
\hline \multirow[t]{3}{*}{ Age of Firm } & mean & 26.5 & 38.7 \\
\hline & median & 20 & 36 \\
\hline & st. dev & 19.4 & 25.5 \\
\hline
\end{tabular}

Source: Author's survey of Canadian contract furniture sector, 2010 
Table 2.7: Size of firm summary Number of employees, in percentage (\%)

\begin{tabular}{|c|c|c|}
\hline & Anglo America & $\begin{array}{c}\text { Continental } \\
\text { Europe }\end{array}$ \\
\hline $5-50$ & 77.5 & 56.0 \\
\hline $51-100$ & 15.0 & 8.0 \\
\hline $101-550$ & 7.5 & 28.0 \\
\hline$>550$ & 0 & 8.0 \\
\hline mean & 51.7 & 208.2 \\
\hline median & 18 & 17 \\
\hline st. dev & 92.3 & 446.8 \\
\hline $\mathrm{p}$ & \multicolumn{2}{|c|}{.115} \\
\hline
\end{tabular}

Source: Author's survey of Canadian contract furniture sector, 2010

\subsubsection{Workplace practices in Canadian contract furniture manufacturing firms}

\subsubsection{Use of training and technology investments}

The analysis of training and technology investments focused on the skill levels of shop floor workers, training practices employed to improve the quality and supply of labour to the firm, the degree of customization and flexibility of operations, and the relative dependence upon labour versus technology.

A comparison between the two sample groups depicts clear and consistent differences among workforce skill levels. For example, 50\% of the CE workforce can be considered skilled, as opposed to $29 \%$ of the AA group, as defined by the percentage of workers having a university degree or college / technical institute training (see Table 2.8). This reveals a significantly higher level of skill development on the part of employees in the CE firms, findings that are supported consistently throughout the interviews. ${ }^{7}$ For example, one senior manager of a German-founded firm says that "Sixty percent of our staff on the floor we considered skilled individuals. We have lots of highly skilled people and that's what gives us our flexibility - they're absolutely critical to us in our

\footnotetext{
${ }^{7}$ Based on a p-value of .000 and a test-statistic of 4.637, CE firms show a significantly higher percentage of skilled employment than AA firms.
} 
innovation." In another example, the engineering manager for a firm whose founder is also of German descent describes the extensive experience required by new recruits, "For years I could only hire people with 10, 15, 20 years of experience." He explains that the need for such highly skilled individuals is a function of the complexity of the production process, which he contrasts with a typical mass production model:

I'll give you the auto industry as an example. They know exactly what the body shape is, they know they are producing thousands of that model and they'll set up product for that piece. Because of the amount of custom work we do, we're putting different pieces through every day so we have to have a more flexible system, and that requires an experienced and knowledgeable workforce.

Likewise, the president of a Danish-founded operation says that it can take between six months and a year for certain occupations (i.e. those in upholstery) to get up to a moderate level of productivity, which attests to the truly highly skilled nature of the manufacturing labour force.

Table 2.8: Skills and training

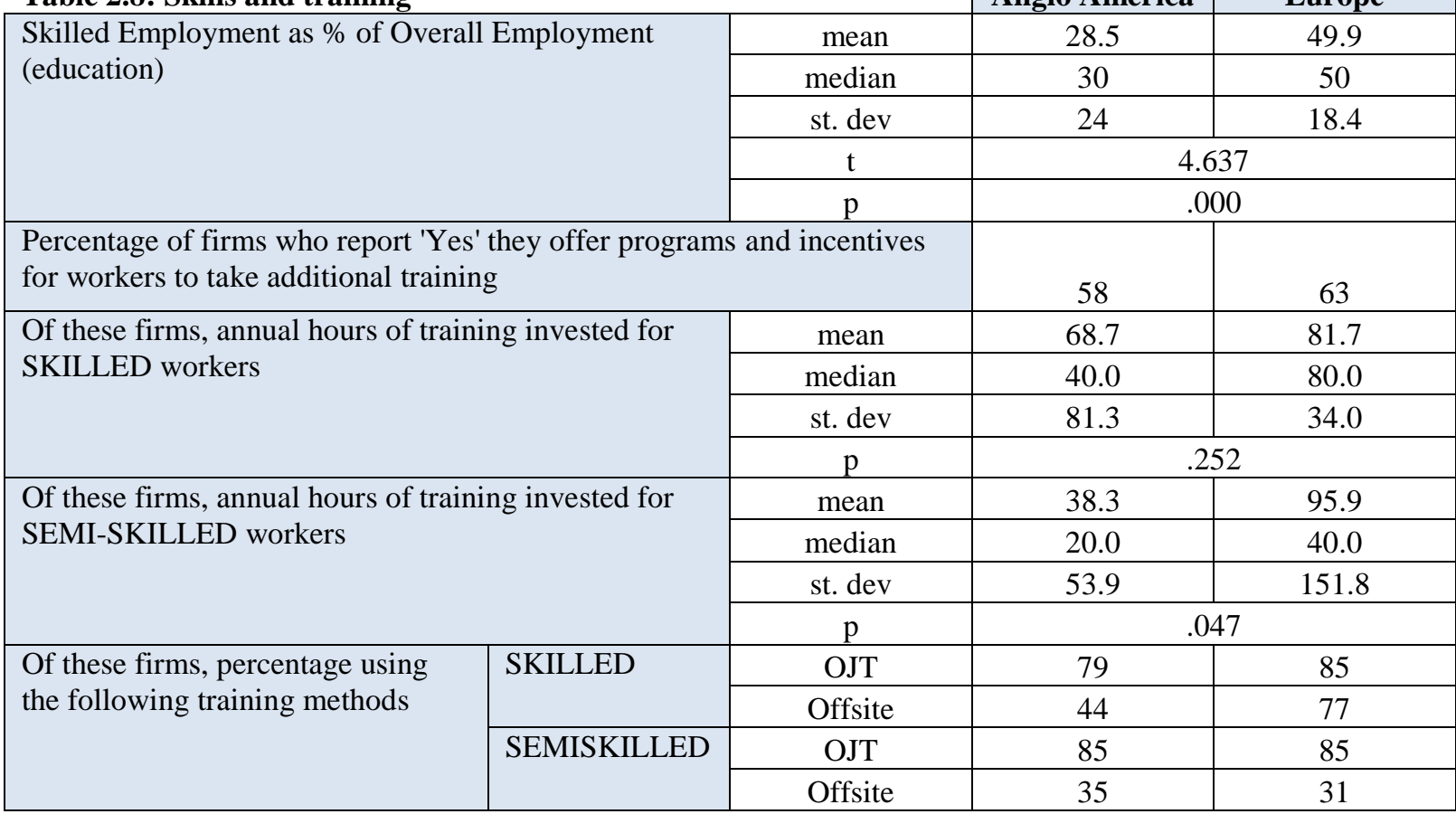


Source: Author's survey of Canadian contract furniture sector, 2010

These experiences can be contrasted with findings from several of the AA companies in the interview sample. For example, the president of a Canadian-founded firm reveals that "Today, most of it is computer-driven. You don't need highly skilled carpenters and a skilled set of hands. Today, the equipment cuts the size." Similarly, the VP of product design and innovation for a US-founded company says that production staff are generally semi- (as opposed to highly-) skilled, and that for his firm, the skill level comes more in the design aspect. In a related vein, the VP of manufacturing for another company whose founder is also of US background implies the Taylorization of production work in order to deliberately deskill it. She says, "We have attempted to create work pieces that are small enough so it's not highly skilled. Skill sets are not required, it's small pieces of work that are repetitive." According to the president of a Canadian-founded firm, most of their processes don't actually require the traditional skilled labour either, and that "Probably within a day or two a person could be $80 \%$ of the way there to being trained. It's not that difficult." This sentiment is echoed by the president of a firm whose founder is also of Canadian background who suggests, "It's not as sophisticated as it sounds. I can train someone in fifteen minutes to run these CNC machines." These various perspectives serve to underscore a significant divergence in skills and training philosophies and practices among firms whose founders hail from either Continental Europe, on the one hand, or those originating from Anglo-American countries, on the other.

The survey questions related to training, which investigated the propensity of firms to offer training programs and incentives, training hours as well as methods 
employed, provides further insight. Not only do the CE firms show higher skill levels among their respective workforces, but also a greater tendency to train their employees, with $63 \%$ of $\mathrm{CE}$ firms reporting that they offer programs and incentives for workers to train compared to 58\% of AA firms (Table 2.8). This resonates with findings that suggest CE firms train their workers for longer periods. For instance, data from the survey reveals that the average time invested on an annual basis by CE firms to train their skilled workers is 82 hours, as compared to 69 hours by AA firms. CE firms spend 96 hours per year training their semi-skilled subset, 14 hours longer than they spend on training their skilled workers, and significantly higher than the 38 hours invested by AA firms. ${ }^{8}$

In terms of training methods, on-the-job training (OJT) proved to be by far the most common technique employed particularly for the semi-skilled segment of the labour force, with over $75 \%$ of firms in each sample group investing in this method for both segments of the workforce (Table 2.8). Yet both CE and AA firms also invested considerably in offsite training for their workers which is presumably a more costly method. Of particular pertinence is the higher propensity to invest in offsite training for the skilled (rather than semi-skilled) sector, especially by the CE firms. The data show that $77 \%$ of CE firms send their skilled workers offsite to train versus $44 \%$ of AA firms who make similar investments. This can be compared to $31 \%$ of CE firms and $35 \%$ of AA firms investing in offsite training for their semi-skilled sectors. This demonstrates not only a greater commitment to workforce development on the part of the CE sample group, but also a visible division between the primary and secondary internal labour markets in this industry (Doeringer \& Piore 1971).

\footnotetext{
${ }^{8}$ Based on a p-value of .046, Mann-Whitney U tests reveal that CE firms train their semi-skilled workers for a significantly longer period of time than AA firms.
} 
Firms were asked to rate the importance of the degree of both customization and flexibility in their operations on a one- to seven-point Likert scale. The mean scores for customization [between 1(high volume production for mass markets) and 7(small batch production for niche markets)] and flexibility [between 1(infrequent changes to product line) and 7(highly flexible and adaptive to markets)] are shown for each sample in Table 2.9. Overall findings reveal a high degree of both customization and flexibility in the industry. In a similar pattern to previous results regarding skills and training, the $\mathrm{CE}$ firms show a somewhat higher rating for customization, at 5.9 compared to 5.7 for the AA firms, and a significantly higher score for flexibility, at 6.5 for CE versus 5.9 for AA. ${ }^{9}$ One senior manager of a German-founded firm considers both factors as key strengths in the organization, a means to respond to market demands and a crucial aspect of everyday business. She provides an example:

We have 14,000 shapes and sizes for our table line, in our 300-page price list. Then we do $30 \%$ custom on top of that each year... In our everyday business, we might do a floor of tables for a building in New York and for an order of 10 tables, 5 might be standard, the other 5 in all different sizes.

A similar situation is described by a manager of a Polish-founded company who reflects on the firm's recent trajectory of growth, "One of our key strengths was our ability to do whatever the customer wanted. And that was what really drove our growth." He goes on to explain that "Everything's made to order. So right away that tells you that you have to have incredible flexibility. You need an extremely flexible workforce that's multi-skilled and you need equipment and technology that's flexible."

\footnotetext{
${ }^{9}$ Based on a p-value of .003, Chi-square tests reveal that CE firms are significantly more flexible than AA firms.
} 
Table 2.9: Mean score between 1 and 7 to describe characteristics of production based upon the following variables:

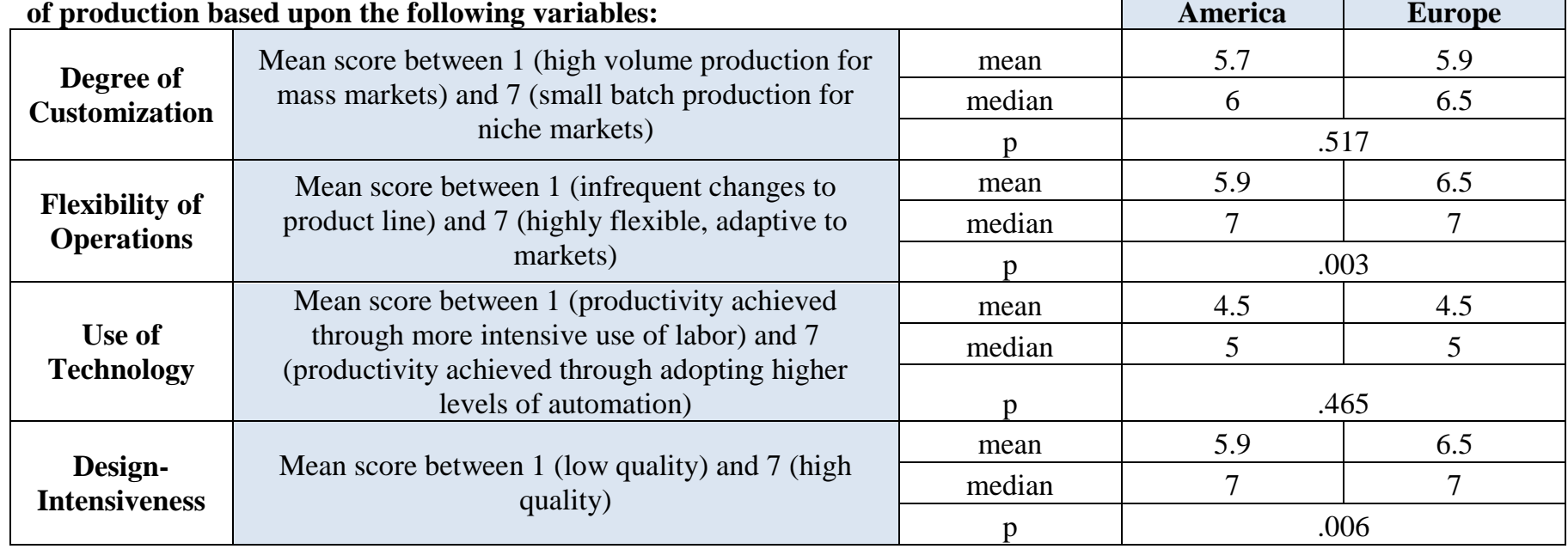

Source: Author's survey of Canadian contract furniture sector, 2010

This very topic of a firm's propensity to enhance productivity through the use of people and/or machinery constituted the focus for the next survey question. In the same one- to seven-point Likert scale, firms were asked to rate their relative reliance on labour versus technology in boosting productivity: between 1 (productivity achieved through more intensive use of labor) and 7 (productivity achieved through adopting higher levels of automation) (Table 2.9). A consistent ranking of 4.5 across both sample groups reveals a strong overall investment in advanced manufacturing technologies (AMT) and what may be considered a capital-intensive industry. These investments may be understood in light of competitive pressures to enhance the quality, flexibility and customization of operations, and to upgrade and transform production processes rather than simply expand manufacturing capacities. One senior manager of a Polish-founded firm discusses the significant advantage of such investments to performance and competitive advantage:

With labour-intensive operations, you can't change the product design as easily, you've got to spend money on new tools and you can't respond to the market demands as quickly. You have to buy a new machine. And the fact that we can just 'Bang, done! Out comes a new part!' is huge! So it costs less and is way faster. And the quality and consistency is better. So when you've got the technology in place, it does it reliably and consistently and you can increase 
your capacity and flexibility. So we've invested significantly. The amount of capital investment in these facilities has been huge. And that's probably the only reason why we're still alive here.

The president of a Canadian-founded company offers a similar viewpoint. He says that technology and machinery are extremely important to innovation and notes, "In order to manufacture equal to your competitors, today you have to have the right equipment. That enables you to manufacture one workstation economically or 500 workstations economically. The equipment allows you to be able to make large batches or small batches economically." In another example, the President of a firm whose founder is also of Canadian origin discusses the advantage of working with lead suppliers who invest in AMT:

\begin{abstract}
We do a lot with suppliers who have technology such as laser cutting, water cutting... all kinds of CNC technologies. We work with one of the leading automotive suppliers for foam. They've got the ability to make almost any mixture of chemicals... whether it needs to be more dense, less dense, more fire retardant, less, it's phenomenal. They can actually shoot more than one density in a single mould, if you want it a little bit softer in the middle.
\end{abstract}

The fact that both $\mathrm{CE}$ and $\mathrm{AA}$ firms show an equivalent rating of 4.5 for investments in AMT may initially seem surprising due to the greater focus on skills development and training for the CE group. A higher degree of productivity and overall performance (see Table 2.6) by CE firms suggests that labour investments have played an important role as complementary input into the production process. The literature on varieties of capitalism would seem to suggest that firms based in coordinated market economies ascribe higher value to training investments as compared to those in liberal market economies, and that stable labour markets provide the optimal condition for investing in training. This is not to say that the CME privileges people over technology; rather that in this system, labour and capital are viewed as complementary components of the high performance workplace. A substantial body of research has shown that the 
implementation of AMT will be most successful when such technologies are also accompanied by changes in the broader organization of work and supported by extensive and regular training, including the empowerment of shop floor workers and their participation in the innovation process and strategic decision making (Wever 1995). Findings from this case study reveal the pervasive influence of these principles and practices particularly among CE firms, and the resultant superior performance of these firms in the marketplace. Results also highlight a distinct manufacturing paradigm in this industry that is both complex and in some ways contradictory - one that may be termed 'high volume quality production.' As the name implies, such a model places equal emphasis upon the ability to produce for high volume / mass markets, on the one hand, as well as customized niche markets, on the other. Such an industrial model requires a combination of a highly skilled and flexible labour force coupled with advanced machinery, technology and automation on the shop floor, and the need for firms to mediate continuously between the two to meet the demands of the market. Interviews support this idea and the multifaceted nature of production on the part of high performance firms in the industry. The president of one German-founded company provides an insightful analysis:

In terms of knowledge on the production floor, all of our staff have to know all the products we make in the plant because we run them all through (regularly), we have so many different options and are running them through essentially the same process... which is very difficult because there are all kinds of variables that are there that impact the production flow and process. (And) there's a lot of knowledge that's needed by most of our people to understand the many different products that we make. That's something we've developed internally by training our people. 


\subsubsection{The nature of employment relations}

The analysis of employment relations investigated the length of employee tenure as well as the practices aimed at achieving worker loyalty and stability in the workplace, with several questions designed to differentiate between the skilled and semi-skilled segments of the workforce. Interview questions were also asked to senior managers and production staff to gauge the degree to which shop floor workers were 'empowered' as a result of organizational structure and their inclusion in innovation and managerial decisionmaking.

Table 2.10: Nature of employment relations

\begin{tabular}{|c|c|c|c|c|}
\hline \multicolumn{3}{|c|}{ Table 2.10: Nature of employment relations } & Anglo America & Europe \\
\hline \multirow{2}{*}{\multicolumn{2}{|c|}{$\begin{array}{l}\text { Percentage of firms saying the ability to retain } \\
\text { workforce is 'Not at all difficult' }\end{array}$}} & skilled & 41 & 47 \\
\hline & & semiskilled & 50 & 42 \\
\hline \multirow{2}{*}{\multicolumn{2}{|c|}{$\begin{array}{l}\text { Percentage of firms saying their rate of workforce } \\
\text { turnover relative to other firms in the same industry is } \\
\text { 'Lower than competitors' }\end{array}$}} & skilled & 59 & 63 \\
\hline & & semiskilled & 53 & 61 \\
\hline \multirow{5}{*}{\multicolumn{2}{|c|}{ Number of workers lost to other firms $2007-2009$}} & mean & 6.8 & 3.8 \\
\hline & & median & 4.5 & 2.0 \\
\hline & & st. dev & 6.0 & 3.8 \\
\hline & & $\mathrm{t}$ & \multicolumn{2}{|c|}{1.826} \\
\hline & & $\mathrm{p}$ & \multicolumn{2}{|c|}{.0385} \\
\hline \multirow{9}{*}{$\begin{array}{l}\text { Percentage of firms saying they use } \\
\text { the following labour management } \\
\text { techniques during an economic } \\
\text { downturn }\end{array}$} & \multicolumn{2}{|l|}{ cut overtime } & 51 & 54 \\
\hline & \multicolumn{2}{|c|}{ encourage voluntary leave } & 17 & 31 \\
\hline & \multicolumn{2}{|l|}{ lay off workers } & 45 & 62 \\
\hline & \multicolumn{2}{|l|}{ cut wage rates } & 4 & 0 \\
\hline & \multicolumn{2}{|c|}{ increase worker productivity } & 14 & 19 \\
\hline & \multicolumn{2}{|c|}{ short work week/shifts } & 54 & 54 \\
\hline & \multicolumn{2}{|c|}{ share workers/collaborate } & 4 & 3 \\
\hline & \multicolumn{2}{|c|}{ reallocation of core workers } & 7 & 19 \\
\hline & \multicolumn{2}{|l|}{ work share } & 23 & 35 \\
\hline
\end{tabular}

Source: Author's survey of Canadian contract furniture sector, 2010

The review of literature has indicated that stable labour markets and long-term employment structures are a fundamental precondition to the development of a high- 
skilled manufacturing workforce. To get a sense of tenure, survey participants were asked to rate both the difficulty of retaining their labour force over long periods, and workforce turnover relative to other firms in the industry. Results show that in the skilled worker category, CE rates consistently higher for employee tenure, although AA shows less difficulty in retaining semi-skilled staff (Table 2.10). This data is further reinforced by results from the next survey question inquiring about the number of workers lost to other firms from 2007 - 2009 - a particularly strong indicator of employment practices with respect to retention. Findings are unequivocal: CE firms report a significantly lower number of workers lost to other firms, and thus higher tenure, with a mean value of 3.8 workers as compared to 6.8 for AA firms. ${ }^{10}$

This data complements results from the survey question about labour management techniques during economic downturns (Table 2.10). Both sample groups show some degree of attempt to prevent layoffs through more progressive tactics, namely 'increasing worker productivity' (with 19\% of CE firms and 14\% of AA firms employing this technique) as well as 'long term reallocation of core skilled workers (i.e. craftsmen) to new tasks' (19\% of CE firms, 7\% of AA firms). However there is a surprisingly strong propensity across both sample groups to cut staff through layoffs, the cutting of overtime and the allocation of shorter work weeks and shifts. These results may initially appear contradictory to previous findings which seem to emphasize firm strategies aimed at stability and workforce development, particularly among the CE firms. However such findings support the institutional literature which argues that firm practice is embedded in institutions at the national scale, in this case the Canadian market-driven model which

\footnotetext{
${ }^{10}$ Based on a p-value of .0385 and a test statistic of 1.826 , AA firms have lost a significantly higher number of workers to other firms from 2007-2009 than CE firms.
} 
engenders hire / fire strategies in the wake of economic recession. This also attests to the hybrid nature of industrial practices in this case study, in which firms attempt to combine aspects of both Continental European labour relations with Anglo-American-style contingent employment practices in the production of design-intensive, high quality products. As would be expected, evidence from the interviews indicates that layoffs are more pronounced among the semi-skilled (as opposed to the skilled) segment of the manufacturing workforce which is consistent with earlier evidence that depicts a strong division between primary and secondary labour markets in this industry (see Doeringer and Piore 1971; Piore 1970, 1975).

In order to assess the degree of empowerment among the manufacturing labour force, a series of interview questions were posed to senior managers and production workers relating to the flatness of organizational structure (to improve knowledge flow and engage workers), the use of teamwork and collaborative practices, and worker participation in innovation and strategic decision making. Interviews consistently show that firms in the industry are characterized by a flat organizational model, and that teamwork and collaborative practices are widespread, and there was minimal evidence of variation among sample groups. "We have a relatively flat structure," says the president of a German-founded company, "which I think allows us to move quickly in comparison to some competitors. As a result, we are relatively nimble in terms of how quickly we are able to jump on things." Comments from the vice president of manufacturing of a USfounded firm depict a similar structure, "We don't have multiple levels of leadership. We eliminated levels within the organization to make it easier for people on the floor to 
communicate and get action taken." The VP of manufacturing of a Danish-founded

operation offers a related perspective regarding the benefits of such organizing principles:

We have a flat organization, we don't like titles. It's really about empowerment. In order to be agile and move and respond, you've got to empower your people. Not everything has to filter through a bureaucratic process to get the results you're looking for.

Collaborative practices such as teamwork to enhance flexibility were also found to be prevalent among firms in the interview sample. For example, one worker says that "We pretty much work as a team. It's difficult to work independently because we're a big department. If I'm behind, they've got to help me and if I'm ahead, I've got to help them." Another worker provides a complementary perspective and suggests that teamwork is critically important, as is the relationship with one's supervisor, "You ask him and others to help you all the time and you also have to help them, and you have to be on good terms with everyone in the factory." These are but some examples from the interview material but depict a clear pattern across both sample groups and among leading firms.

Interviews also show that for the most part, workers have not only the opportunity to contribute their ideas and knowledge, but are encouraged to do so and in many cases there are formalized structures in place to support this practice. One senior manager from a firm whose founder is of Polish descent contends that "The workers are the ones who come up with some incredible ideas where you think - why didn't we think of that?” A shop floor worker from the same organization provides her perspective, "Let's say you have an idea, you can't be afraid to go forward. You can talk to your supervisor about it, or your lead hand, or your manager. You can go up to your manager's office and explain to him why." Her coworker in the plant discusses an incentive program whereby 
employees whose suggestions are implemented receive a certificate of achievement and a $\$ 50$ reward from the company. The president of a Danish-founded operation remarks on the value of ideas coming from the factory floor:

I can always make a suggestion of how we can change foaming or do a design change or something like that. But really it's the person at the work station that needs to understand it or has the more valid input because they deal with it day after day. So we definitely get feedback from the employees. We're not just using them for their hands. I'm paying them for their hands but also their brains too.

However despite willing intentions to engage workers on the part of senior management, the following experience by a Canadian-founded firm suggests that manufacturers are ultimately up against institutional constraints which may undermine such goals. In what follows, the VP of production describes a failed attempt to involve workers in continuous improvement:

We had Kaizen meetings in the plant ... and we tried to involve everybody. And that doesn't work. The difference between what we do and what the Japanese did was the Japanese had jobs for life. So they worked on all these projects and nobody lost their jobs. Whereas we had these meetings, worked on these projects and then two weeks later six people were gone.

In other words, workers in Canada are vulnerable to layoffs, a reality that constitutes an endemic disincentive to engage beyond one's day-to-day duties in the plant.

The literature on national business systems and varieties of capitalism claims that in the typical Continental European model, there are certain institutional mechanisms in place that promote worker engagement and the sharing of knowledge between the shop floor and management. Although organizational structures tend to be more hierarchical and with stronger demarcations between occupational ranks, knowledge flow is perpetuated and workers' voices heard through other means such as the works council. In the absence of these institutional features, firms in Anglo-American countries are dependent upon a greater degree of flexibility in their work practices, including a flatter 
organizational structure, teamwork and collaborative engagement. Not surprisingly, these very practices that are characteristic of the Anglo-American system prevail in this industry. This demonstrates the necessity of manufacturing firms to adapt to the institutional conditions of their environment, and further reinforces the hybrid nature of industrial practice in this industry. Given that firms are operating in a Canadian institutional context, the challenge that certain manufacturers face in engaging their workforce due to market volatility and the potential for layoffs is therefore not surprising.

\subsubsection{Use of design}

The analysis of design use focused on the quality and design-intensity of manufacturing operations as well as the nature of design practices carried out in the industry. Overall, survey and interview findings depict a high degree of emphasis on quality and designintensity in the case study, as well as a strong orientation towards in-house practices, suggesting that design is a core competency of firms (see Tables 1.9 and 1.11). There were also some distinct patterns evident among sample groups, for example, CE firms scored significantly higher in 'design-intensiveness' (6.5 out of a possible 7 versus 5.9

for the AA sample). ${ }^{11}$ Although both sample groups reported a similar percentage of firms who 'carry out design activities', at just under 75\% each, the mean proportion of firm expenditures on design was somewhat higher for the CE group, at $15 \%$ as compared to $12 \%$ for the AA firms.

\footnotetext{
${ }^{11}$ Based on a p-value of .006, Chi-square tests reveal that CE firms are significantly more design-intensive than AA firms.
} 
Table 2.11: Use of Design

\begin{tabular}{|c|c|}
\hline Anglo America & $\begin{array}{c}\text { Continental } \\
\text { Europe }\end{array}$ \\
\hline 80 & 83 \\
\hline 73 & 74 \\
\hline 12 & 15 \\
\hline 77 & 81 \\
\hline
\end{tabular}

Of those firms who carry out design activities, percentage of expenditures that are for IN-HOUSE (rather than OUTSOURCED) design services

Source: Author's survey of Canadian contract furniture sector, 2010

The review of literature on the geography of innovation highlighted the complex knowledge base of design-intensive manufacturing and raised questions as to the optimal employment structure and work organization that drives creativity and innovation for this type of industrial activity. This theory provoked a series of questions in the interview guides focusing around the nature of employment structures among the design labour force, a firm's motivation to choose a particular employment model, and the advantages of each. Interview results suggest that half of all firms who carry out design activities combine both the services of external designers on a project basis with a more permanent, in-house design component that has a strong relationship with engineering and manufacturing. Interviews reveal that those firms who employ an in-house team do so due to the importance of close proximity between design and other functions of the product development process. For example, the president and CEO of an AA firm says, "The proximity between design and manufacturing always creates a natural think tank on how to improve the product. You gain a very strong awareness between the product design and then your ability to manufacture it on a consistent basis. Plus, you have people on the shop floor who have ideas about product improvements and enhancements." The VP of design and innovation of a CE firm remarks, "Over time, those that are in-house 
gain the expertise of what works in our system and what the limitations and capabilities are of the manufacturing process. (In-house) design has a very strong relationship with manufacturing." These complementary perspectives point to the importance of maintaining a close association between and interplay with design and other production activities in the firm, and imply the embedding of design in manufacturing and product development. A long-term employment structure (i.e. the presence of an in-house team) would seem to underpin this important aspect of design innovation in the industry, one that is suited to the process of incremental product enhancement.

The literature on varieties of capitalism implies that labour market institutions and market governance regimes in Canada provide the suitable institutional conditions in which mobile, open design labour markets may thrive, those that are characterized by short-term employment structures and the hiring of independent (design) talent on a temporary, project basis. As expected, a proportion of firms in the interview sample employ this very model. Research reveals that firms engage in this type of temporary, flexible employment practice for a number of compelling reasons, namely to bring an influx of new ideas to the table, for fresh thinking, an objective approach and to glean a variety of perspectives. These inputs are of critical importance to a firm's ability to introduce new and innovative products to the market. One designer who has worked with a number of leading firms in the industry remarks that "An outside designer will provide the obvious advantages in terms of, you know, creativity and offering an injection of new ideas and knowledge to a company." Another designer offers a similar viewpoint, "I think the benefits are bringing new and fresh ideas into the company. You know external 
designers are influenced less by day-to-day needs and the business as a whole." One interviewee comments on the superior market knowledge of the external consultant:

An outside perspective is always going to be led more by where the market is going and is able to predict trends, than the internal design perspective... You can also bring knowledge from one industry to another and thus you have a

broader perspective. Whereas if you're inside a company, maybe you have a more micro-perspective.

A firm's decision to bring both in-house and external design functions together leverages a two-fold competitive advantage. On the one hand, the internal design team plays a crucial role in working with engineers and manufacturing staff to continuously improve a firm's catalogue of existing products, whereas the steady influx of ideas from project designers facilitates a firm's ability to introduce new - often radically innovative products to the marketplace. These different employment structures seek to capitalize on design inputs into the product development process and attest to the hybrid nature of employment relations in this sector, which combine elements of both Anglo-American and Continental European institutional features.

\subsection{Implications for institutional economic geography}

This chapter began by making a number of observations. The widespread migration of highly skilled individuals is increasingly central to the process of globalization, and can have a positive impact on the economic performance of receiving countries due to the diffusion and international dissemination of knowledge. This central idea has been informed by literature in management and economic geography on the ability of corporate actors to transfer and use tacit knowledge (in the form of practice) across countries and institutional divides. Canada's contract furniture manufacturing sector provides a compelling case in which to investigate these processes. The prevailing nexus 
of institutional characteristics that exists in Canada is said to be incompatible with a highskilled, advanced manufacturing strategy because it engenders labour mobility and endemically low levels of workforce development. Yet despite these apparent institutional constraints, the industry has flourished in Canada following the advent of trade liberalization during the late 1980s. Recognition of the disproportionate number of senior managers and firm founders hailing from Continental European countries and manufacturing regimes begged the question as to the role played by these immigrant entrepreneurs in propelling the industry to success. The goal of this chapter has therefore been twofold. First: to observe and compare practices in these Canadian operations in order to ascertain the extent to which distinctive features of manufacturing practice originating in Continental Europe have been transferred and replicated in Canada. Second, to determine the role of immigrant entrepreneurs and other mobile actors as agents of tacit knowledge transfer in driving the Canadian industry to success.

The analysis presented here indicates that the transfer of corporate knowledge and industrial practice from Continental Europe to Canada has indeed taken place; yet its adoption and application in the Canadian context is both varied and complex. One of the most clear and consistent observations is the distinctly hybrid nature of industrial practice in the industry, combining characteristics of both Anglo-American and Continental European production systems. While there is an understandably strong focus on training, given the importance of design and quality in this segment of the furniture industry, the degree to which CE style training practices are actually implemented is often significantly constrained and the dominant tendency is to rely on the least expensive and most informal type of training, on-the-job training. The limited adoption of training 
methods and practices in Canada is not surprising given the endemic disincentive to make training investments by firms in the Canadian economy. However, findings also suggest that learned behaviour by firm owners has some bearing on this, since the CE firms are more likely to make use of the more expensive offsite, formal training, particularly for their skilled workers. In the area of employment relations, there are several parallels to the hybrid and contradictory ways in which the implementation of industrial practices plays out. Despite what initially appeared to be firm strategies aimed at stability and long termism, a feature one would associate with the typical CE regime, a curious finding is the propensity for firms to shed staff in the event of an economic downturn. Of course, such practices remain a dominant characteristic of the AA market governance model in which firms in the case study are embedded, and highlights that firm strategy alone cannot simply overcome the influence of this aspect of the institutional environment in which firms operate. In the area of design practice, the industry shows both short- and long-term employment structures, any variation of which a firm will embrace in order to capitalize on design inputs to product development. This is but another example that underscores the hybrid nature of industrial practices that prevail in this case study whereby firms attempt to combine both Continental European labour relations and Anglo-American flexible work practices to underpin 'high volume quality production'.

Other evidence points to a more coherent application of CE manufacturing knowledge in Canada. Consistent differences in manufacturing practice between sample groups show a greater emphasis not only on skills, training and tenure by the CE sample group, but also a significantly higher focus on design and flexibility, and to a lesser degree, quality and customization. A stronger overall performance in the marketplace by 
these firms (based on annual sales and productivity, see Table 2.6) suggests that knowledge of Continental European manufacturing practice has indeed been fundamental to firm success in high volume quality production, itself a hybrid industrial model.

The successful transfer and implementation of Continental European practices in the Canadian contract furniture industry is enabled by two important factors. For one, Canada offers a middle ground between the highly coordinated market regime of Germany and the unfettered free market US variety due to its stronger social and labour policies. This is well documented in the areas of employment protection, unemployment protection, trade union density, length of employment tenure and strength of vocational training, where Canada falls consistently higher on the scale than the US in comparative analyses of advanced industrialized economies (Estevez-Abe et al. 2001; Hall and Soskice 2001). This suggests that the Canadian regulatory environment may be more conducive to the influence of coordinated market practices than its US neighbour, for instance. Second, the high level of private firm ownership that is observed in the case study likely has some bearing on firm behaviour (see Table 2.1). Because private firms by nature rely on self- rather than shareholder-investment, they are not subject to constant pressure for rapidly increasing return on investment from investors, as do their publiclyowned counterparts. This has implications for the organization and deployment of labour in the firm, since an owner / manager can simply opt to retain her workforce through a downturn even at a short term loss, if such a practice will prove beneficial in the long run. Both the varied nature of industrial practice and the superior performance of firms in the CE sample points to the pervasive influence of Continental European knowledge in the case study. We can therefore conclude from this research that immigrant 
entrepreneurs from CE countries, as well as other senior managers who have studied, lived and trained there, have played an important role as agents of manufacturing knowledge transfer. This knowledge has been crucial to the ability of firms to organize their respective workforces, deploy labour, and use design in such a way as to leverage their performance in global markets. However the hybrid and varied nature of industrial practice that is observed can also be understood as resulting from the limited application of CE practice in the Canadian institutional setting. While firms in Canada have attempted to implement a high skill, long term employment strategy in which workers are engaged in innovation and strategic decision making, such a strategy is undermined in the wake of market volatility and economic downturn. These findings therefore highlight the difficulty of transferring industrial knowledge across national borders, particularly when the host environment constitutes a dramatically different institutional setting, which is certainly the case between the coordinated market economies of Continental Europe and the liberal market economy of Canada. Nevertheless, this research supports a core argument in the theory of institutional economic geography that, while institutions may shape firm behaviour and industrial practice, they do not wholly determine it (Gertler 2001, 2010). There is still a major role for individual agency, in this case the immigrant entrepreneur whose knowledge of alternative institutions and practices has been a critical asset in propelling the Canadian industry to global success. It is only through such detailed case studies that we can hope to gain an understanding of the complex ways in which institutions and agency interact to shape firm behavior, industrial practice and competitive trajectories over time. 


\section{Chapter III}

\section{Learning from designers: a time-spatial analysis of knowledge creation and industrial practices}

\subsection{Introduction}

It is widely acknowledged that profound changes have taken place in the landscape of traditional manufacturing in the economies of advanced industrialized countries in recent decades. The demise of mature manufacturing in these economies has been foretold by scholars and policymakers alike, many of whom have argued that the present knowledge economy is centered less on the physical processing of goods and more on knowledge processes, and that low-tech production activities can be undertaken more efficiently and economically in low wage contexts.

Yet empirical work on manufacturing in Europe, the UK and Canada reveals that high-wage, high-cost nations can effectively compete in a global manufacturing economy by demanding economic restructuring towards a less price- and a more quality- and design-oriented competitive niche. In other words, shifting product ranges towards more diversified, customized demands of high quality markets can insulate production from the pressures of price competition (Best 1989; Rusten 1997; Maskell 1998; Maskell et al. 1998; Lorenzen 1998; Leslie and Reimer 2006). Implicit in this work is the notion that if manufacturing in mature industries has a future in high-wage economies, it is likely to 
depend on firms' success in renewing both their products and their production processes. The adoption of new designs that enhance product quality and value-added, further reinforced by the implementation of employment practices that leverage the capacity of the labour force, are likely to be fundamental elements of a more resilient corporate strategy.

Much research in geography has investigated the labour market practices that underpin growth in the cultural industries, whose primary input is said to be 'creativity' (Scott 2000, 2001, 2004; Grabher 2002; Florida 2002; Christopherson 2002; Power and Scott 2004; Vinodrai 2006; Currid 2007). In a related vein, several bodies of work consider the dynamics of learning and innovation in more traditional, resource-based, low-tech manufacturing sectors such as furniture production and the garment industry (Scott 1996; Maskell 1998; Maskell et al. 1998; Lorenzen 1998; Rantisi 2002, 2004; Leslie and Reimer 2006). However, there has been limited discussion of the nature of employment relations and work practices that support innovation in a distinctly hybrid industrial activity that combines traditional industrial processes with creative inputs and contemporary design principles. This is surprising given the fact that a design-led manufacturing strategy is increasingly prevalent in the contemporary economy, particularly among high-wage nations seeking to compete in a global manufacturing market.

The objective of this chapter is to begin to address this gap. Design is an inherently complex economic activity that combines at least two forms of industrial knowledge that are produced by employment practices and modes of work organization that are temporally divergent. Motivated by some of these conflicting findings, I take a 
knowledge-base approach to attempt to unpack these contradictions and provide an understanding of the geography of knowledge flows within a design-led manufacturing sector, and the possibilities for joint knowledge production and innovation at a distance. My analysis brings together the literature on the economic geography of innovation and labour market dynamics and draws on a case study of the Canadian contract furniture manufacturing sector, which has a large design-oriented focus and has undergone dramatic growth following North American trade liberalization beginning in the late 1980s.

In this chapter, I begin by discussing the rise in importance of design and quality to the contemporary production of goods. I then proceed by drawing on the knowledge base approach that has emerged within the geography of innovation literature to identify a two-fold industrial knowledge base that predominates in design-oriented manufacturing - synthetic knowledge and symbolic knowledge - with each said to rest on dramatically different labour market dynamics, as indicated. I then investigate the specific practices that support each sphere of knowledge, both long- and short-term employment structures, which firms in the case study adopt in order to incorporate design capability into the development process. Next, I explore the geography of these practices, and consider how alternative geographies in turn shape different spheres of knowledge and processes of innovation. I then outline findings in which spatially distant designers engage in longdistance learning and knowledge translation with their product development counterparts inside the manufacturing firm, and I consider the mechanisms and conditions that facilitate the flow of design knowledge at a distance. Finally, I conclude by summarizing the central insights of this research. 


\subsubsection{The rise in importance of design in the contemporary production of goods}

One of the core ideas that has emerged within geography and the social sciences in recent decades is the key role that creativity and culture play in the contemporary economy, and the growing importance of symbolic and aesthetic inputs into the production of goods and services (Lash and Urry 1994; Zukin 1995; Landry 2000; Scott 2000; Florida 2002; Grabher 2002; Christopherson 2002a; Currid 2007). Lash and Urry (1994), for example, discuss the increasing design-intensity across all facets of economic and social life, that both derives from and further shapes what they describe as an inextricable linkage between culture and economy in contemporary society. Physical goods that are imbued with a high degree of creative and semiotic content, they argue, will have certain intangible qualities that serve as the basis for their economic success; in other words, the design element comprises an increasing component of the value of goods, providing the decisive competitive advantage. Scott suggests that as a result of the growth of disposable consumer income and the expansion of discretionary time in modern society, the consumption of design-oriented objects, what he calls "cultural products", is expanding at an ever-accelerating pace. He predicts that those sectors that can most creatively and consistently exploit the symbolic aspects inscribed in their products will undoubtedly define the forefront of modern capitalism (Scott 1997, 2000).

The major restructuring of capitalist social and economic relations that is said to have begun in the early 1970s has brought about the emergence of an increasingly fragmented consumer culture which has had a substantial impact on producers throughout most industrialized countries (Piore and Sabel 1984; Amin and Thrift 1992; Lash and 
Urry 1994; Stoper 1997; Cooke and Morgan 1998; Scott 2000; Florida 2002; Power and Scott 2004). This restructuring has been manifest, above all, in a strong shift away from Fordist forms of mass production and by the proliferation of new flexible, craft- and design-oriented industries of the kind that Scott describes, along with a great surge in niche markets for design- and information- intensive products. Scott observes that "A provocative but revealing manner of designating this trend might be to label it as a postmodern expression of changing consumer tastes and demands involving a general aestheticization and semioticization of marketable products" (1997, 326).

On the supply side, these characteristics encourage firms to engage in highly competitive marketing strategies based on insistent differentiation of output. In pursuing these smaller, more fragmented and quickly changing niche markets, firms are therefore compelled to concentrate on making small and specialized batches of output in order to cater to these tightly-defined and constantly changing market segments. In so doing, they are pressured to compete on the basis of quality, distinctiveness and innovativeness, or suffer extinction. In adapting to this new competitive environment, manufacturers have been compelled to adopt radically new sets of practices and forms of work organization, and to embrace a competitive strategy based on quality, value and design-intensity.

\subsubsection{Understanding the complex knowledge base of a design}

The knowledge base framework that has emerged within the geography of innovation literature conceptualizes the core differences in the nature of work organization, labour market dynamics, and innovation processes across the economy (Asheim and Gertler 
2005; Gertler 2008). This perspective suggests that different industries rely on different knowledge bases for activities that are most central to their competitiveness. While the lead proponents of this view acknowledge that knowledge involved in innovation is increasingly complex and multidimensional (see also Sunley et al. 2008 for a thorough discussion of design knowledge), they nonetheless imply that there are at least two different kinds of industrial knowledge that support innovation in a design-led production model: synthetic knowledge and symbolic knowledge. Implicit in this view is that processes of learning and knowledge creation are structured by divergent labour practices and alternative time horizons. For instance, synthetic knowledge is found to be dependent upon long-term employment relations that produce a highly skilled labour force, whereas symbolic knowledge tends to be fostered by short-term, flexible practices that promote creativity.

Inherent in this approach is that synthetic knowledge largely involves the novel application or combination of existing knowledge in context-dependent scenarios or engineering-related problem solving (Asheim and Coenen 2005). While some of the knowledge involved is based on partially codified knowledge, synthetic knowledge tends to have a larger tacit component by nature, which means that important parts cannot be removed from their human and social contexts. It depends on "know-how" which draws on experience gained at work through applied testing and on-the-job learning in the creation and diffusion of knowledge (Gertler 2008). As well, given the importance of frequent producer-user interaction and face-to-face communication, it tends to be sensitive to distance, is often created within firm boundaries, and involves incremental developments. Moreover, this type of industrial knowledge rests on the capacity of an 
organization to build a wealth of skill and problem-solving capability among its workforce through many years of training and learning-by-doing. Of fundamental importance is the ability of workers to develop a high level of expertise through consensus-based working relations that are cultivated over the long-term.

Innovation in this production model is also dependent upon creative and design inputs, for which symbolic knowledge is crucial. Symbolic knowledge is said to underpin economic activity that is focused on creating aesthetic meaning and symbolic value, and involves the creative process (Asheim, Coenen, and Vang 2007; Gertler 2008). Unlike analytical- or synthetic-based industries that may compete primarily on the use-value of their products, the economic value of symbolic-based industries tends to arise through intangible assets, namely their aesthetic character or "sign-value" (Lash and Urry 1994; Scott 2000). Symbolic knowledge also has a large tacit element, and is continually acquired through learning-by-doing and on-the-job training (Wong and Radcliffe 2000).

The growing literature on project ecologies contends that the creative process (and symbolic knowledge formation) is facilitated by short term employment structures, open labor markets, and the rapid movement of skilled workers between firms and projects (Grabher 2002; Christopherson 2002a). Creative individuals are said to play a vital role as mobile agents of knowledge transfer in symbolic knowledge creation, bringing ideas and practices with them from firm to firm (Florida 2002; Saxenian 1994, 1999). Mobility is driven not only by the nature of employment structures that underpin the creative process itself, but is also fostered by a strong incentive for workers to continually learn in order to remain productively employed and to consistently upgrade their skills. The ability for individuals to move from one opportunity and organization to 
another is also a means by which workers seek to minimize risk and tenuous employment relationships that are inherent in many creative industries (Ekinsmyth 1999). Moreover, social capital and personal networks provide the basic social infrastructure, in other words, "know-who" is a key component of success (Grabher 2002). Social relations and mutual loyalties between creative professionals often transcend organizational boundaries for the duration of the project, driving collaborative practices, innovation, and competitive advantage. Creative work such as design is said to embody a diversity of specialized technical and artistic skills that are needed to accomplish complex tasks, and therefore defies conventional employment arrangements and modes of work organization (Grabher 2002). Such flexible working conditions are fundamental to the very nature of competition within creative (and also high-tech) industries in an era of intensified global competition and the drive for rapid change, continual innovation and product development ahead of competitors (Benner 2002).

\subsubsection{The economic geography of innovation: local and global knowledge networks and flows}

Both synthetic and symbolic forms of industrial knowledge are noted as having a high tacit knowledge content, with the former said to rest on face-to-face, communal interaction between economic actors inside the firm and between suppliers and customers, and the latter dependent upon a highly socialized production process that may or may not transcend firm boundaries. The emphasis on geographic proximity between economic actors in the creation and sharing of tacit knowledge resonates with a broad body of literature in geography and the social sciences that investigates the central role of tacit knowledge in the process of learning-through-interacting. At the heart of the 
contemporary literature in economic geography is the idea that economic activity based on tacit knowledge transmission and application will tend to cluster spatially with other actors involved in the innovation process, while codified information can be transferred and linked in national- or international-scale networks. Tacit forms of knowledge are by definition more difficult to share in written, symbolic form and over long distances than their codified counterparts, and are said to be collective in nature, highly context specific, and can only be produced in practice. The geographical clustering of economic actors is said to facilitate the exchange of tacit knowledge between them, and likewise, the interaction that supports tacit knowledge sharing is enabled by spatial concentration because it enriches close, collaborative interaction (Scott 1988; Porter 2000; Maskell and Malmberg 1999; Malmberg and Maskell 2002; Gertler 2003).

These ideas are at the heart of several bodies of research that have had a profound influence on contemporary debates in management and economic geography. For example, Porter's cluster thesis introduced geographical considerations into the field of management to describe systems of geographically interconnected firms and institutions that play an important role in innovation and its subsequent commercialization (Porter 1990, 2000). This view suggests that the mere presence of economic actors within a cluster (which may exist at various spatial scales) creates the potential for economic value. On the horizontal dimension, for example, geographic proximity is said to accentuate competition by enabling competitor firms to continuously monitor and compare one another, which enhances rivalry and produces incentives for product differentiation and variation. In other words, geographical proximity underpins the joint production, circulation and sharing of knowledge. 
Since the late 1980s and early 1990s, investigation into innovation processes, in the broader research context of economic geography and regional development studies, has been shaped by a resurgence of interest in the region as a scale of economic organization and political intervention (Scott 1988, 1996; Amin and Thrift 1994; Storper 1995, 1997; Cooke and Morgan 1998; Braczyk et al. 1998). This literature suggests that there is an overtly regional component to the innovation process. Within the geographically bounded space of a region, it is argued, firms become embedded in close vertical and horizontal relationships with nearby firms, and within a rich, thick institutional matrix that facilitates the formation of trust and informal relations among actors, and the flow of local knowledge between them, both tacit and codified (Breschi and Malerba 2001; Storper and Leamer 2001).

Storper and Venables (2004) characterize this localized flow of specialized, highly tacit knowledge as the 'buzz' that distinguishes economically dynamic and innovative places. Local buzz describes the information and communication ecology that is created by face-to-face interaction and collaboration of people and firms within the same place, and the network of communication and information linkages that develop within a cluster. The nature of buzz is said to be both spontaneous and fluid, and the copresence within the same social and economic context generates opportunities for personal encounters, which fosters institutional similarities by those who participate. In this view, it is almost impossible to avoid acquiring information about other firms in the cluster through the many opportunities for interaction that exist locally.

The emphasis on spatial proximity between actors as a necessary precondition to the formation and circulation of tacit knowledge, which necessarily limits innovative 
economic activity to the confines of a local milieu, has more recently been challenged in the literature. Bathelt et al. (2004) argue that global knowledge networks and flows are also an important source of innovative ideas for a growing number of economic activities. According to this view, new and valuable knowledge will always be created in other parts of the world, and firms are therefore compelled to pursue such useful knowledge pools that are not otherwise a part of their repertoire. The particularly successful clusters are the ones that not only produce knowledge locally, but can build and maintain a variety of channels for the exchange of knowledge with relevant 'hotspots' around the world that are at the forefront of practice, knowledge and research in a particular field. The ability of firms to build and maintain 'pipelines' to these global sites of excellence creates real economic value for local firms by providing a more variegated set of knowledge resources than would otherwise be available within the confines of the local cluster. It is said that these external sources of knowledge are often important triggers to stimulate growth within the local cluster, and information that is acquired through pipelines may spillover to surrounding firms. The idea of pipelines resonates with the concept of absorptive capacity (Cohen and Levinthal 1990) which suggests that the ability of a firm to evaluate, assimilate and use outside knowledge is dependent upon its reservoir of past knowledge-producing assets, including R\&D- and production-intensities, which are cumulative and thus shaped over time.

While an important conceptual contribution, the pipelines argument stops short of providing insight into the precise mechanisms and conditions that might facilitate the flow of long distance knowledge. The learning economy thesis (Lundvall and Johnson 1994) that is discussed in Chapter One reminds us that interactive learning in the 
contemporary economy rests on a broad participation in the learning process, social interaction, cooperation and collaboration, and new combinations of knowledge at a greater number of interfaces, both within and outside the firm. I invoke such a conceptualization because it provides a useful backdrop to our understanding of the notion of 'communities of practice' in the literature on economic communities (Lave and Wenger 1991; Brown and Duguid 1996, 2000; Amin and Cohendet 2004), which recognizes that knowledge is born at these multiple interfaces out of habituated practice. Communities of practice are defined as teams of expertise consisting of individuals who share a common interest, skill and purpose, and held together by routines and varying degrees of mutuality. They are said to be the elementary locus of the formation and generation of 'actionable' knowledge (i.e. know 'how', know 'that') that emerges out of daily practice; in other words, knowledge is said to derive from the daily social interactions and strategic and routine practices of distributed communities. Of particular significance to this analysis is that members of a community are just as likely to be geographically distant from one another as they are to be close. Communities are therefore key mechanisms that drive the joint formation, accumulation and circulation of knowledge, both locally and at a distance.

Literature on proximities suggests that in the latter case, that is, if the condition of geographic proximity between economic actors is not achieved, other conditions may be met to facilitate the transfer of knowledge over long distances. One area of research suggests that it is wrong to associate proximity with its geographical meaning, and that other forms of 'relational' proximity can serve in its absence to reduce uncertainty, solve problems of coordination, and facilitate the flow of tacit knowledge within global 
networks and flows (Boschma 2005). This resonates with research by Gertler (2008) who shows that the achievement of relational proximity is reliant upon a host of cultural and experiential commonalities and social affinities among individuals, including shared culture, language, education, profession, organization, occupation, sector, and national business system. In the absence of strong enough social affinities of these various dimensions, geographical proximity alone is likely to be insufficient to support effective communication and mutual understanding between actors. Moreover, Amin and Cohendet (2004) suggest that a number of strategies can be adopted to enhance relational proximity and support distanciated learning, namely advanced communications technologies that enable virtual interaction, as well as periodic long distance travel to support face-to-face meetings where necessary.

The very idea that learning between economic actors is not the sole purview of a localized cluster but may occur effectively at a distance if mediated within communities and if the above conditions of relational proximity are met is of pertinence to our understanding of innovation within a design-oriented production model. As discussed, such a model is by nature complex, since it combines spheres of industrial knowledge that are themselves produced by employment practices that are temporally divergent. Given the variegated and often conflicting nature of the labour dynamics that underpin such a regime, it stands to reason that knowledge creation, learning and innovation derive, too, from multiple geographies. In this sense, the questions driving the analysis in this chapter are: How is design organized to support innovation? What is the geography of design practice? Do different design geographies promote distinctive processes of 
innovation? If so, what are the mechanisms and conditions that shape and constrain the flow of design knowledge at a distance?

\subsection{Case study and research design}

The Canadian contract furniture manufacturing sector provides a valuable case study in which to address questions about design practice because it exhibits a high degree of design-intensity, product quality, and customization / specialization. This is indicated by collaborative research conducted by Industry Canada, the Association of Canadian Manufacturers and Exporters, and the Design Exchange (2010) analyzing the extent to which Canadian manufacturers invest in product design and development (PD\&D). When compared with other manufacturing industries, furniture ranks high on 'PD\&D Investment Intensity' which is a measure of how critical PD\&D is to a particular industry (see Figure 3.1). This is insightful, especially given the fact that the industries that rank more strongly than furniture - industrial electronics, electrical equipment, aerospace, motor vehicle parts - represent high performance, capital- and technology-intensive industries. The report goes on to suggest that:

Many office furniture manufacturers are investing in $P D \& D$, have a large design-oriented focus, and are developing mass customization / design solutions for their customers, as a means to differentiate themselves from producers who rely on lower labour costs.

Moreover, research by geographers and other scholars points to the success of Canadian furniture producers in shifting product ranges towards more diversified, customized demands of high quality markets. Several areas of work show that furniture producers in Canada demonstrate high levels of innovation, having adopted 'high road' strategies by narrowing product categories and basing competition on product quality and 
sophistication rather than cost (Gotlieb 2002; Leslie and Reimer 2006; Drayse 2010).

One stream of research reveals that Canadian companies have invested heavily in a combination of labour, advanced manufacturing technologies and advanced business practices in order to compete effectively in a high quality, design-oriented niche (Drayse 2010). Another stream of work hones in on the contract furniture subsector and finds that following North American trade liberalization in the 1990s, successful firms were those that upgraded the quality, responsiveness and timeliness of production, adopted new forms of work organization, and embraced more technologically sophisticated, flexible operations. As a result of these approaches, this research implies, Canadian companies were able to achieve tremendous success in export markets (Gotlieb 2002).

\section{Figure 3.1: Product Design and Development Investment Intensity in Canadian} Manufacturing Industries 2008, in percentage (\%)

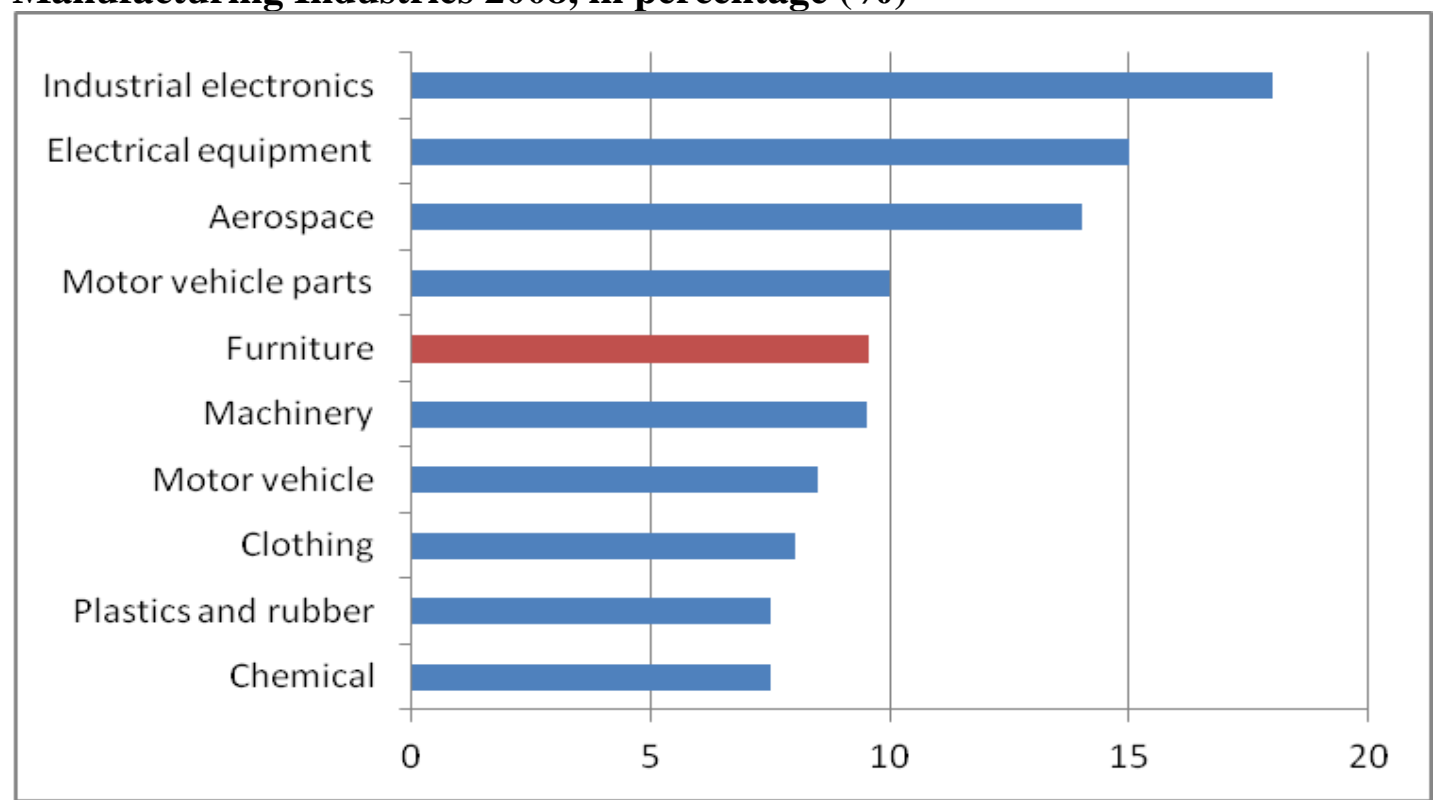

Source: Industry Canada et al., 2010

The research presented in this chapter is based on a multiple-method research approach and draws on two primary modes of inquiry: an online industry survey to the 
full population of firms $(\mathrm{N}=220,46 \%$ response rate: $\mathrm{n}=101)$, and 59 in-depth, semistructured interviews with senior managers and designers representing 20 leading firms, as well as representatives from intermediary organizations and government agencies. Fifty out of the 59 interviews were carried out in person, with the remaining 9 conducted over the phone. The breakdown of interviewees by occupation is as follows: 43 participants are senior managers and in some cases firm founders, 14 are designers, and 8 are representatives from trade / professional associations and government agencies. Of the 14 designers, 6 are in-house senior designers (who overlap with the above senior managers), and 8 are external designers (see Tables 3.1 and 3.2, and Figures 3.1 and 3.2 for tabular and graphical representations of this data).

The geographical representation of the interviewees, as rendered below in Figure 3.3, is: 23 senior managers are from Ontario firms, 12 from firms in Western Canada, and the remaining 8 represent firms in Quebec. Four in-house designers are from Ontario firms, 1 is from a producer in the West, and 1 from a Quebec-based manufacturer. Four external designers are based in Ontario, 2 live in the West, and 2 are located in Quebec; however 2 of the Ontario-based industrial designers have a considerable amount of experience working for manufacturers in the other two regions. In summary, of the 51 interview participants from manufacturing firms, 27 represent Ontario-based firms, 14 represent firms from Western Canada, and 10 represent firms from Quebec.

The interview sample is therefore well balanced along both occupational and geographical lines. In addition to these primary methods of research, I also participated in 2 international trade fairs, as well as lengthy tours of 8 plants representing all three regions: 4 facilities in Ontario, 2 in the West, and 2 in Quebec. 
Table 3.1: Breakdown of interview participants

\begin{tabular}{|c|c|c|c|c|}
\cline { 2 - 5 } \multicolumn{1}{c|}{} & Ontario & West & Quebec & Total \\
\hline Senior Managers & 23 & 12 & 8 & 43 \\
\hline Internal Designers* & 4 & 1 & 1 & 6 \\
\hline $\begin{array}{c}\text { Representatives from intermediary } \\
\text { organizations and government agencies }\end{array}$ & $\mathrm{n} / \mathrm{a}$ & $\mathrm{n} / \mathrm{a}$ & $\mathrm{n} / \mathrm{a}$ & 8 \\
\hline External Designers & 4 & 2 & 2 & 8 \\
\hline Total Interviews & 28 & 14 & 10 & 59 \\
\hline
\end{tabular}

* this group overlaps with senior managers and is therefore not included in the count

Table 3.2: Breakdown of representatives from trade associations and government agencies

Canadian Manufacturers and Exporters

Industry Canada Service Industry and Consumer Product Branch/ State of Design Project

Business and Institutional Furniture Manufacturing Association

Association of Registered Interior Designers of Ontario

Ontario Furniture Manufacturer's Association

Figure 3.2: Breakdown of interview participants by occupation, in percentage (\%)

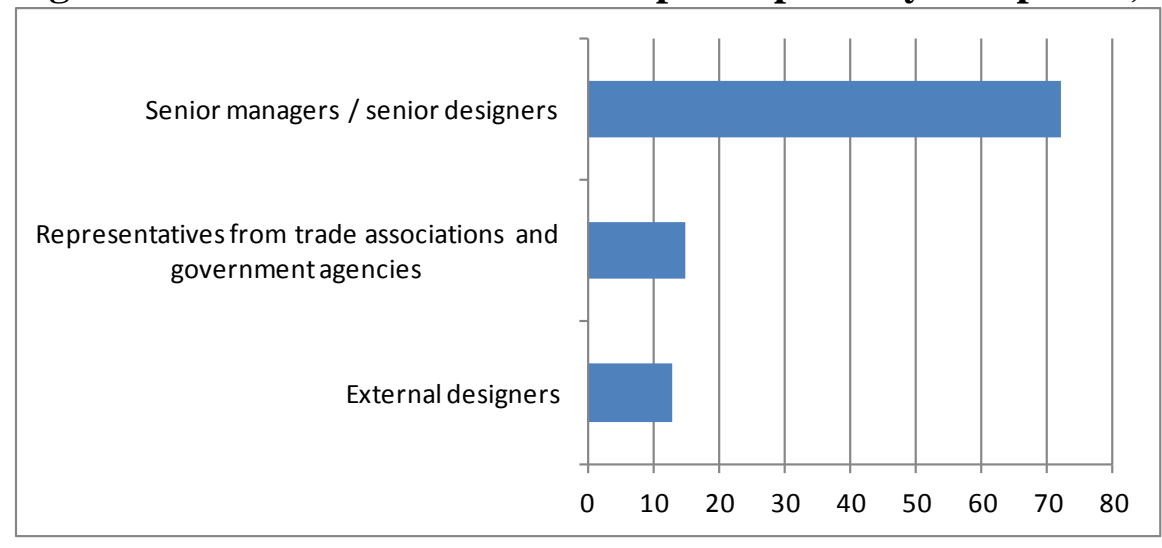


Figure 3.3: Breakdown of interview participants by geography, in percentage (\%)

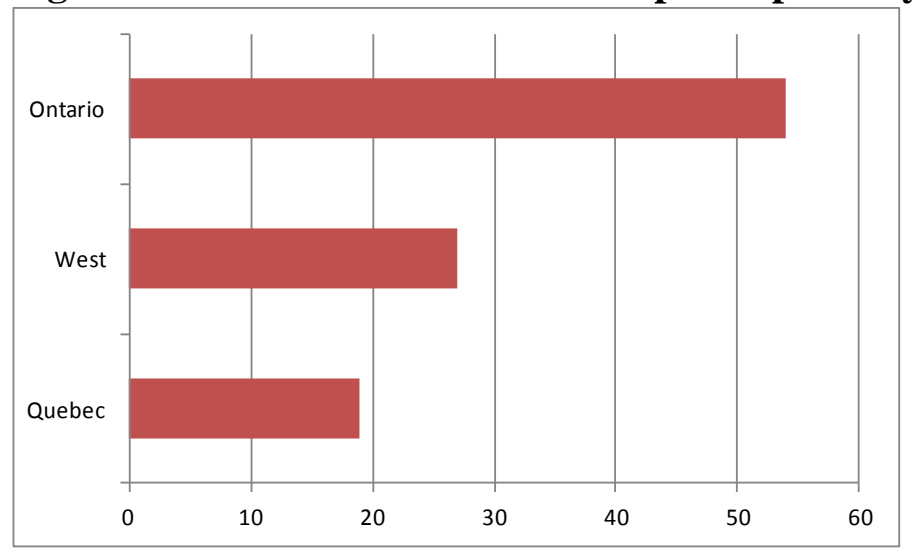

\subsection{Analysis}

\subsubsection{General characteristics}

Table 3.3 groups firms by size / number of employees (5-50, 51-100, 101-550, >550), and compares data across groups on several core firm characteristics and performance measures including: age of firm, skilled employment as a percentage of overall employment, annual sales 2008 , and productivity 2008 . Figure 3.4 shows that there is a (not surprisingly) positive correlation between size of firm and annual sales performance of 0.944 , since one would expect that successful firms are those that have been able to expand over the years not only in sales but in employment. In Table 3.4, results from the survey are grouped by geographic region (Ontario, Quebec, West) and indicate that firms in Ontario are both larger and have higher annual sales performance than firms in the other two regions. Given that south central Ontario is historically the manufacturing and industrial heartland of Canada, these findings, as well as the larger concentration of firms in this geographic region, are to be expected. 
Table 3.3: Comparison of key firm characteristics and performance levels, grouped by firm size / number of employees

\begin{tabular}{|c|c|c|c|c|c|}
\hline \multicolumn{2}{|c|}{ Firm Size } & Age of Firm & $\begin{array}{c}\text { Skilled } \\
\text { employment as a } \\
\% \text { of overall } \\
\text { employment } \\
\text { (education) }\end{array}$ & $\begin{array}{c}\text { Annual Sales } \\
(\mathrm{CAD}, \text { in } \\
\text { millions })(2008)\end{array}$ & $\begin{array}{c}\text { Productivity } \\
\text { (2008) }\end{array}$ \\
\hline \multirow{4}{*}{$5-50$} & $\mathrm{~N}$ & 73 & 75 & 41 & 40 \\
\hline & Mean & 31.33 & 36.25 & 3.35 & $187,889.50$ \\
\hline & Median & 27.00 & 34.00 & 2.20 & $146,428.50$ \\
\hline & Std. Deviation & 17.267 & 27.571 & 4.30 & $150,548.09$ \\
\hline \multirow{4}{*}{$51-100$} & $\mathrm{~N}$ & 8 & 7 & 4 & 4 \\
\hline & Mean & 29.88 & 32.00 & 12.34 & $146,073.50$ \\
\hline & Median & 32.50 & 23.00 & 11.75 & $149,798.00$ \\
\hline & Std. Deviation & 8.132 & 17.176 & 4.70 & $34,732.70$ \\
\hline \multirow{4}{*}{$101-550$} & $\mathrm{~N}$ & 12 & 12 & 10 & 10 \\
\hline & Mean & 34.92 & 37.50 & 42.38 & $172,904.70$ \\
\hline & Median & 27.50 & 41.50 & 344.19 & $176,759.00$ \\
\hline & Std. Deviation & 30.823 & 22.424 & 28.37 & $43,832.13$ \\
\hline \multirow{4}{*}{$>550$} & $\mathrm{~N}$ & 4 & 4 & 3 & 3 \\
\hline & Mean & 68.25 & 39.00 & 284.23 & $218,843.33$ \\
\hline & Median & 56.00 & 37.50 & 120.00 & $180,180.00$ \\
\hline & Std. Deviation & 44.365 & 20.183 & 301.95 & $85,043.93$ \\
\hline
\end{tabular}

Figure 3.4: Correlation between size of firm and annual sales performance (2008)

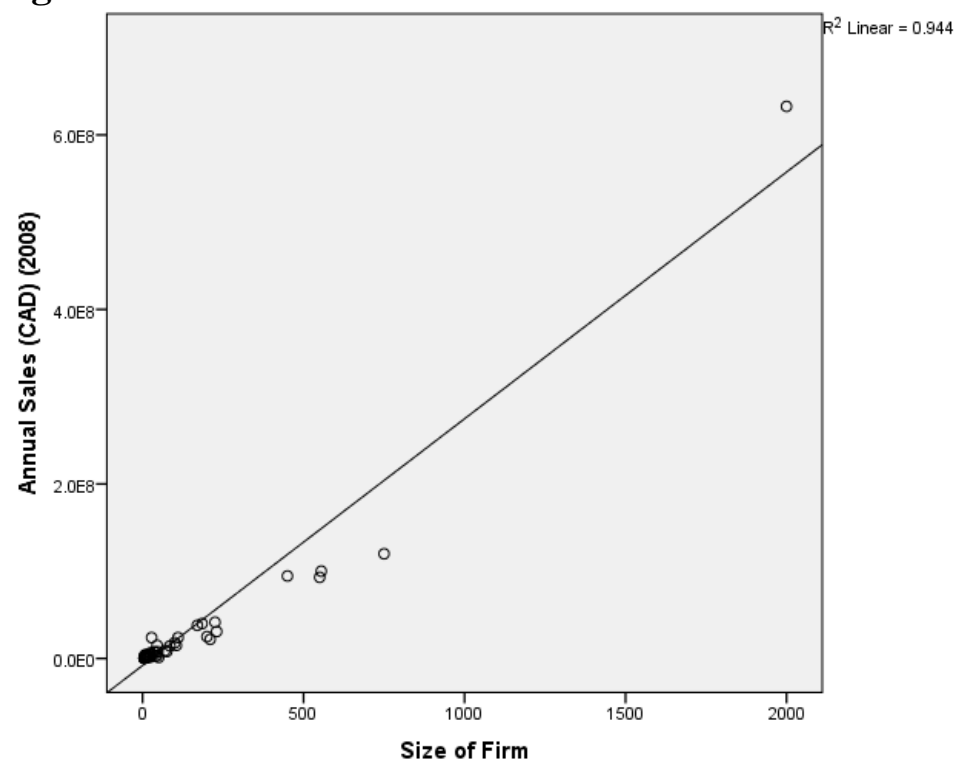


Table 3.4: Comparison of key firm characteristics and performance levels, grouped by geographic region

\begin{tabular}{|c|c|c|c|c|c|c|}
\hline \multicolumn{2}{|c|}{ Geography } & Age of Firm & Size of Firm & $\begin{array}{c}\text { Skilled } \\
\text { employment as a } \\
\% \text { of overall } \\
\text { employment } \\
\text { (education) }\end{array}$ & $\begin{array}{c}\text { Annual Sales } \\
(\mathrm{CAD}, \text { in } \\
\text { millions })(2008)\end{array}$ & $\begin{array}{c}\text { Productivity } \\
\text { (2008) }\end{array}$ \\
\hline \multirow{3}{*}{ ON } & Mean & 34.61 & 115.94 & 35.30 & 34.06 & $208,136.42$ \\
\hline & Median & 29.00 & 30.00 & 36.50 & 4.20 & $161,000.00$ \\
\hline & Std. Deviation & 24.371 & 298.462 & 24.861 & 110.11 & $155,305.73$ \\
\hline \multirow{3}{*}{ QC } & Mean & 30.11 & 92.56 & 31.28 & 13.70 & $117,704.22$ \\
\hline & Median & 30.00 & 13.50 & 32.00 & 0.93 & $122,222.00$ \\
\hline & Std. Deviation & 15.885 & 222.208 & 21.196 & 37.44 & $50,678.752$ \\
\hline \multirow{3}{*}{ West } & Mean & 36.00 & 76.41 & 42.06 & 13.49 & $170,507.40$ \\
\hline & Median & 31.00 & 23.00 & 40.50 & 3.50 & $166,667.00$ \\
\hline & Std. Deviation & 22.147 & 133.817 & 24.770 & 24.40 & $73,987.20$ \\
\hline
\end{tabular}

Source: Author's survey of Canadian contract furniture sector, 2010

Figure 3.5: Comparison of firm size and annual sales performance (2008), grouped by geographic region
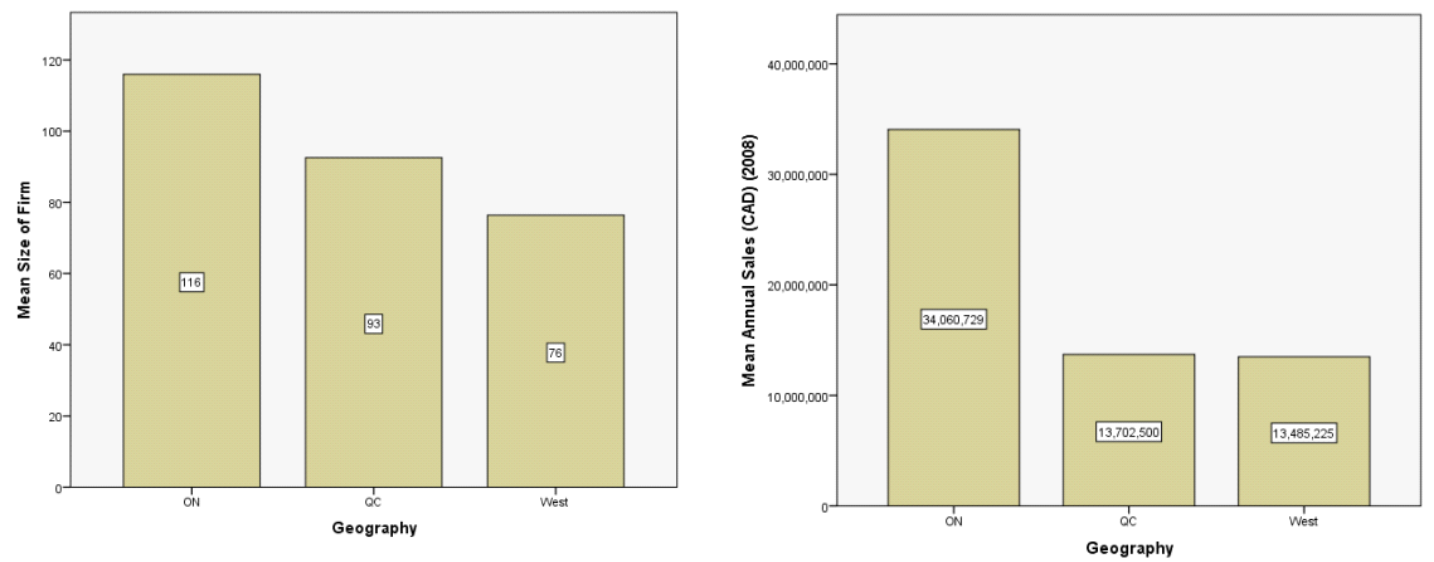

Source: Author's survey of Canadian contract furniture sector, 2010 


\subsubsection{Design-intensity of manufacturing operations}

In Figure 3.6, survey respondents were asked to rate the importance of fourteen factors to the success of their firm, and a remarkable finding is that 'Quality of design', along with 'Close relationship with lead customers', was the most highly rated factor, reported as more important than many of the more established, conventional factors one would typically associate with a traditional industry such as furniture. This emphasis on quality of design suggests that producers are competing in the high end of the market.

\section{Figure 3.6: Percentage of respondents rating factors as 'highly important' to success of firm $(n=101)$}

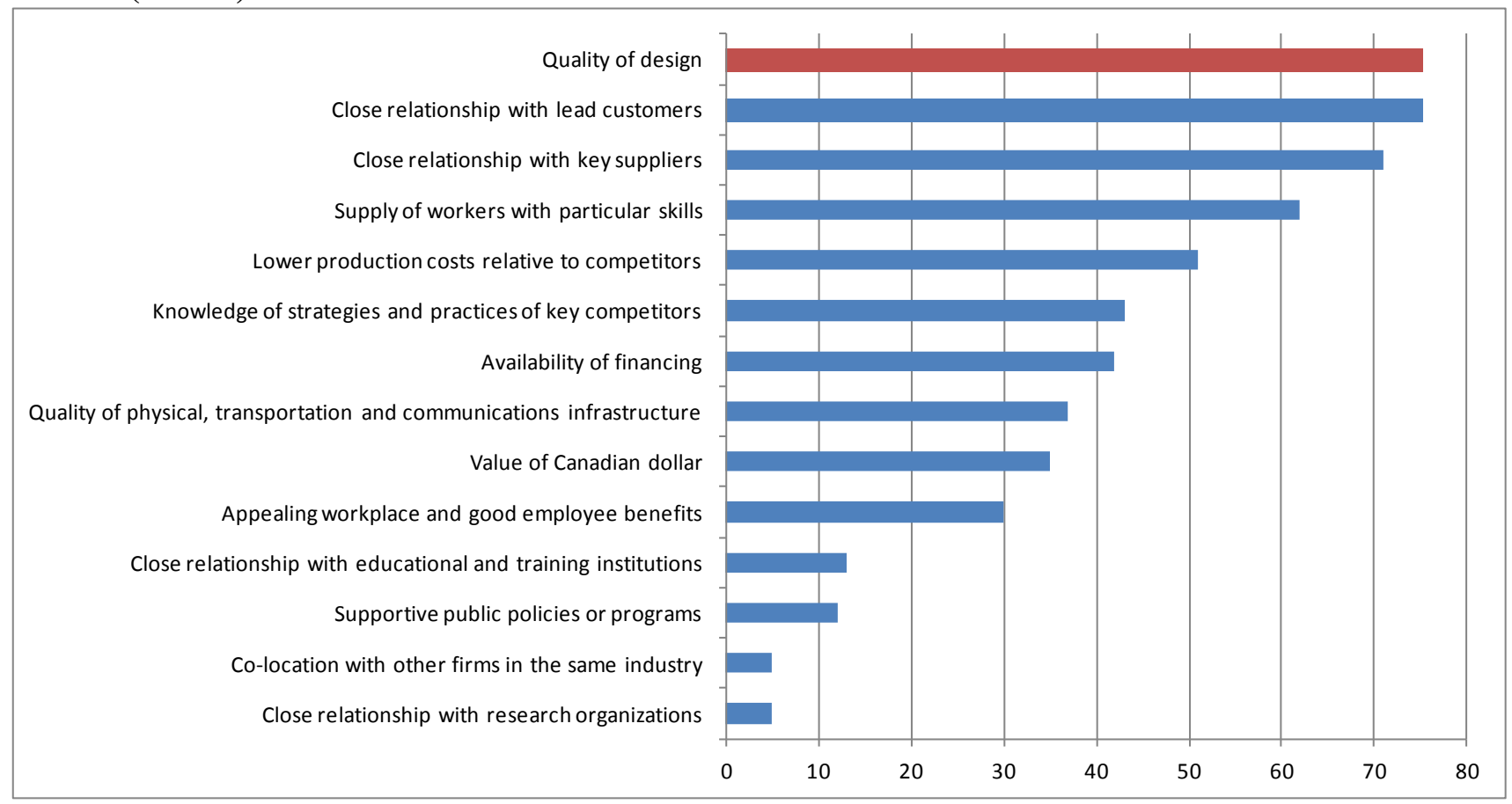

Source: Author's survey of Canadian contract furniture sector, 2010

The next survey question asked participants: 'Do you carry out design?', to which $80 \%$ replied 'Yes'. Table 3.5 and Figure 3.7 group firms by 'Yes' and 'No'. Firms in the 'Yes' group are not only larger in terms of number of employees, but they also boast a 
higher percentage of skilled employment in their respective labour forces than firms in the 'No' group, and show greater performance levels as measured by both productivity and annual sales. In fact, 'Yes' firms report over six times the annual sales level compared to firms in the 'No' group, at $\$ 31.7$ million compared to $\$ 4.8$ million, signifying considerable performance advantages by those who invest in design.

Table 3.5: Comparison of key firm characteristics and performance levels, grouped by firms who 'Carry out design' (YES) and firms who 'Do not carry out design' (NO)

\begin{tabular}{|c|c|c|c|c|c|c|}
\hline \multicolumn{2}{|c|}{ Do you carry out design? } & $\begin{array}{l}\text { Size of } \\
\text { Firm }\end{array}$ & Age of Firm & $\begin{array}{c}\text { Skilled } \\
\text { employment as } \\
\text { a \% of overall } \\
\text { employment } \\
\text { (education) }\end{array}$ & $\begin{array}{c}\text { Annual Sales } \\
\text { (CAD, in } \\
\text { millions) } \\
(2008)\end{array}$ & Productivity \\
\hline \multirow{4}{*}{ YES } & $\mathrm{N}$ & 80 & 80 & 82 & 44 & 43 \\
\hline & Mean & 104.10 & 33.13 & 38.09 & 31.70 & 191,511.21 \\
\hline & Median & 18.00 & 29.00 & 39.00 & 4.60 & $160,000.00$ \\
\hline & Std. Deviation & 263.882 & 21.850 & 25.751 & 97.17 & $135,270.63$ \\
\hline \multirow{4}{*}{ NO } & $\mathrm{N}$ & 19 & 19 & 18 & 14 & 14 \\
\hline & Mean & 33.79 & 33.79 & 30.89 & 4.89 & $160,747.79$ \\
\hline & Median & 15.00 & 29.00 & 25.00 & 1.75 & $139,142.00$ \\
\hline & Std. Deviation & 42.502 & 18.082 & 27.170 & 9.72 & $108,136.06$ \\
\hline
\end{tabular}

Source: Author's survey of Canadian contract furniture sector, 2010 
Figure 3.7: Comparison of firm size, percentage of skilled employment, annual sales performance (2008) and productivity (2008), grouped by YES (carry out design) and NO (don't carry out design)
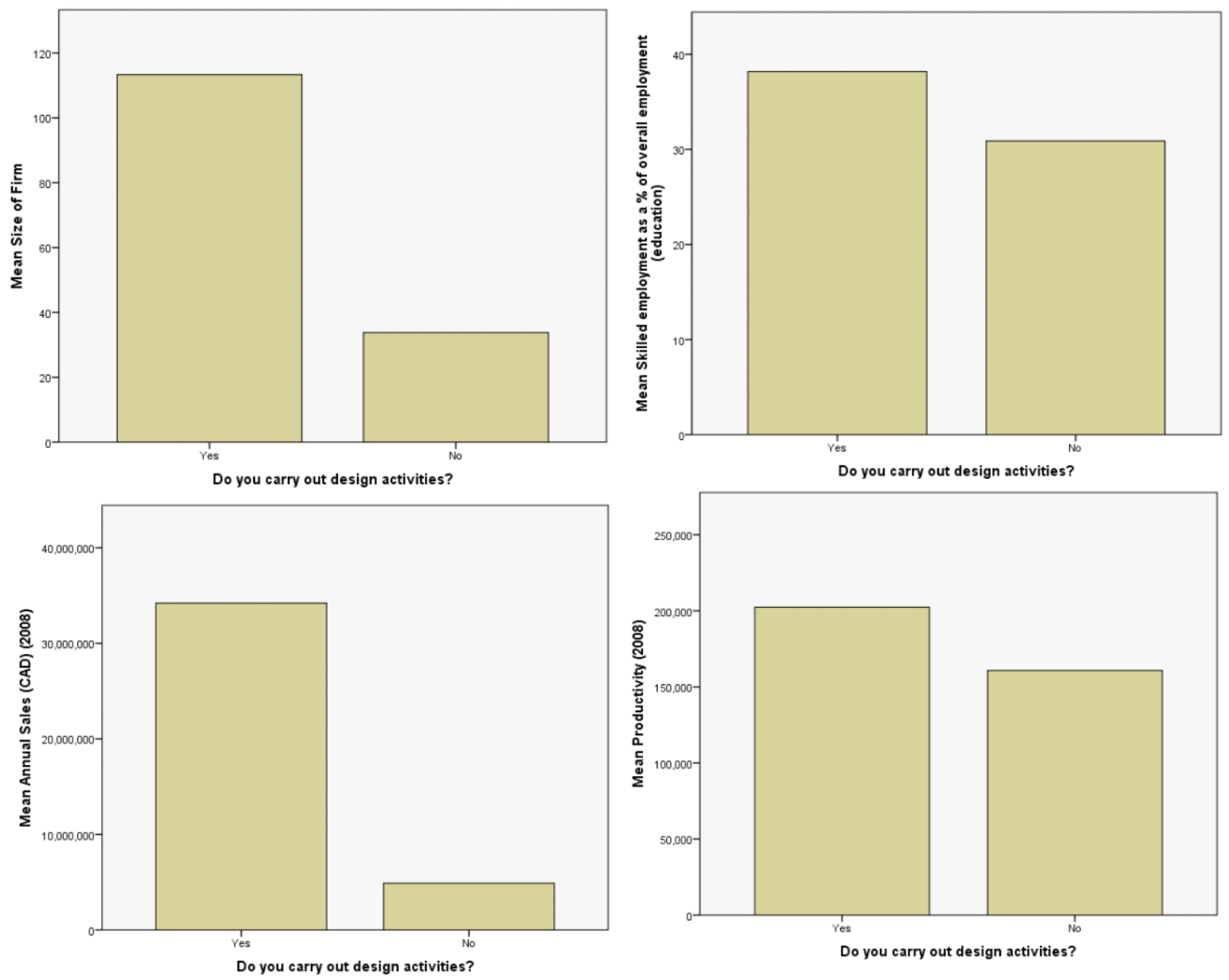

Source: Author's survey of Canadian contract furniture sector, 2010

Table 3.6 reveals that firms who 'carry out design' have distinct production practices underpinning their higher levels of performance, showing higher degrees of both customization of operations and flexibility of operations. As we would expect, manufacturers in the 'Yes' group who report that they carry out design show a higher level of product design-intensity than firms in the 'No' group. Likewise, the 'Yes' 
producers also show a greater degree of product quality and product cost. Overall, the data indicates that there is a relationship between investment in design, level of labour force skill, and marketplace performance, with firms investing in design boasting a more highly skilled workforce, higher annual sales, and better productivity.

Table 3.6: Mean score between 1 and 7 for the following production strategies, grouped by YES (carry out design) and NO (don't carry out design)

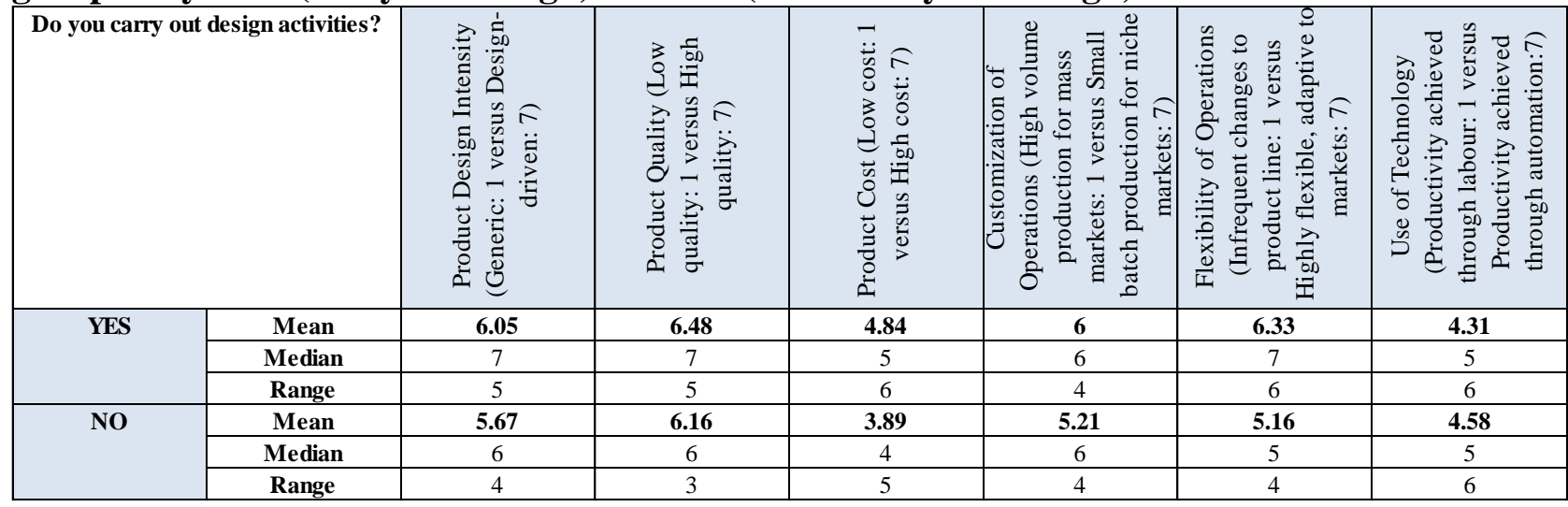

Source: Author's survey of Canadian contract furniture sector, 2010

For firms in the 'Yes' group, not only can products be considered highly designintensive, but data shows that the design process is being carried out primarily in the manufacturing firm itself. Firms who carry out design report investing $14 \%$ of their overall annual expenditure on design in 2009 , with $85 \%$ of that expense allocated for inhouse (as opposed to outsourced) design services, in other words, processes that are managed by the manufacturing firm (Table 3.7). This data underscores a high degree of emphasis on quality and design-intensity in this case study, as well as a strong orientation towards in-house practices, suggesting that design is a core competency of furniture manufacturing firms. 
Table 3.7: Characteristics of firms that carry out design

\begin{tabular}{|c|c|}
\hline $\begin{array}{c}\text { Of those firms who carry out design activities, percentage of } \\
\text { overall firm expenditure on design (2009) }\end{array}$ & $\begin{array}{c}\text { Of those firms who carry out design activities, percentage of } \\
\text { expenditures that are for IN-HOUSE (rather than } \\
\text { OUTSOURCED) design services }\end{array}$ \\
\hline $\mathbf{1 4}$ & $\mathbf{8 5}$ \\
\hline
\end{tabular}

Source: Author's survey of Canadian contract furniture sector, 2010

\subsubsection{Design practice}

\subsubsection{1: Introduction}

One of the central ideas that emerged from the knowledge base and creative labour markets literatures is that the time horizon of labour practices is crucial to the structuring of learning and innovation processes inside and outside the firm. On the one hand, the production and dissemination of synthetic knowledge is said to be promoted by longterm, interactive learning processes, and on the other hand, symbolic knowledge creation was shown to be underpinned by short-term practices and labour mobility. It is not surprising therefore to find that firms in the case study adopt practices aimed at incorporating design capability that are both long and short in duration. Specifically, the long-term practice that predominates in the case study involves the employment of an inhouse design team within the organization on a permanent, full-time basis. The shortterm arrangement entails the engagement of industrial designers who are outside the firm on a temporary, contractual basis. We shall begin by considering how long-term structures influence the dynamics of learning and innovation, and then proceed with a discussion of the role of temporary design consultants. 


\subsubsection{Long -term employment structures: the internal design team}

The practice of employing a permanent, in-house design team is both prominent and widespread in the case study, with three quarters of firms in the interview sample adopting this method (15 out of 20 firms). Of this group, one third have in-house designers as their exclusive practice ( 5 firms), whereas the remaining balance of firms adopt an in-house team in addition to other sources, namely hiring temporary project design consultants (10 firms), to be addressed in the subsequent section.

Evidence from the interview sample shows that long-term practices and the inhouse team are conducive to industrial processes and the production of synthetic knowledge, and in three complementary ways. First, such an employment model enables an organization to maintain close proximity between and interplay with designers and other actors of the product development process. The president of a large firm in Quebec, for example, discusses the importance of the collaborative aspect of the in-house team to the research and development process in his organization. He says that "The proximity between design and manufacturing always creates a natural think-tank on how to improve the product. Plus, you have people on the shop floor who have ideas about product improvements and enhancements." In another example, the vice president of design and innovation for a mid-sized Ontario manufacturer talks about how critical face-to-face interaction between designers, engineers and manufacturing staff is, implying that innovation for this type of industrial activity derives from routine practice within a permanent, in-house structure,

I don't know how companies do without it. It's a fundamental requirement. In the design and development phase, it's about the interaction of ideas. You know, someone might say something, and it 
just triggers something invaluable, in combination with the sketches and other ideas within the group. And the more face-to-face you have, the faster and better your ideas get, really. We do a lot of interaction here. We are constantly, you know, back and forth, talking.

To further illustrate the importance of spatial proximity to the formation of synthetic knowledge, I invoke the experience of an industrial designer who, although technically outside the organization, was compelled to be at the manufacturing firm on a full-time basis for the duration of one project. This implies something between 'in-house' and 'external', of which he says,

I had my own desk and my own phone. I was there all the time, basically. I was involved in all aspects of it, not just what I would narrowly call design, which I think is the way designers ought to operate. You know, investigating technology when working with toolmakers, everything.

These various examples demonstrate that the long-term structuring of design practices inside the manufacturing organization support an interactive, face-to-face environment that promotes the generation of industrial, synthetic knowledge.

Second, spatial proximity between team members that is achieved by the in-house structure is found to support the incremental, group-based, on-the-job learning process that is critical to innovation in advanced manufacturing. As the following quote by the vice president of marketing for a mid-sized firm in western Canada depicts, skill and knowledge development derive from a close-working, consensus-based relationship between the various actors who are involved in the development process,

Over time, those that are in-house gain the expertise of what works in our system and what the limitations and capabilities are of the manufacturing process are. Design has a very strong relationship with both engineering and manufacturing. The attachment is very close. Whenever they create a design, they have to base it on the engineering criteria and create a prototype for manufacturing to see if it's doable. This is all a part of the design criteria. 
In another example, the vice president of manufacturing for a mid-sized firm based in

Quebec provides a similar analysis, emphasizing that the embedding of designers within

the organization and their close interaction with other team members fosters the

development of a specific kind of design expertise,

It's a lot easier when on a permanent basis, (design) people are inside the organization because they already know that a certain proposed change might be a silly idea because of the limits of the manufacturing processes, or the raw material, or the subcontractors, and so on. There are a lot of occasions where you say 'this is a neat thing to look at' but we know it's not feasible. So you gain that very strong awareness between the product design and the ability of a product to have success in the marketplace and then your ability to manufacture it on a consistent basis.

These perspectives illustrate that the long-term employment structure achieved by the inhouse team underpins a specific learning process (that is interactive and group-based), and promotes a distinctive design knowledge (that is characterized by strong expertise in engineering and manufacturing criteria).

Third, interviews also show that the long-term structure would seem to underpin an important aspect of design innovation that is suited to the process of incremental (rather than radical) product enhancement. The president of a mid-sized Ontario manufacturer reflects on the role of his internal team in focusing on incremental improvements in response to client specifications. In his words, "The team basically supports and reacts to the clients, and the specific and ongoing requirements." In a related vein, speaking on behalf of his team of in-house designers, the director of design innovation for a large company based in Ontario suggests that development is more about 'evolution' than 'revolution'. He notes:

It's about overseeing a large portfolio of product, and understanding where you are changing that group of products in ways that respond to new ways of working or trends that you're seeing in the workplace. So we try to maintain the stuff we have, we also try to come up with 
changes, addendums, improvements, to all the existing stuff, as well as trying to come up with ideas of: what's next?

In other words, there are varying degrees of incremental innovation, entailing both the modification of existing products and processes, as well as the introduction of new products to the marketplace. Research from the case study reveals that the long-term, inhouse team structure plays a crucial role in shaping both aspects of product development that are incremental, evolutionary, and gradual in nature.

\subsubsection{Constraints of the in-house structure}

Findings from the case study also reveal that while this type of long-term practice may be well suited to the labour requirements of the industrial manufacturing and synthetic knowledge aspect, it stops short of effectively leveraging the creativity of the workforce. The president of a mid-sized firm in western Canada comments on the limitations of the in-house team model. He notes, "The way our team sees things is based on their own experiences and abilities. And it's sometimes the case with an internal design team that you can get a bit of an inward focus because they're just not out there every day." In other words, "Sometimes you can't see the trees for the forest," explains the vice president of design and innovation for another mid-sized manufacturing firm in Ontario, "and you need to get fresh blood." The vice president of world markets for a large Ontario producer echoes this view, and contends that with the in-house team, "You tend to get fixated in one direction, in one design language." He goes on to suggest that "You sometimes want the thinking from the outside, even from different industries and different countries." By 'fresh blood' and 'outside thinking', the interviewees refer to the common practice in the industry of engaging industrial design consultants who are 
outside the organization on a contractual basis and often for the temporary duration of the product development process, as 15 out of 20 firms in the interview sample do. Of this group, one third employ outside designers as their exclusive design practice ( 5 firms), with two thirds adopting this method as complementary to the internal team (10 firms).

\subsubsection{Short -term employment structures: temporary project designers}

Research from the interviews shows that this type of temporary engagement with independent industrial designers who are outside the organization fosters creativity and supports the formation of symbolic knowledge, and in three related ways. First, this temporary employment practice enables a manufacturing firm to bring in fresh ideas and outside perspectives that promote creativity and the design integrity of a product line. The design director for one mid-sized firm based in western Canada reports that "Outside designers bring new fresh ideas into the company - they are less influenced by the day-today needs." The president of another organization of similar size in Quebec contends that "Bringing in outside designers allows us to get a different and broader perspective because they bring an influx of new ideas to the table." The vice president of design and innovation for a large Ontario-based company echoes these sentiments and says that "I usually tap into outside consultants for fresh thinking and to look at things objectively." In another example, the president of a mid-sized producer in the same region suggests that the main benefit of bringing in designers from the outside is because "their world view of the marketplace and products is different from what our teams is going to be." He goes on to explain,

If you're a product designer that's in the marketplace designing products for a lot of different companies, if you're out there every day in the middle of what's happening in the marketplace, that's a very different 
focus than an industrial designer who's here every day. It's hard to replace being out there.

Comments by the president of a mid-sized manufacturer in Ontario reveal that simply employing external project designers is not sufficient; an essential strategy involves the periodic rotation of a group of individuals whose design philosophies and values complement the firm's commitment to design excellence. Such an approach enables a firm to maximize its creative engagement with outside experts, capitalize on design inputs, and minimize the risk of encountering periods of creative block.

According to this view,

There is a style to it. By having several designers move in and out of the 'zone' - I'll call it the zone... because sometimes they're hot, or they're in a groove or... like writers, you have writer's block. So some designers are really prolific at moments in time, others need a little bit of a break, or maybe you're getting a sameness, so you need to push the envelope by going to someone else.

These perspectives highlight the way in which temporary employment structures and the use of outside design experts, best engaged on a rotating or cyclical basis as described, promote a high degree of creativity and excellence in design.

The second way in which short-term practices engender symbolic knowledge creation is by supporting industry-specific learning and skills development via external labour markets (Lam 2000, 2002). A highly mobile career working for different companies on multiple projects, perhaps even across sectors and places, enables an individual to cultivate a unique expertise in design that differentiates her from her counterpart working inside the manufacturing firm. One industrial designer based in Ontario describes such a trajectory. He established his own design consultancy with a partner, and worked in a freelance capacity for as many as nine manufacturing firms in a three-year period, oftentimes balancing multiple concurrent projects, 
So we did a lot of work with Allseating. At the same time I had an independent consulting business. We did other furniture work outside the contract sector. And we did some work for Teknion - a series of wood side chairs. And then we started working in other industries as well. And we continued to do other work for Umbra.

Another independent designer in the same region reveals that working across different product sectors enhances his ability to be creative. Formerly a transportation designer, he brings a unique approach to a public seating solution for an airport,

For me it is important for an object to have a dynamic to it, because I find that a lot of furniture tends to be more static. We were looking at the seats and seeing they were kind of shaped like an airplane wing, and that became the genesis of the product idea. However we could, we should try to make something aeronautical about it. When looking at transportation objects, they look like they're moving even when they're still. I've gone the other way too - I've had concepts for cars that were inspired by knock-down furniture.

These mobile practices and skill development through external labour markets

produce a design expertise that is fundamentally different from the knowledge of the inhouse employee. Research from the case study shows that the contract designer has a broader and more conceptual, theoretical knowledge than her counterpart inside the firm. An industrial designer from a consultancy in Ontario, for example, contrasts the broadbased market knowledge of the outside expert with the more micro perspective of the internal designer,
We often work with companies that already have internal design resources and we find we have very different perspectives. The outside perspective is always going to be more led by where the market is going than an internal design perspective, which is more about responding to where immediate sales are being driven. We are looking to what they haven't even figured out yet - where we need to go next.

In another example, the vice president of operations of a mid-sized Ontario firm talks about the highly conceptual approach to design that is typical of the outside designer. Although they produce highly innovative design solutions, their more limited knowledge of engineering and manufacturing criteria can be problematic. He notes, 
From my perspective, design is the ultimate wish list of a design person. The reality of what can be accomplished using the materials, budget, the needs, where it is going to go, the projected life cycle, quantity, all those will go into an engineering and manufacturing decision. As opposed to a designer who will come in with a 'This is the ultimate! This is my creation, this is what $I$ see.'

In other words, although the external designer may bring a highly theoretical approach and strong design sensibility based on extensive market knowledge, there may be a disconnect between the proposed design solution and what may successfully be engineered and manufactured in reality.

The final way that these short-term engagements leverage the creativity of the workforce and the generation of symbolic knowledge is that they can contribute to radical product development. It is often the case that outside experts play a central role in shaping highly credited design solutions that may constitute a radical departure for a company. One industrial designer discusses the 'game-changing' nature of product design that comes from outside consultants, "If a company wants some game-changing, super creative design, like a product that they launch and go 'wow - where did that come from?', they will hire an outside designer who comes in with a different point of view." Along similar lines, another designer points out that "Sometimes you want those Eureka things, those designs that come out of nowhere that are so amazing. And that's why you use outside designers." These comments imply that contract designers can play a fundamental role in raising a firm's caliber of design sophistication and its ability to introduce new - often radically innovative and highly acclaimed - products to the marketplace.

The magnitude of design influence that is conveyed by the outside expert can best be described by drawing on an analogy by the president and founder of one of the leading contract furniture companies in the industry, a mid-sized firm that is located in Ontario. 
In articulating the core contribution of the outside expert designer, he also captures the precise contours of the division of labour between design, engineering and manufacturing. He says,

Once we have a product concept, we can create it beautifully with tooling and engineering and all the things necessary to bring a product to the production line. But there is a gap between the concept that's been defined and the starting point of developing the product - and that's the idea. So if you take the need to create the product, there's this gap, and it's the creative spark that the designers provide that take us from down here to up here (gestures). We take it this far, they jump us over, and we take it the rest of the way.

Albeit intangible, that 'creative spark' may constitute the difference between, on the one hand, commodity, and on the other, design excellence that positions a manufacturer at the forefront of contemporary design.

\subsubsection{Design at a distance}

Research from the case study reveals that certain producers are compelled to go beyond the local labour market in pursuit of internationally recognized design talent. The president of a mid-sized manufacturer in Ontario explains that "We try to be at the forefront of innovation and we like to collaborate with forward-thinking designers, oftentimes in New York, Los Angeles, London, and sometimes Europe, too." In another example, the president of a firm of similar size and within the same region, well known in the industry for its collaboration with high profile international designers, says, "We believe that commitment to design is the power that drives creative solutions. Our designers are among the best in the world." This strategy supports Bathelt et al.'s 'pipelines' argument (2004), and enables Canadian firms to access state-of-the-art design knowledge that is produced in the world's most dynamic labour markets, global sites of excellence that are at the frontier of contemporary design. 
However, the ability to tap into the expertise of internationally recognized designers rests on a producer's distinct 'path dependency', in other words, its heritage of past practices which have successfully positioned it at the forefront of contemporary design (Nelson and Winter 1982; Penrose 1995; Maskell and Malmberg 1999). As one industrial designer puts it, "In order to bring in the big name talent from the US and beyond, you have to raise your game as a company. There are so few Canadian companies working and producing product at that level." Along similar lines, the design director for a mid-sized Ontario producer explains that "Small companies that don't have a strong design persona tend not to be able to attract the big name designers." Moreover, firms that have the capability to work with these renowned global actors must also learn how to absorb, process and use these external knowledge inputs effectively, suggesting that these very producers boast a higher 'absorptive capacity' than their competitors who are unable to attract global designers in the first place (Cohen and Levinthal 1990).

Those firms that have the resources to engage internationally recognized designers benefit from an important source of innovative ideas and economic advantage. The president of world markets for a large Ontario-based firm suggests that this practice is fundamental to his company's ability to differentiate its products in global markets. He contends that "We need the input from outside designers in other places, because otherwise, everything can end up looking very much the same." Similarly, the vice president of design and innovation for a mid-sized Ontario manufacturer highlights the importance of the aesthetic influence that comes from working with international consultants. He says,

I've started to tap into a few design firms in the States. And now we're talking about exploring Europe as well, just to get that European flavor. There's a whole different appreciation for how design is approached in 
Europe versus North America. European flavors bring in a very strong, simplistic design approach.

According to the president of a mid-sized firm in the same region, it is the specialized market knowledge embodied by the nonlocal designer that is the greatest asset. "I like the outside design influence," he says, "because we sell in other areas like in the United States, and I feel we should employ designers in the markets where we sell." The president of another mid-sized Ontario manufacturer provides perhaps the most succinct yet compelling account of the benefits of engaging global experts on a short-term, project basis. He says, "You have to take an international view. We are not a Canadian company. We are an international, world-class seating manufacturer that happens to be located in Canada."

As we know from the preceding section on short-term design practice, the predominant type of knowledge that we are dealing with in our analysis of long distance learning is symbolic in nature. Literature on the geography of innovation shows that symbolic knowledge is strongly shaped by its social and cultural context, highly embedded in particular places, and thus varies widely in its meaning from one place to another (Asheim et al. 2007; Gertler 2008). We would therefore expect that its long distance transfer from global 'hotspots' of design excellence in the US, UK and Europe, where international designers in the case study reside, to plants in Ontario, Quebec and western Canada, to be fraught with difficulty. Compelling as this may be in theory, results from the case study indicate otherwise, that in fact, these individuals wield a powerful design influence. This begs the final question that is at the heart of the analysis in this chapter: what are the precise circumstances and conditions that shape and constrain the flow of design knowledge at a distance? 
We can assume that linguistic affinity is generally high between outside designers in other places and their innovation partners comprising the community of practice in the Canadian plants since business is conducted in English. Because industrial designers on both sides of the partnership have similar educational, industrial and professional backgrounds, occupational affinity is also deemed to be high. However, due to the fact that external designers are by nature outside the manufacturing organization, organizational proximity can be considered low. For outside experts hailing from the US and UK, institutional proximity is high, since market governance regimes and national institutions of labour markets and industrial relations in these countries are similar to those in Canada. By contrast, institutional affinity can be assumed to be low between Continental European designers and their Canadian counterparts, given the wellestablished institutional differences between Continental Europe and Canada (see Chapter Two for a more in-depth analysis of this issue).

The effects of weak organizational proximity have undoubtedly constrained the degree to which symbolic knowledge is able to transfer smoothly at a distance. Drawing on one example in the case study, the president of world markets for a large Ontariobased firm talks about the common difficulty that is encountered in incorporating outside designers into the organizational practices of the manufacturing firm, in particular, its concurrent design process. Given the fact that the lion's share of design consultants for the company hail from international markets, his perspective is indeed pertinent to our understanding of distanciated learning processes. In his words,

It's (concurrent design process) very stressful, especially for designers. It's a go-fast process, and it's very disciplined. Because designers like to 'blue-sky think' and toss things around all day and try alternatives. But the gates are disciplined in order to meet the timelines... The outside 
designers don't work to that concurrent process. And that in itself causes delays and issues.

Moreover, these challenges are found to be exacerbated due to the type of knowledge that predominates. Symbolic knowledge, at the heart of our analysis of long distance learning within communities of design practice, is highly embedded in place, and may not lend itself well to the process of transfer between economic actors over long distances. In one example from the case study, the vice president of manufacturing for a mid-sized company in the same region comments on the inherent difficulties of working with designers who are located remotely, and therefore not always in on the 'day-to-day',

There's a disconnect because it's hard when you're evolving a product. There are often trade-offs between what the designer wants and what you can do. So it's always better to have the decision maker right there in the ebb and flow of the process. Because it's kind of hard the way we do it now, when they're not always there. They're not in on the day-today decisions, which creates challenges.

This supports the view of Gertler (2008) that the frictional effects of distance are dependent to an extent upon the type of knowledge supporting innovation.

Despite such constraints, there are means by which Canadian firms in the case study are able to enhance relational proximity and the sharing of symbolic knowledge between distanciated designers and their communities of practice inside the Canadian plants. Evidence suggests that in addition to facilitating periodic visits by the designer to the manufacturing site, firms employ the typical tools of long distance communication, including email, conference calls, webinars and videoconferencing. The president of a mid-sized firm in Ontario discusses how the advent of one technology in particular rapid prototyping - has been an invaluable tool to enhance communication among development teams when designers are not close by. He says, 
3D model. It helps me design - I can shape it and carve it and it gives me the accuracy I can never get on the drafting board or anywhere else. I can check to see whether the design idea is good or not, and if it's no good, I simply throw it out. I can share it with anybody, anywhere, as long as they have access to the technology.

These various strategies have enabled firms to minimize the detrimental effects of distance between outside designers and their counterparts in the manufacturing firm during the critical design and development stage.

\subsection{Summary and conclusion}

This chapter began by recognizing a rise in importance of design and quality to the contemporary production of goods, signifying the importance of understanding labour dynamics that support innovation in a design-oriented manufacturing regime. It then identified a two-fold industrial knowledge base that underpins learning and innovation processes within a design-led strategy, consisting of spheres of knowledge that are produced by employment practices that are qualitatively and temporally divergent. Given the conflicting nature of employment relations that underpin innovative dynamism within this type of industrial activity, this chapter posed the following questions: How is design organized to support innovation? What is the geography of design practice? Do different design geographies promote distinctive processes of innovation? If so, what are the mechanisms and conditions that shape and constrain the flow of design knowledge at a distance?

The analysis presented here indicates that Canadian furniture manufacturing firms in the case study employ both long and short-term practices aimed at incorporating design capability into the manufacturing firm. Stable employment relations in the form of an in-house design team foster a work organization that facilitates face-to-face, 
interactive, group-based learning that is conducive to synthetic knowledge creation. Moreover, these long-term practices encourage the development of a specific design expertise that is characterized by an in-depth understanding of industrial criteria, and underpins incremental product development. However, at the same time, this mode of work organization may constrain an organization's ability to harness the creative potential and advance the design sophistication of its workforce. In this way, such practices may limit the extent to which a manufacturer can produce exceptionally innovative design.

By contrast, short-term structures and the hiring of design consultants on a temporary, contractual basis enables a producer to tap into the highly developed market knowledge and creativity of the outside expert. Evidence from the case study indicates that this form of work organization promotes symbolic knowledge creation and the development of highly creative design expertise through external labour markets, and can contribute to radical product development. However, research also shows that a firm's long distance engagement with designers who are located in global markets, a strategy aimed at maximizing its creative capability and design sophistication, but also a way of gaining access to localized tastes, preferences and trends in the global market, has the detrimental effect of undermining the face-to-face, interactive environment that is crucial to the product development process. In this way, it limits a firm's ability to produce and diffuse synthetic knowledge.

There are both benefits and costs associated with combining long- and short-term employment strategies. A firm's decision to bring both in-house and external design functions together, as $50 \%$ of the firms in the interview sample have done, leverages a two-fold competitive advantage, and is consistent with both synthetic and symbolic 
knowledge formation. On the one hand, the internal design team plays a crucial role in working with engineers and manufacturing staff to continuously improve a firm's catalogue of existing products. On the other hand, the steady influx of ideas from project designers facilitates a firm's ability to introduce new, often radically innovative and highly acclaimed, products to the marketplace. These different employment structures seek to capitalize on design inputs into the product development process. However, at the same time, practices that promote knowledge creation in one sphere appear to undermine the other, or simply do not mesh as easily as anticipated.

Finally, leading firms that are at the forefront of contemporary design benefit by collaborating with internationally recognized talent and, in doing so, access knowledge that is produced in the world's most dynamic labour markets. It is highly likely that smaller firms who do not have these capabilities benefit from the information that is acquired by their competitors through pipelines, and which then spills over and stimulates growth within the surrounding industrial cluster (Bathelt et al. 2004). Knowledge flow at a distance is supported by the development of relational proximity shared by members of the community of design and development practice, which derives from a number of social affinities including common language, occupational and professional background, and in most cases, national business system or variety of capitalism. Firms attempt to overcome the frictional effects of distance that derives in part from weak organizational proximity and the inherent resistance to long distance transfer of symbolic knowledge by exploiting various communications technologies and through establishing temporary forms of co-location, where necessary. This research therefore confirms not only the ongoing importance of spatial proximity to the joint formation, accumulation and 
circulation of design knowledge, as well as providing insight into the conditions under which non-local learning might be effective. It also reinforces the significance of a knowledge base approach (Asheim and Gertler 2005; Gertler 2008) to our understanding of the dynamics of learning and innovation within complex economic processes such as design. 


\section{Chapter IV}

\section{Learning from customers: the social and spatial dynamics of user-producer interaction in the innovation process}

\subsection{Introduction}

Beginning around the mid1980s, economic geographers and other social scientists began to observe some important changes in the nature of capitalist production systems that involved a shift away from mass production and towards mass customization which required firms to implement new and more flexible process technologies and practices. Closely related to these internal changes was a restructuring in the wider division of labour between firms and a process of vertical disintegration. As firms reorganized their production to suit the rapidly changing, variegated consumer markets that had emerged during this period known as 'After Fordism', they opted to perform fewer functions for themselves in-house, and instead to outsource these activities to external specialist suppliers. Production systems transformed themselves towards an increasingly social basis of organization and the importance of geography became greatly enhanced because spatial proximity between firms and other actors minimized transaction costs. As firms' production needs shifted, so too did their input needs, and the pressure to achieve successful innovation in products and processes became a central focus. As production processes underwent inter-organizational rearrangement, the locus of innovation 
expanded from the internal resources of the firm towards external networks and knowledge pools.

One of the most significant of these knowledge pools is that of the user or consumer of product offerings. In the business innovation literature, the role of the user has long been recognized as an essential source of information in product development (Lundvall 1985, 1988, 1992; von Hippel 1976, 1977, 1989, 2001, 2005). Research in business strategy has examined the qualitative dimensions of local demand conditions and the role of sophisticated users and niche customers in providing producers with a wider and deeper view of the market. This work has argued that demanding consumers will not only pressure firms and related industries to innovate and provide new offerings, but that users themselves may play a direct role in these processes, becoming participants in shaping the differentiation of products (Porter 1990, 1994, 1998, 2000). More recently, users have been recognized as calculative actors who are actively involved in the qualification and evaluation of products (Callon, Meadel and Rabeharisoa 2002; Callon and Muniesa 2005).

The degree of user involvement in innovation processes is unprecedented in certain sectors, particularly in the post-Internet era and the advent of one particularly extreme example, 'open-source development', where innovation, development and consumption can potentially be organized entirely by users. Moreover, there has been an increasing attempt on the part of firms to harness this vital source of market intelligence and feed it back into the development process, so as to shape their products more carefully in line with the specifications of differentiated market segments. 
However, despite these trends that are playing out in practice, the role of users in customizing products to suit their demands, their interaction with producers, and the geography of these phenomena have received limited attention within the field of economic geography, with several notable exceptions. Gertler (1995, 2004), for instance, has investigated the interaction between German producers of advanced machinery and user plants in Canada and the US to find that user-producer relations are constrained by starkly different macro-regulatory environments and institutions regulating labour markets, industrial relations, corporate governance and capital markets between Germany and North America. Grabher has also made some important contributions in the area of user involvement in innovation. His empirical work in the new media industry shows that project ecologies in creative industries involve intense client participation as well as shifting patterns of temporary collaboration and co-presence (2002). In more recent work of a conceptual nature, in which he and colleagues critique a 'producer-fixated' view of innovation, they argue that there is a blurring of the boundaries between user and producer in the contemporary economy, and an interdependence between production and consumption and technology-push and demand-pull (Grabher et al. 2008).

Overall, however, questions interrogating the practices, spatiality and temporality of user-producer interaction and knowledge creation remain underspecified in the literature. The goal of this chapter, therefore, is to begin to address this gap. I do so through an empirical analysis of the co-development practices and the social and spatial dynamics of user-producer interaction in Canada's contract furniture manufacturing sector, which, as previous chapters have pointed out, is heavily dependent upon quality, design, and the customization and specialization of its products and production processes. 
The emphasis on customization as a core element of a firm's business model is evident in the following quote by the president of one mid-sized Ontario producer who reports that,

It's contract furniture, so it's made to order, and it's essentially customized for every customer. And we've also put a lot of focus on product quality, which is a challenge in furniture because of the tremendous variation in what we're producing as well as the inherent and imperfect nature of some of the materials like wood. We have, literally, millions of different versions of our product, and it's incredibly complex that way because of the level of customization. Does that make it easier for anything to go wrong? It certainly does.

The high degree of variability in product offerings that is depicted in the above comments is quantified in another example by the vice president of manufacturing for a similarsized company in the same region who points out that "In our table line, for instance, we have 14,000 shapes and sizes in our 300-page price list. Then we do $30 \%$ custom on top of that." These examples imply that a contract furniture producer's capability to customize and tailor to such a precise degree of detail, while maintaining high levels of quality, results from their success in tapping into the specialized demands and innovative ideas of their users. The goal of this chapter is to investigate the evidence supporting this claim.

This chapter proceeds over five sections. Drawing on empirical work in industrial organization theory, innovation, and evolutionary economics of technical change, I discuss the importance of user knowledge in complex goods production as well as the implications of proximity and distance to the success of user-producer interaction. I then introduce the users in the Canadian contract furniture manufacturing sector by considering the geographic and occupational profile of lead (end) users, as well as the roles of the furniture dealer and the interior designer, who fit with Lundvall's description of professional users. Following this I consider issues related to research design and 
methods. The subsequent analysis section addresses the importance of user engagement in the innovation process, and I then examine the co-development practices that predominate in the case study, both informal and formal practices. I conclude the analysis by considering the importance of trust-based user-producer relations, as well as the spatiality and temporality of co-development practices. By way of conclusion, I summarize the key insights of this research, and reflect on questions of theory, firm practice, and government policy.

\subsubsection{Complex goods production and the value of learning from users}

Within the literatures on industrial organization theory, innovation and evolutionary economics of technical change, research on capital goods production has found that for certain products that are characterized by systemic technological complexity and rapid change, an accurate understanding of user need is a core factor that discriminates between commercially successful industrial goods innovation projects, one the one hand, and those that fail, on the other (von Hippel 1976 [scientific instruments], 1977 [silicon-based semi-conductors and electronic subassemblies], 1986 [circuit boards], 1988; Rosenberg 1982 [aircraft]; Lundvall 1985, 1988 [complex production equipment]; Gertler 2004 [advanced manufacturing technologies]). Manufacturers engage in a risky exercise every time they introduce a new product into the market. Indeed, a major insight arising from the innovation literature is that many important, innovative ideas originate with users such that producers' interaction with them can be crucial to competitive success. Producers will develop a stronger hold on their markets if, through the development of long-term understanding of their users' needs, they can provide a superior product to the 
market. Conversely, producers who may be indifferent or complacent towards the needs of users cut themselves off from a valuable source of innovative ideas.

\subsubsection{Characteristics of products and markets that rely on learning-by-using}

A number of contributions in the empirical literature, investigating industries ranging from extreme examples such as aircraft, to capital machinery and equipment, to videogaming, point to the key characteristics of products and markets that benefit most strongly from user involvement in innovation. In his work on the aircraft industry, Rosenberg (1982) has described the features of products to include a high degree of complexity, rapid change, and interacting components, whereby development entails significant costs and long lead times, and maintenance and repair constitute a considerable portion of operating costs. In addition, product reliability is said to be a major consideration, and uncertainty about performance characteristics cannot be fully understood until after prolonged experience and use.

Lundvall's theory of user-producer interaction $(1985,1988)$ echoes the ideas of Rosenberg to some extent to suggest that certain types of products can only be adopted in a process of cooperative interaction between user and producer: those that he describes as expensive, and whose use characteristics are complex and rapidly changing. By contrast, he notes that if the good is simple and standard, if its use-value changes but slowly and if the expenditure for its procurement forms a negligible part of the user's budget, the product will typically be developed by the producer alone, or bought 'off-the shelf' by the user. 
Outside the capital goods sector, a more recent work by Aoyama and Izushi (2008) on video-gaming indicates that commercially successful products that embody a high cultural, symbolic or semiotic content and / or entertainment value, and a high level of specialization / customization, are often heavily dependent upon user inputs in the innovation process. By extension, markets for such products are said to be characterized by considerable uncertainty, heterogeneity, and strong turn-over in demand.

\subsubsection{Unpacking the multiple ways of learning from users: deductive and inductive approaches}

It is helpful at this point to distinguish between conventional marketing strategies and the more user-centered approaches that are pervasive in the types of product industries that have been described. Marketing is a common practice and a necessary aspect of the corporate strategy of producer firms operating in a wide variety of product sectors, and beyond, as a means by which to identify key trends affecting promising market segments. According to von Hippel (1986), these formal methods may range from the intuitive judgment of experts to simple trend extrapolation to more complex correlational or econometric modeling techniques. Research by Grabher et al. (2008) classifies marketing as a deductive approach to learning from users, which constitutes a critical input into the innovation process. However such approaches and techniques tend to simplify and homogenize demand, this work suggests, harnessing general needs and knowledge about the customer (rather than of the customer). While deductive practices provide detailed and useful insight into general patterns of demand, they shop short of addressing the increasingly fragmented and volatile niche markets that have come to dominate the consumer landscape. In deductive approaches, the customer is not in a position to 
influence the innovation process directly. Rather, at best, she provides indirect feedback to the producer after development is complete. von Hippel (1986) points out that such an approach simply cannot accurately predict the precise design and performance characteristics for products that embody a high degree of complexity and / or undergo rapid change.

Research by Rosenberg (1985) provides an understanding as to why this is the case, in other words, why deductive approaches such as conventional marketing are an insufficient means by which to tap into user knowledge in order to support product development for complex goods. According to this view, complex product development is dependent upon 'learning-by-using' because performance characteristics for such products are often highly uncertain and can only be accurately revealed following intensive, and in some cases, prolonged use. The early experience with a new technology leads to a better understanding of the relationship between design characteristics and performance that permit subsequent improvement. An optimal design involves many iterations and a given modification on its own may raise new, unanticipated difficulties that involve trade-offs with other desired performance characteristics. Out of this confluence of learning-by-using, Rosenberg argues, comes a steady flow of small improvements in products, as well as alterations in maintenance and operating procedures that can become embodied in future iterations.

What Rosenberg calls learning-by-using (or Lundvall's term, 'user-producer interaction') exemplifies what Grabher et al. (2008) categorize as inductive approaches to learning from users. Whereas deductive strategies such as marketing move top-down from the aggregate market to the representative customer, the inductive approach works 
bottom-up from the individual customer. And rather than harnessing knowledge about the customer, inductive strategies seek to acquire knowledge of the individual user to draw wider conclusions on actual and potential markets. Moreover, in this model, development tends to be carried out with customers rather than for customers and the user may contribute critical knowledge throughout the entire development process, shaping the course of the process more directly (Grabher et al. 2008).

\subsubsection{Lundvall's framework: user-producer interaction and the sharing of knowledge}

\subsubsection{Incentives for knowledge exchange}

The literature thus far has focused on the importance of user involvement in the innovation process in a wide variety of industries, the specific characteristics of products and markets that are most dependent upon user input, and a general distinction between conventional marketing practices and the more sophisticated user-centered approaches that underpin competitiveness in complex goods manufacturing. Implicit in this discussion is an understanding that user and producer somehow unite in a process of interactive co-development in order to share their knowledge, expertise and innovative ideas with one other. In what follows, I discuss why each partner might be incentivized to do so.

Research by Lundvall on the capital equipment industry $(1985,1988)$ provides a point of departure on these questions. As we have discussed (and what might otherwise be obvious), producers are motivated to monitor the activity of users as part of their broader corporate strategy. Logically, this would allow them to keep abreast of new opportunities in rapidly widening markets, to estimate a respective user's capability to 
adopt new products, and to access the highly valuable experience and know-how embodied by their users. On the other hand, users will be engaged in a constant search for new technical opportunities which may result in higher performance. To this end, they will be motivated to monitor not only the competence and reliability of specific producers of their capital goods, but also to acquire information about new products and how they may relate to their specific needs (which, if successfully adopted, will ultimately assist them in meeting their competitive goals).

\subsubsection{The importance of trust-based relations}

Lundvall $(1985,1988)$ indicates that successful user-producer interaction is dependent upon the formation of mutual trust and mutually respected codes of behaviour between innovating parties, which enables economic actors to overcome information uncertainty associated with complex transactions. The uncertainty factor weighs heavily on both user and producer. For instance, not only is the user buying a product with unknown characteristics, he is also investing in the cooperation of an external party for a future period. There is considerable room in these circumstances for opportunistic behaviour on the part of the producer. The same goes for the producer, who has an interest in disclosing the full capacity of his product and in giving the user insights into his technical competence, which the user can then spillover to competitor producers with whom he might also be engaged. This type of disloyal behaviour can only be restrained, it is argued, if codes of conduct and mutual trust form a core element of the user-producer relationship. 
Moreover, already-existing relations are said to be path dependent and reinforced over time. This is because the development of common codes of understanding and information channels that permit the flow of complex product information between parties are costly and time-consuming to actors on both sides of the partnership, making established relations both enduring and resistant to change. As a subset of users and producers gets more experience from interaction, the elements of mutual trust are reinforced, the exchange of knowledge becomes more open, and the codes and channels of information become more effective in transmitting complex messages related to innovation (Lundvall 1985, 1988).

\subsubsection{The implications of proximity and distance}

The literatures on the geography of innovation and evolutionary economics of technical change remind us that geographic and cultural proximity are critical variables in the successful flow of complex product knowledge between user and producer, for two related reasons (Lundvall 1985, 1988; Gertler 2004). First, trust-based relations between economic actors are said to be best achieved when parties are close-by and within easy reach of one another, since trust and 'social capital' (Putnam 1993) are forged through repeated personal interactions (Gertler 2004). Second, if we consider the situation whereby user and producer are separated by considerable 'distance', it becomes clear that the exchange of information between parties is rendered both more costly and less effective, particularly if the information involved in the process of innovation is complex, which is certainly the case for capital goods. This is because distance, of both a geographic nature as well as differences in language and culture, will impair the 
communication and interpretation of codes, thus demanding greater investments in information channels to decipher the complex messages exchanged.

Yet how close must users and producers be to one another in order for effective interaction to take place? Several bodies of work discuss the importance of the nation state. Certain institutional characteristics of nation states, as well as distinct national systems of innovation and common sets of standards of regulation are said to foster easier interaction between user and producer within the same country than the same interaction across national borders (Freeman 1987; Stowsky 1987; Nelson 1988; Lundvall 1988; Gertler 2004). Other research points to the importance of co-location of parties in the same region or urban area. Lundvall, for example, argues that a key determinant of the development of an innovative sector is the quality of demand arising from the 'home' (local) market, because competent, demanding users will pressure firms to generate innovative products (1985). This idea is later picked up by Porter (1990) who suggests that competitive success derives from the territorialized clustering of producers serving the needs of sophisticated local users, who may play a direct role as active participants in shaping a producer's offerings.

A core idea in Lundvall's framework of user-producer interaction is that the knowledge involved in the innovation process between user and producer is highly complex due to the multifaceted nature of the products and their embodied technologies. Thus spatial and cultural proximity between economic actors underpins the development of trust-based relations and facilitates the flow of information that is vital to the innovation process. I suggest that these basic principles can be applied beyond the capital goods sector and to 
the contract furniture industry, as these industries might be considered analytically complementary. At the scale of the individual product, office furniture may be regarded as far less technologically intensive than the capital machinery at the heart of Lundvall's analysis (although perhaps not necessarily less information-intensive given the importance of design and quality). However, the high degree of product specialization and customization at the scale of the typical corporate order means that the knowledge involved in the average furniture transaction is indeed highly complex. (This reminds us of the discussion in Chapter Three, which focused on the complex nature of industrial knowledge that underpins innovative activity in contract furniture production, which combines both synthetic and symbolic forms of knowledge, each resting on employment practices that are qualitatively and temporally divergent.) Adopting Lundvall's theory of user-producer interaction to the Canadian contract furniture manufacturing sector, the questions driving the analysis in the paper are these: How important is user involvement in the innovation process in a manufacturing sector that is dependent upon a high degree of customization, specialization, quality and design-intensity? Moving beyond conventional (deductive) marketing approaches, what are the organizational and social practices through which user knowledge is integrated into development processes? How are user-producer knowledge relationships in a design-led niche organized spatially and temporally? Is co-location an absolute necessity, or are there conditions under which it may be successfully relaxed? 


\subsection{Case study and methods}

\subsubsection{Who the users are}

Lundvall (1985) makes a fundamental distinction in his work between 'professional users', who are said to be acting in the formal part of the economy, and 'final users', or the actual consumers of goods. The former are said to embody expert knowledge and, as he puts it, are active problem solvers who engage in systematic research for new products, oftentimes embarking on extensive formal training and 'learning-by-doing' to adapt to new technologies, trends and opportunities in the marketplace. By contrast, final endusers of products do not contribute expert knowledge per se; rather, they are valued for their capacity to share the experiences they have gained in everyday practice to convey motivation for adoption (or consistent non-adoption) of goods (Grabher et al. 2008). As von Hippel has pointed out (1986), end-users are 'constrained by the familiar', meaning that their insights into new product / process needs and potential solutions are often limited by their own real world experiences. In other words, users 'steeped in the present', as he explains, lack foresight and are unable to describe a product that conflicts with the familiar and does not exist. In this way, end-users are much more passive and informal participants in the user chain, and are often dependent upon the expertise of professional users to carefully abstract from their tacit and latent knowledge regarding the attributes they feel are important in products. In this paper, we shall mainly be concerned with userproducer relationships where the user is a professional one. Case study evidence reveals that the professional user actors in the Canadian contract furniture sector include: 1 - the furniture dealer, and 2 - the interior designer / architect, whose roles I elaborate on in the coming discussion (see also Figure 4.1). However before examining these key market 
intermediaries, we consider the end users themselves so as to provide a framework for understanding how these actors are helpful in sharing knowledge with the furniture producer.

Figure 4.1: Multiple channels of learning in the Canadian contract furniture sector

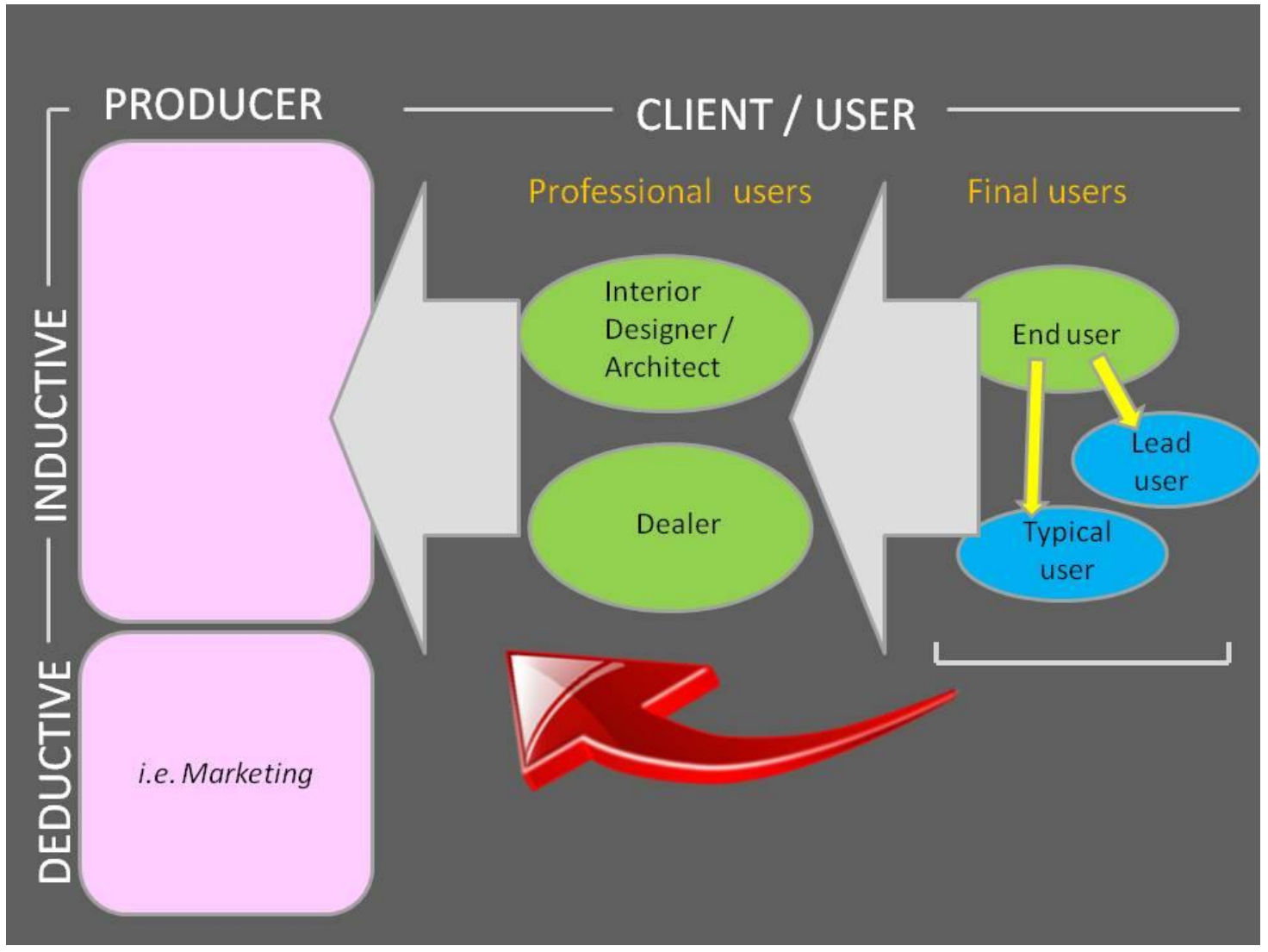

\subsubsection{A profile of lead users}

According to von Hippel (1988), lead users are highly innovative users that are positioned at the frontier of a given marketplace because they face needs months or even years in advance of the bulk of the population. Therefore their experience constitutes an 
important source of market intelligence for predicting industry trends over time in a given product area. In the Canadian contract furniture industry, lead users tend to be large commercial and corporate clients operating in sectors as diverse as finance, insurance, law, science and technology, and manufacturing, as well as all levels of government, and emerging markets in higher education, healthcare and hospitality.

Figure 1.3 in Chapter One provides a map of key furniture markets in North America based on metropolitan regional populations of over 1 million inhabitants. As evident, markets of particularly high demand are located along the eastern seaboard in the region around New York City (which is also within close proximity to major centers of production in Canada), Southern California, Chicago, Dallas, Miami and Toronto, as well as smaller city-regions throughout the US and Canada. An analysis of the geography of demand indicates that Canadian producers rely not only on strong centers of demand beyond the Canadian border, but also the local consumer base of cities such as Toronto, Montreal and Calgary. This resonates with research by Porter (1990) who suggests that local demand conditions shape the competitive success of firms because a producer's ability to satisfy the standards of a sophisticated local consumption constituency is an important determinant of success in distant export markets.

Lead users in intensely competitive industries such as high technology and finance constitute a particularly valuable source of innovative ideas because they are at the frontier of changing patterns of employment and work in the economy. The position of these lead firms at the forefront of a given market coupled with the intensely competitive nature of the industries in which they operate means that these actors often pioneer innovative labour market trends such as flexible forms of labour, mobility and 
rapid turnover, networking and team-based, collaborative practices, and temporary, nonstandard forms of employment. In fact, many of these trends started in the high technology enclaves of Silicon Valley in Southern California during the so-called 'dot com boom' of the 1990s, yet later diffused to other geographic regions and industries (Benner 2002). By understanding these trends in real time through engagement with lead users in key markets, Canadian furniture producers are able to predict future patterns among the broader workforce, giving them a valuable source of innovation and competitive advantage.

\subsubsection{The furniture dealer: the structure of distribution and the role of dealers}

Much like the auto industry (Sturgeon et al. 2008), distribution in the contract furniture industry is organized primarily through dealerships, with the dealer involved in some $70 \%$ of transactions. The role of the furniture dealer is not only to bring products to endusers in the market, but also to act as a local point of contact for after-sales service, to ensure that the product is working for the end user client, to assist with add-ons or additional business, and so on. For smaller projects that may be less design-intensive, and for which an interior designer is not already present via the client, the dealer might provide interior design capabilities and bring a design firm to the sale in order to assist with layout and user specification.

Although dealers are the manufacturer's representative in the local market, they are not internal to the firm. Rather, they are independently owned and operated, and maintain a contractual obligation with the producer to carry and sell their products. In North America, dealerships are structured such that a small group of large producer firms 
have established 'aligned relationships' with dealers. This means that the dealer is obligated to carry only that manufacturer's offerings, and not the brands of the other major competitors. This arrangement has enabled this handful of large producers to exert a significant degree of power and influence over distribution, effectively blocking other firms from their own dealer channels and making it difficult for smaller players and producers in other markets to penetrate the system and acquire market share.

The industry is increasingly dominated by these large firms that control the margins because they control the distribution. By contrast, the dealers do not wield significant influence, but rather are merely 'middlemen' intermediaries distributing furniture from producer to user. The ability of the large producer firms to appropriate value in the furniture commodity chain distinguishes the industry from its household counterpart, which is increasingly dominated by a low-margin retail sector focusing on price (Leslie and Reimer 2006). In the contract furniture industry, the power exerted by the large firms ensures that their brands are privileged, and by extension, the importance of design over low cost concerns.

The balance of manufacturing firms who are not a part of this group depend on the services of independent dealers. In this alternative system, the dealership will represent multiple brands and typically offer complementary products from a number of different producers. In other words, unlike the aligned structure that privileges the products of a particular producer, this system means that as a producer, your products will not be a lead line in a dealership. Because these firms do not control distribution, they do not exert the same kind of influence over the furniture value chain that the larger, more innovative producers do. 


\subsubsection{The role of the art and design community}

The role of the art and design (A\&D) community is also very important in most commercial purchases of furniture. The interior designer or architect is a critical market intermediary who is employed by the end user to find a creative design solution for an interior environment, or in some cases, is brought in by the dealer. As part of their broader design vision, the interior designer will prepare specifications for the furniture and identify a shortlist of possible furniture vendors. The designer will then administer the bids and make the final decision as to which vendor will ultimately be invited to the project.

An invitation from an interior designer to a producer to partner on a design solution for an end user client is shaped by a couple of important influences. Revisiting Lundvall's theory, professional users are said to have a strong incentive to opt for the more competent and capable of producer firms. An important benchmark in the industry is the degree to which a producer embraces a philosophy of sustainability in design. Both the A\&D community and the contract furniture industry have been tremendously impacted during the last decade by the advent of environmentalism on a design level. International and national, state- and market-driven forms of environmental governance and certification systems such as Forest Stewardship Certification (FSC), US Green Building Council (USGBC), Greenguard, Canada Green Building Council (CGBC) and Leadership in Energy and Environmental Design (LEED) have propelled the importance of sustainability to the forefront. While the A\&D community has catalyzed the 
environmental drive, the North American contract furniture sector has been a pioneer in the manufacturing industry in its progressive adoption of these principles. ${ }^{12}$

Lundvall has also suggested that compatibility is a crucial factor in a professional user's decision to choose a producer partner on a given project. Given the considerable degree of uncertainty associated with any furniture transaction, particularly if the project is large in scope, logistically complex and demands a high degree of customization, interior designers will tend to favour already-existing user-producer relationships. In other words, they will tend to gravitate to those manufacturers with whom they have successfully worked in the past, where compatibility between innovating parties is already present, and learning capacity known.

As specifier of the furniture product on behalf of the end user client, the interior designer is a critical gatekeeper who exerts considerable sway over both the supply and demand sides of the contract furniture market, in selecting and pulling a producer into a project, and in steering an end user client towards a particular design solution. Aptly termed, the designer is known in the industry as the 'Influencer'. On the supply side, these professional users have played a formative role in maneuvering producers along a designled, environmentally sustainable path so that companies may appeal to the A\&D community with their portfolios. So too on the demand side, where interior designers have wielded significant power in influencing end user specifications, particularly large corporate clients who have gravitated in recent years towards higher certification requirements such as ISO14000, FSC, LEED and Greenguard as a result.

\footnotetext{
${ }^{12}$ Ahead of other product industries, it has developed its own comprehensive product-specific sustainability standards and certification program called level ${ }^{\circledR}$ which includes criteria for evaluating materials selection and usage, energy and atmosphere, human and ecosystem health, and social responsibility impacts (BIFMA 2012).
} 
Geographically, furniture producers tend to work with design firms that are located in the heart of Canada's major urban areas including Toronto, Montreal, Calgary and Vancouver. Scholars in geography have discussed the intensely urban nature of creative work such as design, and the propensity for these industries to gravitate towards distinct metropolitan areas in order to tap into knowledge spillovers, an array of social and cultural influences, and a steady stream of inspiration to support the creative process (Scott 2000; Grabher 2002; Florida 2002). This resonates with research by Gertler and Vinodrai (2004), which shows that Canada's design workforce is strongly urban, and that Canadian cities are the key sites where designers live and work. The overlapping geography of design and furniture production in Canada in these major urban areas (and suburban locales surrounding the city cores) suggests that producer firms benefit from locating in places with vibrant design industries. This is particularly the case in Toronto, which boasts not only the largest critical mass of designers in the country, but is also Canada's most important site of furniture production.

\subsubsection{Research design}

The research presented here draws on a mixed-methods research design that is based on an online-industry survey to the full population of producers in the Canadian contract furniture industry ( $\mathrm{N}=220 ; 46 \%$ response rate; $\mathrm{n}=101)$, and a series of in-depth, semistructured interviews with representatives from producer firms, professional users and individuals representing industry organizations and government agencies. The characteristics of an innovative industrial workplace have been well documented in the literatures on innovation, industrial dynamics, institutional economic geography and 
competitive strategy (Lundvall 1988; Porter 1999, 2000; Hall and Soskice 2001; Gertler and Wolfe 2002; Gertler 2004) and the content of both the survey and interview guides drew directly on these literatures.

The breakdown of interview participants is provided in the following tables (4.14.3). In total, 45 interviews were carried out with individuals from all three producer regions in Canada (Ontario, Quebec and the West), 35 of which were conducted with senior managers or senior designers from producer firms, 4 with professional users, and the remaining balance of 6 were conducted with individuals representing either industry organizations (the Business and Institutional Furniture Manufacturing Association) or related government agencies. In addition to interviews with representatives from producer firms, I also participated in lengthy tours of 8 manufacturing plants in all three regions, and I took part in two international trade fairs held in Toronto.

Table 4.1: Interview research participants

\begin{tabular}{|l|c|c|c|c|}
\cline { 2 - 5 } \multicolumn{1}{c|}{} & $\mathrm{N}$ & Ontario & Quebec & West \\
\hline Producers & 35 & 17 & 8 & 10 \\
\hline Users & 4 & 3 & 0 & 1 \\
\hline $\begin{array}{l}\text { Representatives from } \\
\text { industry organizations and } \\
\text { government agencies }\end{array}$ & 6 & & & \\
\hline
\end{tabular}

Table 4.2: Breakdown of users

\begin{tabular}{|l|c|c|c|c|}
\cline { 2 - 5 } \multicolumn{1}{c|}{} & $\mathrm{n}$ & Ontario & Quebec & West \\
\hline Interior designers & 3 & 2 & 0 & 1 \\
\hline $\begin{array}{l}\text { Representative from Association of Registered } \\
\text { Interior Designers of Ontario }\end{array}$ & 1 & 1 & $\mathrm{n} / \mathrm{a}$ & $\mathrm{n} / \mathrm{a}$ \\
\hline
\end{tabular}


Table 4.3: Breakdown of industry organizations and government agencies

\begin{tabular}{|l|l|}
\cline { 2 - 2 } \multicolumn{1}{c|}{} & $\mathrm{n}$ \\
\hline Business and Institutional Furniture Manufacturing Association & 2 \\
\hline Canadian Manufacturers and Exporters & 2 \\
\hline Industry Canada Service Industry and Consumer Product Branch & 2 \\
\hline
\end{tabular}

\subsection{Analysis}

\subsubsection{The importance of user knowledge}

Survey respondents were initially asked to rate the importance of nineteen sources of information to their innovation activities during the period 2007 to 2009 (Figure 4.2). Results show that knowledge from clients and customers is the most important source of innovative ideas, with $60 \%$ of survey respondents rating it as 'Highly Important' to the process of innovation in their firm. This puts the importance of client and customer knowledge more than $10 \%$ higher than knowledge from key employees such as firm founders, other managers and senior engineering and design staff. Interestingly, it is the only source of information among the top six that is external to the firm, as the other critical inputs all draw from sources within the firm. These survey findings point to the sigificant importance of user knowledge to innovation in the case study. 
Figure 4.2: Percentage of respondents rating factors as 'highly important' to innovation $(2007-2009)(n=101)$

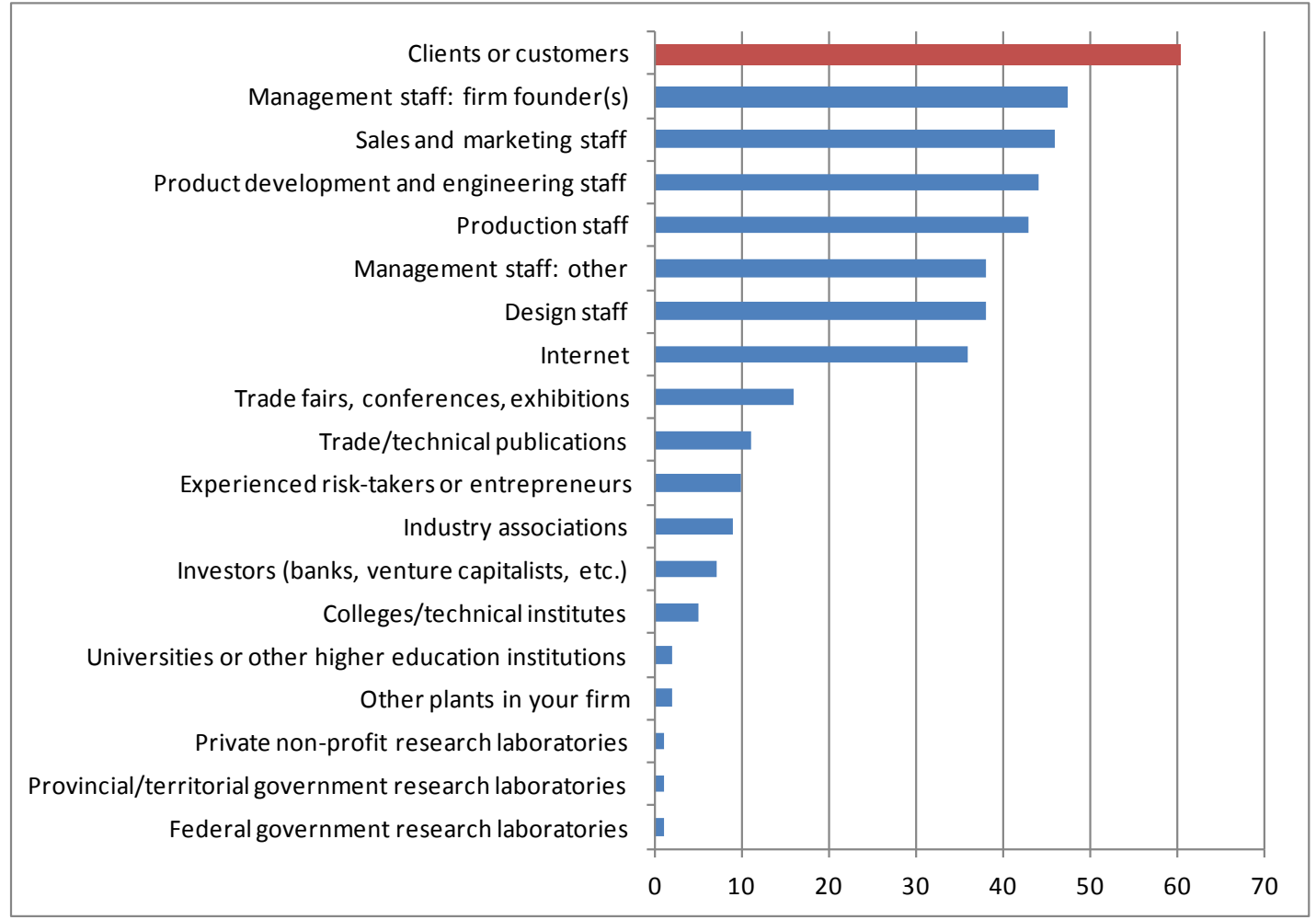

Source: Author's survey of Canadian contract furniture sector, 2010

The next survey question asked respondents to rate the importance of fourteen factors to the success of their firm (Figure 4.3). As we have seen in Chapter Three, 'Close relationships with lead customers', along with 'Quality of design', were the most highly rated factors, with $75 \%$ of respondents indicating they are 'Highly Important' to firm success. We also see that factors ranking among the top four - quality of design, close relations with lead customers, close relationships with lead suppliers, supply of workers with particular skills - are similar in the sense that they involve or imply knowledgeintensive inputs to the manufacturing firm. These types of factors rate consistently higher than the more conventional factors one might typically associate with a 'traditional' industry such as furniture, features such as the quality of infrastructure. These findings 
therefore attest not only to the importance of end user clients and professional users to innovation and competitive success, but also to the high degree of knowledge-intensity exhibited by firms in the case study.

\section{Figure 4.3: Percentage of respondents rating factors as 'highly important' to success} of firm $(n=101)$

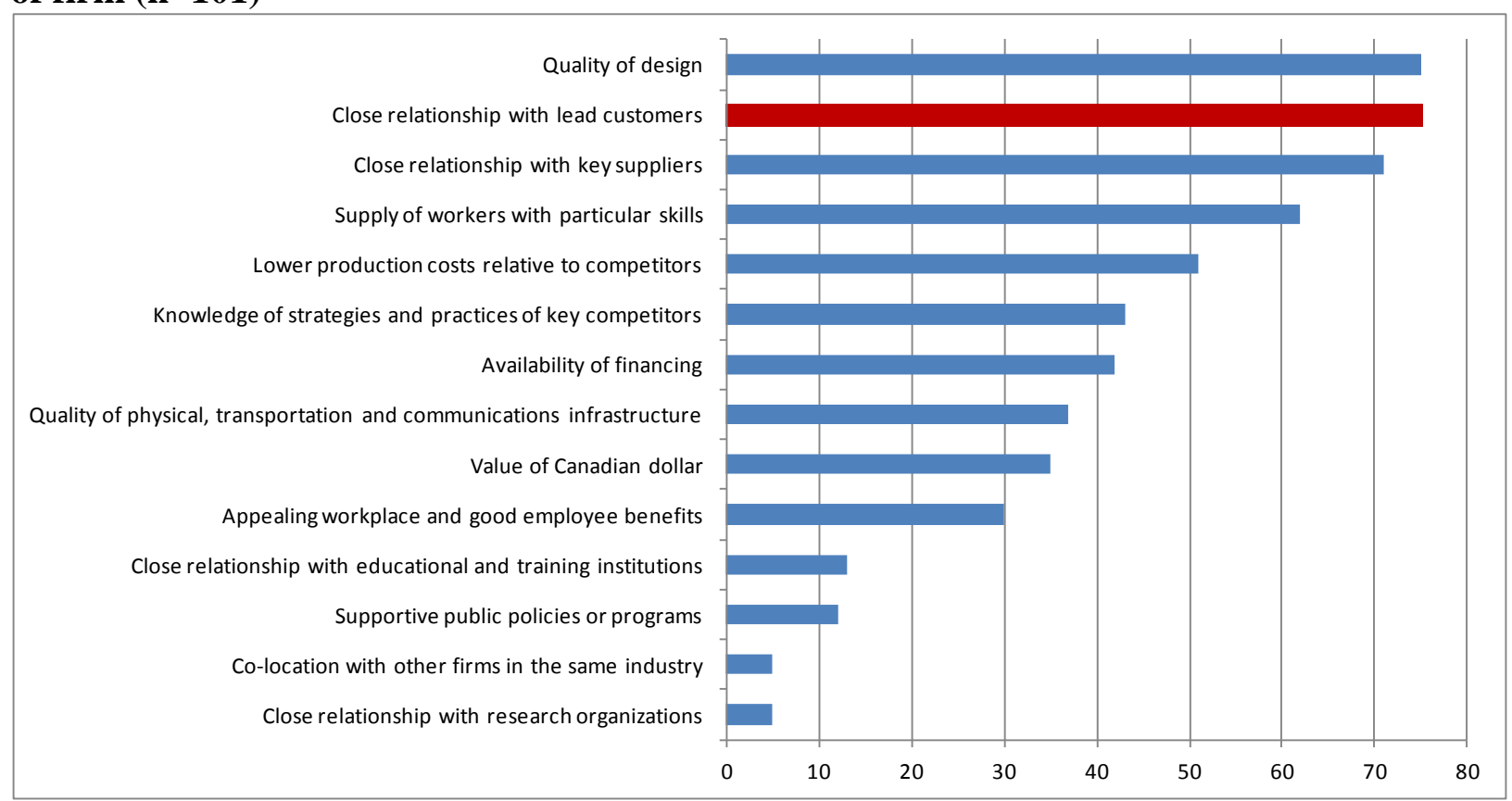

Source: Author's survey of Canadian contract furniture sector, 2010

Survey findings were then grouped into two categories: firms who rated 'Close relations with lead customers' as 'Highly Important' to firm success (the 'Yes' group), and those indicating it is not 'Highly Important' (the 'No' group) (Table 4.4, Figure 4.4). Several key firm variables describing characteristics and performance were compared across groups. Firms in the 'Yes' group are shown to be somewhat older than firms in the 'No' group, at 34.1 mean years of age versus 30.6 years for the 'No' group. Moreover, firms in the 'Yes' category are considerably larger, at more than four times the average 
size (114 employees versus 25). While both groups exhibit a similar 'Percentage of skilled employment relative to overall employment' based on education level, at $34.9 \%$ for the 'Yes' group and 35.2\% for the 'No' group, the 'Yes' group shows higher annual sales performance: $\$ 30,700,000$ as compared to $\$ 6,200,000$ (CAD, 2008). In summary, firms in the 'Yes' group are slightly older, quite a bit larger, and with commensurately higher sales, indicating that close relations with lead customers is an important factor that shapes competitive success.

Table 4.4 Comparison of firm characteristics grouped by YES (close relations with lead customers highly important to firm success) and NO (close relations with lead customers not highly important to success)

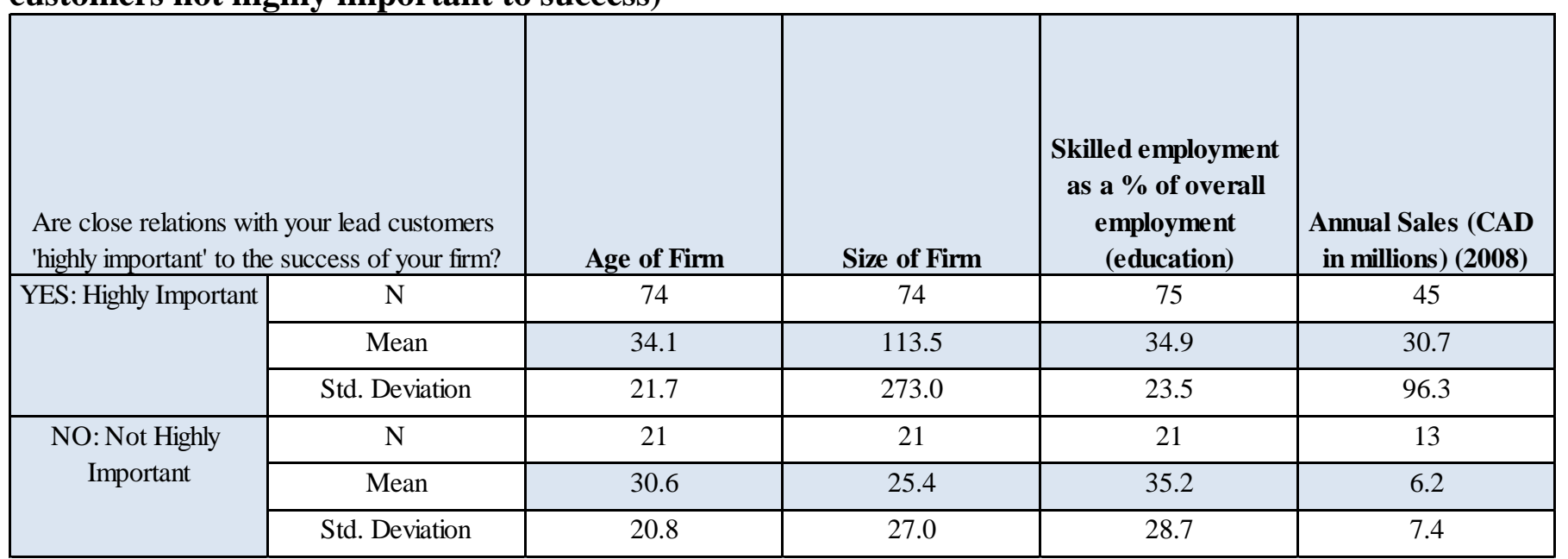

Source: Author's survey of Canadian contract furniture sector, 2010 
Figure 4.4: Comparison of YES and NO groups, firm size and annual sales performance (2008)

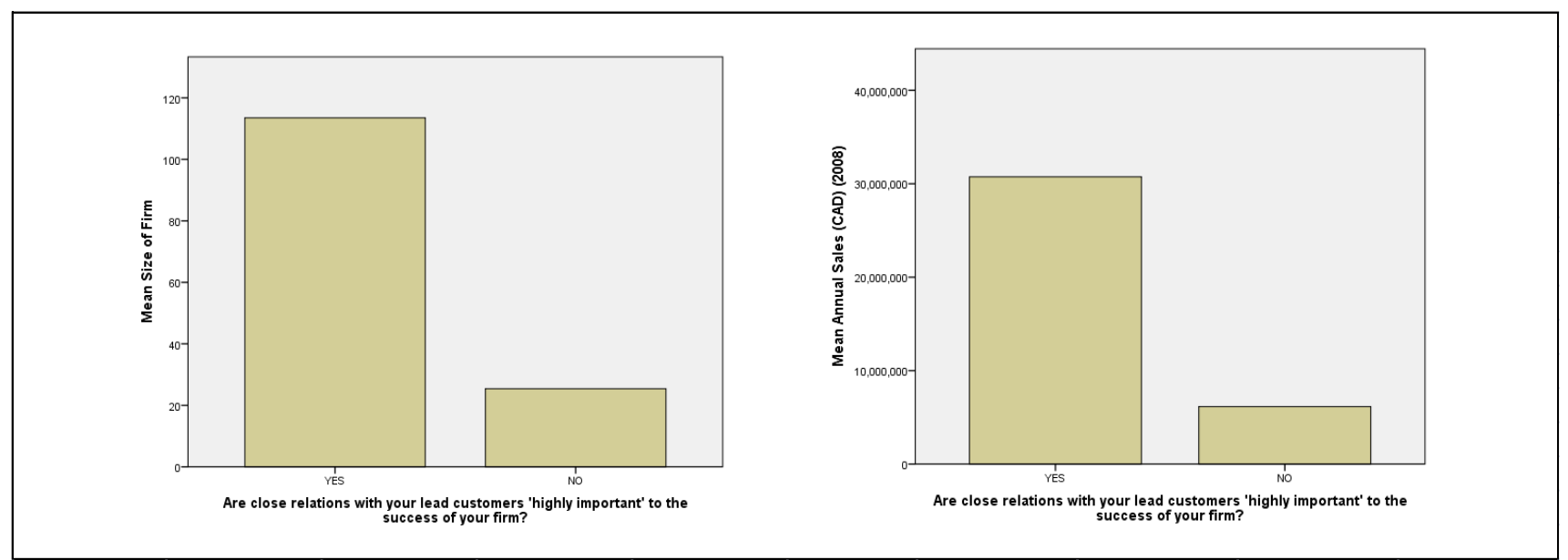

Source: Author's survey of Canadian contract furniture sector, 2010

Findings were then grouped by firms who rated clients and customers as 'Highly Important ' sources of information to innovation (the 'Yes' group), and firms who indicated that this information is not 'Highly Important' (the 'No' group) (Table 4.5). Several key variables describing production strategies were then compared amongst the two groups. For example, firms in the 'Yes' group reported having higher product quality than those in the 'No' group, with a mean score between 1 and 7 of 6.6 , compared to 5.9 by the 'No' group. Firms in the 'Yes' group also show a higher level of customization of operations (5.88 versus 5.30) and a higher rating for flexibility of operations (6.16 compared to 5.87). Surprisingly, product design-intensity is lower for the 'Yes' group; however overall, this data seems to suggest that firms who rely more on information from end user clients and professional users have a more flexible manufacturing operation that supports a higher level of customization to suit the individual needs of the client base. 
Table 4.5: Comparison production strategies (mean score between 1 and 7) grouped by YES (information from clients and users highly important to success) and NO (information from clients and users not highly important)

\begin{tabular}{|c|c|c|c|c|c|c|c|}
\hline \multicolumn{2}{|c|}{$\begin{array}{l}\text { Is information from clients and users } \\
\text { 'highly important' to your innovation? }\end{array}$} & 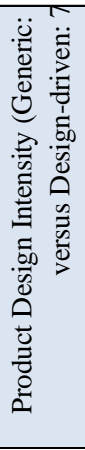 & 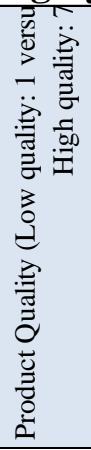 & 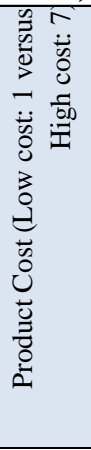 & 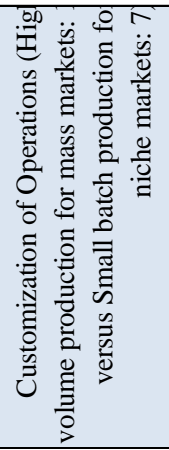 & 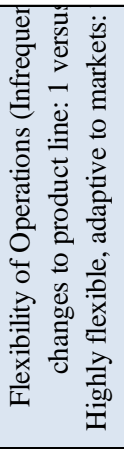 & 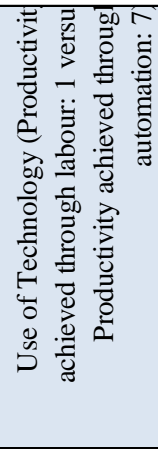 \\
\hline \multirow{4}{*}{$\begin{array}{l}\text { YES: Highly } \\
\text { Important }\end{array}$} & $\mathrm{N}$ & 59 & 60 & 60 & 59 & 61 & 59 \\
\hline & Mean & 5.88 & 6.60 & 4.47 & 5.88 & 6.16 & 4.44 \\
\hline & Median & 6.00 & 7.00 & 4.00 & 6.00 & 7.00 & 5.00 \\
\hline & Range & 5 & 3 & 6 & 4 & 6 & 6 \\
\hline \multirow{4}{*}{$\begin{array}{l}\text { NO: Not Highly } \\
\text { Important }\end{array}$} & $\mathrm{N}$ & 22 & 23 & 23 & 23 & 23 & 22 \\
\hline & Mean & 6.00 & 5.91 & 4.65 & 5.30 & 5.87 & 4.59 \\
\hline & Median & 6.00 & 6.00 & 5.00 & 6.00 & 7.00 & 4.50 \\
\hline & Range & 3 & 5 & 5 & 5 & 4 & 5 \\
\hline
\end{tabular}

Source: Author's survey of Canadian contract furniture sector, 2010

The importance of user knowledge to innovation and competitiveness is

highlighted consistently throughout the interviews as well. The president of world markets for a large firm in Ontario, for example, discusses how vital information gleaned from customers is. He says, "What we get back from the end user is critical. For us, it directs us more than our own market research." The vice president of marketing for a mid-sized manufacturer in the same region echoes this perspective, suggesting that the ability to understand market requirements is more important than anything else. As he puts it, quite simply, "If you cannot identify the front-end need properly, it doesn't matter how good you are in manufacturing." In another example, the senior manager of sales for a large US producer with operations in Western Canada says, 
Everything we do is based on what our customers are looking for to be more successful. We need to take those ideas. We collect those ideas through the A\&D [Art and Design] firms and through straight contact. And yah, we consult with the clients all the time. What are you looking for? What's the new best thing? What's keeping you up at night? A lot of our knowledge comes from our customers.

These quotes are but a few select examples that illustrate the value of client knowledge, a theme that was articulated repeatedly by senior managers and senior designers representing producer firms in the interview sample. Together, both survey and interview research attest to the vital significance of this source of market intelligence to the competitive success of producer firms in the Canadian contract furniture manufacturing sector.

\subsubsection{Co-development practices in the Canadian contract furniture manufacturing sector}

User-producer interaction in the Canadian contract furniture manufacturing sector can be categorized into two broad groups: 1 - informal practices (consisting of producer relations with the furniture dealer, and identifying trends through customization), and 2 - formal practices (entailing producer relations with the A\&D community, and advanced usercentered research practices). In what follows, I address each of these dimensions and the qualitative findings from the study.

\subsubsection{Informal practices}

\subsection{The furniture dealer: acquiring and sharing market knowledge}

As critical actors on the ground in the local market, furniture dealers are positioned to acquire extensive and detailed knowledge of their end user client needs and the broader local market environment. One key informant and executive director of a North 
American trade organization explains that because the dealer has the relationship with the end-user, he will bring that local market knowledge to the partnership with the manufacturer. He says, "They are the eyes, ears and feet on the street in the local market. They should have that intimate knowledge of the business community and what's going on there."

This knowledge is then shared with the producer in an informal manner. The president of a mid-sized Ontario firm reports that "It just kind of happens through osmosis because the (end) user will put pressure on the dealer for a certain solution. And then that dealer will come back to us to translate it and say 'I'm looking for this "special,"' or 'Can your furniture do this?' So we collect those pieces of information." He goes on to estimate that $50 \%$ of their design innovation comes through that informal user-dealer channel. This resonates with comments by the vice president of manufacturing for a small Ontario-based company who indicates that "The end user will send communication to our dealer and our (sales) rep network. They will take advantage of the tools available to them to communicate up the line, right up the chain." However while critical user specifications are garnered by the furniture dealer, the producer ultimately controls how that information will shape product design in the end, according to the president of a midsized Quebec-based company. As he explains,

Currently the biggest way of interfacing with the end user in our business model is with the dealers. And they have their own designers in many instances and there is a very strong connection between our design group and dealers on a regular basis discussing enhancements and product improvements. But at the end of the day, it's our own people discussing which items or which improvements or ameliorations can be taken and selected and put in place.

Research reveals that because the dealer is external to the manufacturing firm, the dealer-producer relationship can be challenging. This resonates with research by Grabher 
et al. (2008) who suggest that whereas producer-producer relations entail interorganizational ties, producer-customer relations involve a more complex sociology that blends organizations, communities and individuals. While the dealer may have strong incentives to share his knowledge with the producer, being dependent as he is on a source of supply, quality, on-time service and the completion of orders, he may be selective in precisely what he chooses to bring forth. As one key informant explains, being outside the company means that the dealer has an arm's length relationship with the producer. Although he wishes to be valued for his market intelligence, he does not want to surrender too much so as to render himself dispensable. These findings remind us of the delicate balance between information sharing and the possibilities for opportunistic behaviour discussed by Lundvall $(1985,1988)$, suggesting that the development of trustbased relations between parties may not always overcome the problems of information uncertainty that characterize complex furniture transactions. Moreover, in addition to this process of information selection that is effectively taking place, knowledge can simply become filtered and lost during its journey from the end user client to the producer via the dealer, a theme that was commonly raised by interviewees. As the sales manager for a mid-sized Ontario company puts it, "Information gets lost, there's no doubt about it, no matter how well you document."

\subsection{Identifying trends through customization}

Another informal means by which user knowledge is drawn into the product design process is through the identification of trends through customization requests. A number of representatives from manufacturing firms in all three regions suggest that producers 
get a lot of valuable information through customizing. As the president of a mid-sized Ontario firm explains, "If a client's constantly asking us to change a product, we ask why. What is it that's not right about the product in the first place that you need to keep changing it?" He goes on to suggest that it usually ends up giving the producer a feature that the client wants. In another example, the sales manager for a US company with sales operations in Ontario implies that a sufficient volume of customization requests is essential before that product can eventually become standardized. He notes "If we had a custom idea that we've done a hundred times, maybe that's a good idea of something that's missing in our product line. It should no longer be custom - we should be taking the idea and feeding it into the development cycle and making it standard."

\subsubsection{Formal practices}

\subsection{The art and design community: acquiring and sharing design knowledge}

Both Lundvall (1985) and von Hippel (1986) remind us that end-users are often passive actors in the user chain and thus inherently constrained in their ability to identify solutions beyond what they already know and experience. This idea was highlighted time and time again by a number of interviewees, as in one example of the vice president for a mid-sized Ontario producer who explains that "The customer typically does not know what he wants. If you asked, let's say you go to Google and say 'What kind of furniture do you need?' Do you think any of those guys can answer it? Absolutely not." This central idea is echoed in the comments of a representative from a professional design association based in Ontario who points out that,

They (end-user clients) don't always know what their need is, 'Do I need open work stations and collaborative areas, or do I need private offices?' And they don't know how to articulate it. But what they do 
know is how their teams are most effective and what is most important from a business strategy perspective. They don't know how it would manifest itself in furniture - but that's the designer's role.

As implied in the aforementioned quotes, the function of the interior designer or architect is to draw on the explicit knowledge, and to abstract from the tacit and latent knowledge of the end-user, in order to identify their product / process needs and potential solutions. As Lundvall (1985) explains, an external observer might be able to discover needs which the user has not yet been able to put on his agenda. This resonates with a number of research findings in the case study. According to one interviewee, the vice president of design and innovation for a mid-sized Ontario producer, "The role of the designer is to go in there and work with the customers and see how they work. Designers have those skill sets and insights - finding that little need out there that people aren't able to articulate." Interior designers and architects are accredited professionals who are qualified through a rigorous process of education, practical experience and examination, thus they fit well with Lundvall's description of professional users who 'actively seek out new technical opportunities and new ways to solve problems', and sometimes embarking on extensive training to do so. In order to uncover the complex, hidden and unknown needs of their end user clients, they often follow a systematic and coordinated methodology including research, analysis and integration of knowledge into the design process. As one interior designer based in western Canada puts it, "Through the work we do with clients, we really dig down and find out what's going on and what their needs are." This critical professional user segment, who works closely with the end-user, plays a vital role in sharing that knowledge with the producer firm through the formal designer-producer partnership. One senior manager interviewee, the vice president of marketing for an 
Ontario-based mid-sized firm, articulates how vital this user-producer relationship is to the innovation process. He says, "You can get clues from your end-users and from your dealer, but the person who really matters and actually decides what he wants is the Influencer - the interior designer or architect on the project. The Influencer creates the pull for the customer in terms of what he wants."

\subsection{Advanced research practices}

Research from the case study finds that, not surprisingly, firms employ a variety of marketing approaches, such as focus groups and observational studies, in order to learn from their users. However, a select number of producers move beyond these conventional deductive strategies to a more sophisticated level of analysis to achieve a broader and deeper understanding of their end user needs, often working with the end user client directly and not through an intermediary. According to the lead researcher for a large US company with manufacturing operations in Ontario, this approach, which positions the user at the center of the analysis, is highly effective. She says,

Our consulting process is research-based, putting users at the center. In order to truly understand how work is being accomplished, not only at an explicit but also a tacit level, you have to go to the users. And you can't just ask them, because there's so much that is intuitive and that they don't really think of. You have to find a different way to mine that.

In this particular case, the producer's comprehensive conceptual approach involves three distinct stages of analysis: ask, observe, and experience, and she provides commentary on the effectiveness of such a methodology,

In our workshops, we're unpacking how they work. We get them to bring in photos to document a day in their life. And we pull them apart, and we're looking at patterns of behavior that would suggest challenges that they're having in trying to be effective. We might do a video 
ethnography. We might do model building after we take them through that iterative process that gets them thinking strategically. Because in the act of building, they are able to tell us more of the tacit and the latent than they would ever be able to articulate.

These advanced research capabilities transcend conventional research approaches and underpin an expertise that enables the manufacturer to analyze market segments in new and interesting ways. Moreover, the innovation goal in mind is not simply furniture design, but the creation of a work environment that facilitates the strategic objectives and leverages the innovative capacity of the end user organization.

\subsubsection{Geographies of user-producer interaction}

\subsubsection{The importance of trust-based relationships}

One of the core ideas that has emerged from the literature on the evolutionary economics of technical change is that trust between economic actors minimizes the uncertainty associated with transactions and therefore facilitates the flow of complex information. In the case study, the importance of trust-based relationships between producer and professional user, both the furniture dealer and the interior designer, was a predominant theme that was identified in the interviews, and recognized as essential to the success of user-producer interaction.

First off, the producer-dealer partnership was shown to benefit to a great degree from the development of trust, mutual respect, and positive working relations between innovating partners. In one example, the senior manager of regional sales for a mid-sized manufacturer based in western Canada describes the interdependent nature of this relationship, whereby each side has the opportunity to gain from a successful transaction. In his words, "Having good strong relationships with your dealer network is a top 
priority, just as maintaining a relationship with you is a high priority for dealers. When the tide rises, all boats lift together." This resonates with comments by a key informant and director of a major North American trade organization who discusses not only the reliance that each actor has on the other, but also the complex, challenging nature of a relationship that exists outside the firm and between two separate entities. He says,

It's a relationship outside the company that is very important to the success of the transaction. And challenging because from the dealer's view, 'I want my manufacturer to need me, but at the same time I don't want to show him too many of my cards.' Tremendously important relationship and challenging because they are two independent operations, but they are very dependent upon one another.

These findings align with Lundvall's view that users and producers of innovations are mutually interdependent in complex ways. In a related example, the regional sales representative for a mid-sized Ontario firm talks about the significance of cultivating strong relations with her dealers, even getting it down to a personal level. From her perspective,

Face-to-face is very important. Going up there and seeing my dealers every two weeks - extremely important. I pop in, bring some information. I come in and get to know people on a personal level. You know, everyone's got family. And it's nice when someone wants to hear a story about your kids or share something. People share their frustrations and you get it down to a personal level.

These comments also relate to the perspective of the president of another mid-sized manufacturer in the same region who says "Our relationship with our local dealers is very, very close. We see them, we visit them, they visit us, and they bring their clients into our showrooms during the sales process many times." In other words, the cultivation of this sort of trust-based, personal and positive working relationship between the manufacturer and dealer is not one that happens overnight, but rather takes commitment and time on the part of both parties, and in the above cases are dependent upon 
geographic proximity of actors in the same locality. We shall return to this question of the importance of proximity in the coming discussion.

Trust-based relations are also found to be crucial to the effectiveness of the producer-designer / architect partnership. As one interior designer based in Ontario reports, "We have a really healthy relationship with the manufacturer. In fact, I find them to be extremely innovative and thought-provoking and very forward thinking. In my opinion, we're partners." Much the same as the producer-dealer venture, the producerdesigner partnership is characterized by a high degree of interdependence on the part of both parties, as each brings a distinct expertise that complements that of the other.

According to one key informant, a representative of a North American trade organization,

Manufacturers want to know what the emerging design trends are, what they should be expecting, what's coming in the marketplace, what are the key elements of sustainability, what are the hot button issues for clients. On the other hand, designers have a desire for their producers to be aware of those trends so they are able to provide the appropriate products to meet the client's needs. It's all part of this chain, everybody's a link in the chain and in order for it to function smoothly it's best that the communication happen all up and down the chain.

The relationship is a symbiotic one, according to the director of design innovation for a large Ontario-based firm, bringing benefit to both actors involved, as well as the enduser. He explains,

It's really a symbiotic relationship because you make them (the designer) look good in being able to bring new ideas to them and new products. And the other way around as well. If they have a relationship with you and they can say "I'm seeing this happening on the ground', and you can react by creating a product that they can bring back to their client, then you look brilliant too.

In a final example, an interior designer based in western Canada implies that strong relations with the manufacturer encourages repeated contact, which is fundamental to the producer's ability to tap into and fully leverage a designer's knowledge. In her words "To 
do a good job, we're in constant dialogue with the manufacturer about what we're seeing and what we need and that's a really important feedback loop." These sentiments resonate with broader narratives in the literature on the importance of interpersonal relationships between user and producer based on trust and mutually respected codes of behaviour, which facilitate the sharing of knowledge and innovative ideas between parties, and are critical to the process of innovative production.

\subsubsection{Permanent and temporary forms of co-location}

The literature suggests that because trust is forged through repeated personal interaction, it is best achieved when parties are close by and within easy reach of one another. This is particularly the case between user and producer in the creation of complex products that require a high degree of specialization and customization. Research from the case study supports these ideas and shows that geographic proximity between actors within the same locality or region not only facilitates the formation of trust-based user-producer relations, but is an essential prerequisite. In fact, the industry is structured such that user and producer are permanently co-located, since dealers (professional users) and sales representatives (producers) are brought into the same regional markets as the end-users. Moreover, while the design firm is logically located near the end user rather than the producer, manufacturing firms establish temporary proximity through such means as long distance travel and attendance at major industry events such as trade fairs.

Manufacturing firm interviewees were asked several questions about the importance of geographic proximity with their clients and customers: where their customers are located, the importance of being located close to them, and why. 
"Everywhere," responded the vice president of operations for a small Ontario firm, "Literally everywhere. And how close? Not very. As long as any customer has a representative or a partner willing to respond to their concerns and work with them, geographic location in our company is not so important." By 'representative' or 'partner', this interviewee is referring to the presence of vast sales and dealer networks spread throughout regional markets. He goes on to explain that "We have a network of reps and distributors and dealers around the world. And the end user will give feedback right up the chain." Revisiting his previous comment, what he implied was that it is not important (nor logical) for the manufacturing operation to be located near the end-user, since users are, as he put it, simply everywhere ${ }^{13}$ However, the presence of producer representatives near the end user to provide that point of contact and service, and to cultivate those critical trust based relations, is imperative. As the chief executive officer of a mid-sized western Canadian company explains,

At the end of the day, the client makes the decision. So it's really important for us to get in front of the client. In the field, we have reps that work with our distribution partners. And so the rep can be the one with the client.

This resonates with comments by the senior sales manager for a US company with sales operations in Ontario, who discusses the importance of co-location with the client because of the fact that it is a 'relationship-based business'. Although manufacturing operations are in the US, the company has established a presence in Canada's major urban areas as well as smaller regional markets. As he describes,

\footnotetext{
${ }^{13}$ Although 'lead users' (von Hippel 1988) in the industry tend to be located in vibrant high technology labour markets such as Silicon Valley in California. Lead users are said to be on the frontier of a given market face because they face market needs months or even years in advance of the bulk of the marketplace. Therefore their experience constitutes an important source for predicting market trends over time in a given product area.
} 
It is critical for us to be close to the customers because ours is a relationship-based business. One of the ways we extend our reach and we get close to those customers is through our distribution network. I've got (sales) people in Toronto, Montreal, Ottawa, Winnipeg, Calgary and Vancouver. But I've also got dealers in Edmonton and Halifax and London and Regina. So they help us along with our dealers in the big centers to stay really closely connected to our clients.

These findings from the case study reinforce the importance of spatial proximity to the success of user-producer interaction in a high quality, design-oriented manufacturing niche. In addition, given the strategic positioning of (producer) sales representatives located in vast regional markets throughout the world, this research broadens our understanding of what defines the geographic boundaries of the firm.

In cases where the producer is not located within close proximity to the professional user, there are means by which firms are able to establish temporary copresence. In one example, the president of world markets for a large Ontario-based manufacturer says that senior executives, designers and manufacturing staff simply travel to where the lead users are and observe them working in real time. As he puts it, "We spend lots of time with our clients in their facilities while they're working." In another example, the president of a small firm in the same region discusses the importance of attending trade fairs as a way to access and build relations with clients. In his words, "We're out there with the end customer. We now attend six or seven trade shows a year, some in North America, some around the world. And through the trade show and one-toone visiting time, we develop a very good link to the end customer." This resonates with the literature on trade fairs as 'temporary clusters', and a key mechanism for both circulating established knowledge and enabling the formation of interactive relationships between user and producer through the temporary but repeated opportunities for interaction that they support (Maskell et al. 2006). 
In order to achieve face-to-face time with interior designers, who are not always located in the same geographic market as the producer, companies will often bring them on site. The importance of spatial proximity between the manufacturing firm and this critical professional user segment has been alluded to previously, and is highlighted in the following quote by the director of a North American trade organization. He says,

From the manufacturer's perspective, face-to-face with designers is very important. For the most part, the design firm is located near the client, the purchaser. I know manufacturers frequently arrange visits because they want design firms to come and check out their corporate headquarters and capabilities and so forth. That's why they have corporate planes. Most of the time, it's not to shuttle the executives, it's to shuttle the clients, to make it easier for clients to come to the manufacturing firm, where it may or may not be that easy to get to.

\subsection{Learning from furniture users? Lessons for theory, policy and firm practice}

This chapter began by recognizing the widespread changes that have taken place in the nature of capitalist competition in recent decades, in which the locus of innovation has shifted from inside the manufacturing firm towards external knowledge networks, rendering the user an invaluable source of competitive advantage. Motivated by a lack of existing scholarship in this area, particularly in the field of economic geography, this research set out to investigate the importance of user involvement in innovation as well as the nature of user-producer interaction in the Canadian contract furniture manufacturing sector, which is characterized by a high degree of design, customization and specialization in products and production processes. Drawing on empirical work in industrial organization theory, innovation, and evolutionary economics of technical change, in particular Lundvall's user-producer interaction framework, the questions addressed at the outset were: How important is user involvement in the innovation process in a design-led manufacturing sector? What are the organizational and social 
practices through which user knowledge is integrated into development processes? How are user-producer knowledge relationships organized spatially and temporally? Is colocation an absolute necessity, or are there conditions under which it may be successfully relaxed?

Survey and interview findings show that user engagement in the innovation process is immensely important to the competitive success of manufacturing firms operating in a design-led, high quality niche. Moreover, producers who place greater emphasis on knowledge from both end user clients and professional users as well as building close working relations with their lead users have operations that are more flexible and customized, and are also larger, older and higher performing than firms who tend to rely less on these factors. This attests to the direct benefits derived from the ability of producer firms to tap into this critical source of market intelligence.

Research shows that user knowledge is integrated into development processes in a variety of ways and through both informal and formal mechanisms (Table 4.6). The most important informal channel is via the distribution network and acquiring access to the vast market knowledge embodied by the furniture dealer. However this can be an imperfect source of information because the dealer may wish to withhold some of what he knows, in addition to the fact that knowledge can simply become filtered or lost during its circuitous route from end user to dealer to producer sales representative. Another informal means by which user knowledge is integrated into development processes is through the identification of trends through customization requests. The ability to cater to the detailed specifications of users through the customization of products is a topic that is explored more fully in the preceding chapters. However when a certain volume of a 
specific request comes in, this flags to the producer that there is a gap in the product line. A company will fill that gap by turning that product from custom to standard.

Findings indicate that producer firms also embark on formal practices that draw the user into the development process, and vice-versa (circumstances in which the professional user pulls the producer into the process), enabling both the end user and professional user to exert an influential impact on the course of development. Producers do so through their formal engagement with the A\&D community, whose participation is critical to most commercial and corporate purchases of furniture. When an interior designer or architect who is hired by the end user client specifies a particular furniture vendor, both user and producer engage in a process of interactive learning, in which the end user need (that may be both tacit and latent), interior design expertise (that skillfully unpacks that end user need), and capabilities of the producer (product development team), are carefully merged and leveraged. The larger and more powerful producers may also embark on advanced research practices that enable them to actively solicit detailed knowledge about their end-users and hone a nuanced insight into differentiated market segments. This approach provides a sophisticated understanding of the changing patterns of behavior in the workplace that feeds directly back into the product innovation process.

The development of trust-based relations between both professional user segments (the dealer and the interior designer) and producer is dependent upon the spatial proximity of economic actors, which encourages frequent face-to-face interaction. Co-location of professional user and producer (sales representative) in the same locality or region on a permanent basis is of paramount importance to the end-user-dealer / dealer - producer chain, and this is achieved through the establishment of vast sales and 
distribution networks across regional markets (Table 4.6). By contrast, temporary forms of co-location must often be sufficient to promote interactive learning between the interior designer and producer, since this professional user segment is typically located close to the end user client, which may or may not be near the manufacturing firm. Firms overcome this distance by bringing the interior designer to the manufacturing operation on a temporary, yet frequent basis, to work with the product design and development team directly. Producers also access both the dealer and designer professional user segments through their participation at trade shows which offer intense, temporary periods of engagement.

These findings contribute to our understanding of core theoretical questions in the discipline of economic geography. The co-location of economic actors is found to be essential to the success of user-producer interaction in a design-led manufacturing industry that is dependent upon a high level of specialization and customization. While permanent co-presence provides the optimal conditions for interactive learning to take place between actors, since it enables frequent and ongoing face-to-face interaction, temporary forms of co-location are found to be both effective and sufficient in cases where permanent proximity is simply not possible.

Table 4.6: User producer interaction in the Canadian contract furniture manufacturing sector

\begin{tabular}{|l|c|c|c|c|}
\hline Co-development Practices & Formal / informal? & $\begin{array}{c}\text { User- / producer- } \\
\text { led? }\end{array}$ & User actor & Geography \\
\hline Dealer-producer relationship & Informal & User-led & Professional user & local \\
\hline $\begin{array}{l}\text { Identifying trends through } \\
\text { customization }\end{array}$ & Informal & User-led & $\begin{array}{c}\text { Professional user; } \\
\text { end user }\end{array}$ & local, nonlocal \\
\hline $\begin{array}{l}\text { A\&D community-producer } \\
\text { relationship }\end{array}$ & Formal & User-led & Professional user & local, nonlocal \\
\hline $\begin{array}{l}\text { Advanced user-centered } \\
\text { research practice }\end{array}$ & Formal & Producer-led & End user & local, nonlocal \\
\hline
\end{tabular}


Findings from this research also reveal a bifurcation on the continental scale between a handful of large, technologically sophisticated, innovative and powerful firms who have come to dominate distribution networks and margins through their aligned dealer relations, and the remaining producers in the industry. Not surprisingly, it is the large producers who have also developed the capabilities and acquired the resources to pioneer user-centered research techniques, enabling them to appropriate user knowledge in sophisticated ways, and reinforce their market dominance even further.

It is no coincidence that the Canadian contract furniture manufacturing sector's heavy reliance on learning from users has been a critical factor in productivity growth and performance of the industry following the advent of North American trade liberalization beginning in the 1990s, as discussed at length in Chapter One. A clearer understanding of the locus of innovation and knowledge creation and the importance of user knowledge networks and pools in a design-led niche would surely benefit those trying to manage the innovation process at the firm, industry or government level. Moreover, the role of marketing might be developed in certain instances to better identify user segments with commercial potential. Producers interested in enhancing their competitiveness in a design-oriented sector can afford to devote considerable effort to understanding the practices through which user knowledge is integrated into innovation processes if they are to leverage their capacity to exploit this vital source of market intelligence.

A better understanding of learning from users may further clarify the ways in which advanced industrial societies can generate economic growth through productivity improvements in design-led industries, given the increasing importance of such industries 
to the economic development of high wage nations. Governments interested in promoting manufacturing as a means of enhancing exports, industrial productivity and employment should consider users as well as producers when developing incentive schemes for innovation. 


\section{Chapter V}

\section{Competitiveness by design: reflections on theory and policy}

\section{1: Introduction}

The results derived from the various investigations carried out in this dissertation have already been discussed at length at the end of each empirical chapter. In this final chapter, I will echo some of the major theoretical insights from this research as they pertain to the broader dissertation, and I will conclude by considering the question of industrial policy as well as future research directions.

\section{2: Implications for theory}

\subsection{1: Geography of knowledge flows: the role of proximity and distance in innovative production}

Research from the case study supports a central idea that is at the very heart of the conventional wisdom in the field of economic geography. Data from both the survey questionnaire and the interviews finds that innovative dynamism and economic vitality in the Canadian contract furniture manufacturing sector is heavily dependent upon localized learning networks, relationships and flows that support the joint production, sharing and dissemination of manufacturing knowledge. A firm's spatial proximity to critical sources of learning not only reduces transaction costs but also facilitates the sharing of specialized knowledge between parties that may be either proprietary and sensitive, or 
involve a large tacit dimension. Chapter Three finds that a firm's decision to bring that learning source in-house, or draw it from the local / regional labour market, as in the case of expert industrial designers, supports the interactive, group-based learning process that is critical to incremental product development. The placement of designers inside the organization on a full-time basis creates a natural 'think-tank' because it sets the stage for daily, ongoing, repeated face-to-face interaction between designers, engineers, manufacturing staff, and other actors of the product development team, and creates a social context that is conducive to industrial processes and the production of synthetic knowledge.

In a related vein, Chapter Four shows that user-producer interaction is dependent upon the development of trust-based relationships between professional user and producer in order to minimize the uncertainty associated with transaction costs and facilitate the flow of complex information. Geographic proximity between parties enables repeated personal face-to-face interaction that is crucial to the development of trust between individuals. Spatial proximity is established between the producer and professional user segments in a number of scenarios. First, it is achieved between the producer (sales representative) and furniture dealer, who co-locate in the same regional markets alongside the end user. Second, the location of many design-oriented furniture firms in major urban areas in Canada enhances their proximity to the industry of architects and interior designers, which is strongly urban-based. Third, in cases when the manufacturer is not located near the interior design firm and the designer or architect with whom it is engaged, producers will transport this critical user actor to the production site to work with the product development team directly, on a short-term yet repeated basis. 
This suggests that temporary forms of co-presence can create the appropriate conditions to support interactive learning between producer and interior designer, yet in this case, it can be costly to the producer firm.

In addition to the vital sources of learning that exist locally, a fundamental aspect of success in the industry is the ability of firms to tap into global knowledge networks and flows. As Chapter Two demonstrates, an understanding of Continental European institutions and practices by key corporate actors has been instrumental in the ability of Canadian firms to overcome national regulatory obstacles that run counter to a high-skill model of innovation, and in propelling the Canadian industry to international success. The mechanism and channel through which long distance learning takes place in this example is the embodied knowledge of immigrant and other mobile entrepreneurs, who have lived, studied and worked within the coordinated market economies and high-skilled regimes of Europe.

Chapter Three discusses the increasingly common practice whereby lead firms collaborate with international design 'stars' who are located in far-flung labour markets and major urban areas of the US, the UK and Europe. The capability of producers to draw on the creativity and expertise of these individuals brings significant benefit in terms of access to cutting-edge knowledge at the research frontier that supports radical innovation processes, as well as their understanding of design tastes and trends in foreign markets. Here, long distance learning and knowledge creation is mediated within communities of design practice and supported by relational proximity that derives from a number of social affinities shared amongst innovation partners. Relational proximity is further supported by the use of advanced communications and information technologies, as well 
as the achievement of temporary co-location that enables members of the community of practice to engage within close proximity for short-term stints.

Yet different forces shape and constrain the effective transfer and application of distanciated knowledge in the case study, as evident in the nature of industrial and design practices that are observed. In Chapter Two, a lack of institutional proximity between Continental Europe and Canada has undermined the smooth adoption of manufacturing knowledge in the Canadian industrial workplace. Evidence from survey and interview data depicts, on the one hand, the relatively successful application of CE knowledge in Canada, and on the other, a process that is fraught with difficulty due to the inability of Canadian firms to overcome institutional barriers. The end result is a complex hybridization of industrial practices, in which elements of both coordinated and liberal market institutional features are combined, yet often lack coherence and stability.

In Chapter Three, the effects of weak organizational proximity have constrained the degree to which design knowledge is able to transfer smoothly at a distance between international designers and their counterparts in the Canadian firms. Moreover, these obstacles are amplified due to the high tacit dimension of symbolic knowledge, which is the type of knowledge that predominates in this aspect of the innovation process.

Therefore, findings from this research support several key theoretical insights that are central to the literature on proximity and distance in economic geography. On the one hand, case study data confirms the ongoing importance of spatial proximity to the joint creation, circulation and sharing of manufacturing knowledge. Yet on the other, the ability to tap into spatially distributed competencies and knowledge networks and flows is also a critical determinant in the innovative success of many Canadian firms. 
Moreover, long distance learning is shown to function and thrive in the presence of strong enough social affinities and relational proximities. Yet research also reveals that the impact of institutional and organizational distance, as well as the characteristics of the knowledge base that predominate, may severely restrict and curtail the success with which manufacturing knowledge may effectively travel between far-off places.

\subsection{2: Structure, agency and the institutional embeddedness of manufacturing practice}

This research underscores not only the fundamental role that national macro-economic regulatory structures play in producing (and reproducing) the characteristics of industrial practices, both those inside the manufacturing firm and at the scale of the local labour market, but it also advances our understanding of precisely how the nation state and its institutional legacy wield a crucial influence over firm behaviour. For instance, Chapter Two demonstrates that institutions in the arenas of labour market regulation, industrial relations, education and training, financial markets and systems of corporate governance exert a fundamental influence over firms' choice of practices with respect to the organization and deployment of labour, the implementation of technology, the nature of employment relations, and the use of design. Nowhere is the pervasive force of societal institutions in Canada more evident than findings in which firms attempt to train and retain their workers in order to develop a high performance labour force, a crucial precondition to a design-led manufacturing strategy. Findings from the case study, however, indicate that these approaches are undermined in the wake of market volatility and economic downturn in Canada's market-driven economy, conditions which compel managers to subsequently shed, rather than retain, their staff. These findings are 
particularly compelling given the high proportion of privately-held organizations in the case study (in essence, another institutional form imported from Continental Europe). Even privately-owned and operated firms, which are not shareholder-driven, follow the same practice of downsizing during periods of economic decline, which is a powerful indicator of the institutional and cultural embeddedness of manufacturing practice in Canada. This research therefore highlights the tension between institutional determinism and human agency, in which organizations and individuals cannot simply overcome the constraints of the institutional environment in which they operate.

Yet while institutions generate a set of 'rules' that shape firm practice and competitive outcomes, the agency of individuals and firms, and the ways in which they choose to navigate within these societal structures, matters. In other words, actors still have a degree of agency, however institutionally embedded that human agency might be. The influence of the embodied knowledge of key corporate executives in the industry is evident in Chapter Two, in particular the successful transfer of industrial practices from Continental Europe to Canada and their adoption and application in the Canadian industrial workplace. The agency of these corporate individuals is clearly demonstrated by the statistically significant differences between sample groups in core areas of industrial practices and production characteristics, in which Continental European firms show significantly higher skill levels, longer periods of worker training, and longer employee tenures, in addition to higher degrees of flexibility and design-intensity, than their Anglo-American counterparts. Moreover, these firms also demonstrate higher overall performance in the marketplace, based on annual sales and productivity (see Table 2.6). Findings from the case study therefore show that while firm behaviour and 
choice of practice are shaped and constrained by nationally anchored institutions, they are not entirely determined by them. Rather, institutional structures are shown to interact in complex ways with the decision-making of economic agents to influence competitive outcomes. In the Canadian contract furniture industry, this has resulted in a hybrid industrial workplace that supports 'high volume quality production' - itself a hybrid industrial model.

\section{3: A word on industrial policy}

This dissertation has emphasized that a high performance industrial workplace derives from a complementary set of inputs including not only investments in capital and AMT, but also the broader organization of work and extensive, ongoing training and long-term development of manufacturing employees (see Chapter Two for an in-depth discussion on this topic). Therefore, when considering the question of industrial policy, an obvious path is the ability of Canadian labour market and training and educational institutions to create programs and incentives that are geared towards the development of a multiskilled, technologically sophisticated manufacturing labour force.

While such a recommendation might at first blush appear straightforward, Chapter Two reminds us that there is a gap in manufacturing practice in Canada, whereby the national regulatory environment may not support a high skill model of innovation. As we recall from this previous discussion, market governance regimes and labour market institutions in Canada engender local labour market dynamics that are characterized by mobility and turnover in employment relations, and a disincentive for firms to invest in staff training as a result of the ongoing free-rider problem and a myriad of 
complementary institutional constraints. This suggests that, on the one hand, there are severe restrictions in the way that industrial policy might play a role. In this view, more robust and fundamental changes to industrial practices in the Canadian manufacturing sector cannot be achieved unless the hegemonic institutions of the political economy that shape labour market regulation, corporate governance and industrial relations are also transformed.

However, on the other hand, research from the case study reveals that firms that place a higher emphasis on the development of a highly- and multi-skilled workforce (in spite of the institutional constraints that might counter such goals) have produced a production regime that is more design-intensive, high quality, flexible and customized than their competitors. Moreover, the former firms show a commensurately higher performance than the latter, attesting to the role of corporate strategy in overcoming certain aspects of the institutional environment in which firms operate.

These findings therefore point to the potential of firm practice and industrial policy to shape the skills, training and tenure dimensions of the Canadian industrial workplace, which would involve a number of complementary considerations. For one, the endemic free-rider problem that exists must be addressed, since it fundamentally undermines the ability of Canadian manufacturing firms to create the optimal long-term conditions that encourage investment in the development of their workers. Given the institutional characteristics of the Canadian market economy, one way this might be dealt with is at the scale of the individual firm through strategies and practices that promote worker loyalty, engagement and long termism. These incentives could include competitive salaries and wages, benefits (i.e. paid leave, pension etc.), performance-based 
pay (i.e. bonuses, profit-sharing, stock options / ownership etc.), opportunities for career advancement and growth in the company, strong corporate brand, positive public image, positive working conditions, cooperative management / labour relations, investments in skills and training, and investments in a culture of motivation (i.e. programs to recognize employees).

Second, industrial policy has been shown to be effective in creating programs that enable firms to retain their skilled workers through an economic downturn, rather than the hire / fire strategies that tend to predominate. The Government of Canada Work Share program has been highly successful in assisting Canadian contract furniture firms to avoid layoffs and the costly process of recruiting and training new employees by providing income support during periods of economic decline. This program has also assisted employees to maintain their skills by supplementing their wages with Employment Insurance benefits for the days they are not working.

Moreover, an effective labour policy must consider not only the technological advancement of the manufacturing workforce, but also its multi-skilling through human resources practices such as job rotation. Job rotation strategies, which create a skills overlap on the shopfloor, certainly require considerable resources and investments on the part of the firm. However in an industrial environment where product customization and specialization are crucial to competitive advantage, where much knowledge is tacit and things change quickly and unpredictably, a knowledge overlap among workers can lead to efficient problem identification and resolution, greater flexibility, productivity, and, ultimately, performance. 
However, a widespread shift towards massive vertical disintegration in recent decades has severely reduced the training capacity of individual firms, since most Canadian manufacturing now consists of lead producers that depend on networks of specialized suppliers that provide components and help with innovation. Consequently, producers can no longer develop entry-level candidates through an in-house system of advancement and job rotation to the extent they once did. This phenomenon has led to a debilitating manufacturing skills gap, as documented in the US manufacturing sector (Deloitte 2011), yet very much present in Canada as well.

This suggests that the possibilities for training and job rotation will be highly shaped by the local dynamics of supply chains and industrial clusters. A proposed solution therefore lies in the role of policy to assist self-organizing manufacturing clusters to cooperate to solve training problems. Government grants could help geographically proximate firms in the same or similar industries come together, along with supporting institutions such as community colleges, universities, industry associations, and unions, to identify and solve these problems collectively. Funding should be offered on a competitive basis to self-organized groups of firms and supporting institutions because market failures and institutional constraints in Canada prevent firms from solving workforce development problems individually, which often manifests itself in underinvestments in shared assets. Moreover, addressing these issues on a multi-firm basis means that solutions are more likely to be of broad, long-term benefit to firms, workers, and society at large.

The Bluewater Wood Alliance (BWA) is a cluster of wood products manufacturing companies located in southwestern Ontario, and is a model for sectoral 
cluster organization that aims to solve training problems and confront other innovationrelated issues that are common to member firms. It brings together over eighty companies in the advanced wood products industries for the purposes of joint projects in skills development as well as technology transfer, export development and experiences exchange. In the arena of training, the BWA works with community colleges, high schools and independent education providers in the region to set up a comprehensive skills development program that seeks to upgrade plant workers and pre-train new hires. The benefit to members is the ability to place workers into higher quality training programs (with cross-firm job rotation capabilities) at a lower cost than if individual companies attempt to provide training on their own. Although BWA is reliant upon funding at the federal, provincial and regional / municipal levels to support cluster activity, it is a grass-roots, membership-driven organization. In this example, industrial policy has played an indirect role to support cluster organization and to ensure that the BWA continues to work with the federal and provincial funding agencies to develop infrastructure and project funding. This includes working with educational institutions on the secondary and post-secondary levels to provide skills development for the industry (Bluewater Wood Alliance).

\section{4: Future research directions}

This research has focused on three sources of knowledge that enable manufacturing firms in a design-led, high quality niche to develop innovative products and compete in global markets: learning from immigrant founders and other mobile managers, learning from 
expert industrial designers, and learning from clients and users. Despite the useful contributions that this research makes, the findings in this thesis raise additional questions regarding the role of design-led manufacturing industries in regional and national economic growth. Future research might begin by addressing the remaining sources of knowledge and processes of learning that are illustrated in Figure 1.1: learning from competitors and learning from suppliers. How important is knowledge from competitors and suppliers, and what are the social and organizational practices through which this knowledge is integrated into production processes? What are the geographies of producer-competitor and producer-supplier relations? Given the importance of the spatial proximity of economic actors to the innovation process, in what ways does the globalization of supply chains influence the long-term capacity of firms in high wage nations to innovate? What is the institutional influence on (collaborative) practices between firms and their suppliers within a national regulatory environment allegedly antithetical to such practices? Does firm ownership structure have any bearing on the institutional influence on firm practice? 


\section{References}

Abo, T. 1994. Hybrid factory: The Japanese production system in the United States. Oxford, U.K.: Oxford University Press.

1996. The Japanese production system: The process of adaptation to national settings. In States against markets: The limits of globalization, ed. R. Boyer and D. Drache. London: Routledge, 136-54.

Aguilera, R.V. and Jackson, G. 2003. The cross national diversity of corporate governance: dimensions and determinants. The Academy of Management Review 28:447465.

Amin, A. and Cohendet, P. 2004. Architectures of Knowledge: Firms, Capabilities and Communities. Oxford: Oxford University Press.

Amin, A. and Roberts, J. Community, Economic Creativity, and Organization. Oxford: Oxford University Press.

Amin, A. and Thrift, N. 1994. Living in the global. In Amin A. and Thrift N. (eds) Globalisation, Institutions and Regional Development in Europe. Oxford: Oxford University Press, 257-60.

Aoki, M. 1988. Information, incentives and bargaining in the Japanese economy. Cambridge: Cambridge University Press.

Aoyama, Y. and Izushi, H. 2008. User-led innovation and the video game industry. Paper Submitted to IRP Conference, London.

Asheim, B.T. and L. Coenen. 2005. Knowledge bases and regional innovation systems: Comparing Nordic clusters. Research Policy 34:1173-1190.

Asheim, B.T.; L. Coenen; and J. Vang. 2007. Face-to-face, buzz, and knowledge bases: Sociospatial implications for learning, innovation, and innovation policy. Environment and Planning C: Government and Policy 25:655-670.

Asheim B. T., and Gertler M. S. 2005. The geography of innovation: regional innovation systems. In The Oxford Handbook of Innovation, eds. J. Fagerberg, D. Mowery and R. Nelson. Oxford: Oxford University Press, 291-317.

Bathelt, H., and Gertler, M.S. 2005. The German variety of capitalism: forces and dynamics of evolutionary change. Economic Geography 81:1-9. 
Bathelt, H., Malmberg, A. and Maskell, P. 2004. Clusters and knowledge: local buzz, global pipelines and the process of knowledge creation. Progress in Human Geography 28:31-56.

Battilana, J., Leca, B. and Boxenbaum, E. 2009. How Actors Change Institutions: Towards a Theory of Institutional Entrepreneurship. The Academy of Management Annals 3:65-107.

Benner, C., ed. 2002. Silicon Valley: changing industry structure and employment practices. In Work in the New Economy: Flexible Labor Markets in Silicon Valley. Oxford: Blackwell, 37-79.

Best, M. 1989. Sector strategies and industrial policy: the furniture industry and the Greater London Enterprise Board. In Reversing Industrial Decline, eds. P. Hirst and J. Zeitlin. Oxford: Berg, 191-221.

Bluewater Wood Alliance. "About Us / Member Companies." Bluewater Wood Alliance: The Seeds for Growth. Walkerton: Bluewater Wood Alliance. (available at: http://www.bluewaterwoodalliance.org/AboutUs.aspx) (accessed on February 10th, 2013).

Borjas, G. J. 1994. The economics of immigration. Journal of Economic Literature. 32:1667-1717.

. 1995. The economic benefits from immigration. Journal of Economic

Perspectives. 9:3-22.

Boschma, R. 2005. Proximity and Innovation: A Critical Assessment. Regional Studies 39: 61-74.

Bjorkman, I., and Lu, Y. 2001. Institutionalization and bargaining power explanations of HRM practices in international joint ventures - the case of Chinese-Western joint ventures. Organization Studies 22:491-512.

Braczyk, H.J., Cooke, P. and Heidenreich, M. (eds). 1998. Regional Innovation Systems: The Role of Governances in a Globalized World. London: UCL Press.

Breschi, S. and Malerba, F. 2001. The geography of innovation and economic clustering: some introductory notes. Industrial and Corporate Change 10: 817-33.

Brown, J. S. and Duguid, P. 1996. Organisational learning and communities-of-practice: towards a unified theory of working, learning and innovation. In M. Cohen and L. Sproul (eds) Organisational Learning. New York: Sage, 58-82.

Business and Institutional Furniture Manufacturer's Association (BIFMA). 2005. Sustainability Guidelines for Office Furniture Manufacturers and Suppliers. BIFMA 
International. (available at http://www.bifma.org/documents/SusGdlines.pdf) (accessed on 10 Nov 2012).

Callon, M., Meadel, C. and Rabeharisoa, V. 2002. The economy of qualities. Economy and Society 31:194-217.

Callon, M., and Muniesa, F. 2005. Economic markets as collective devices. Organization Studies 26:1229-1250.

Christopherson, S. 2002a. Project Work in Context: regulatory exchange and the new geography of media. Environment and Planning A 34: 2003-2015.

Christopherson, S. 2002b. Why do national labor market practices continue to diverge in the global economy? The 'missing link' of investment rules. Economic Geography 78: 120 .

Clark, G. 1998. Stylized Facts and Close Dialogue: Methodology in Economic Geography. Annals of the American Association of Geographers 88: 73-87.

Clark, G.L. 2007. Beyond close dialogue: Economic geography as if it matters. In Politics and practice in economic geography, ed. A. Tickell; E. Sheppard; J. Peck; and T.J. Barnes. London: SAGE Publications,187-198.

Clark, G.L. and Wojcik, D. 2007. The geography of finance: corporate governance in a global marketplace. Oxford: Oxford University Press.

Cohen, M. and Levinthal, D.A. 1990. Absorptive Capacity: A New Perspective on Learning and Innovation. Administrative Science Quarterly 35(1): 128-152.

Cook, I. and Crang, M. 1995. Doing Ethnographies: Concepts and Techniques in Modern Geography. Quantitative Methods Study Group of the Institute of British Geographers.

Cooke, P. and Morgan, K. 1998. The Associational Economy: Firms, Regions and Innovation. Oxford: Oxford University Press.

Currid, E. 2007. The Warhol Economy: How Fashion, Art and Music Drive New York City, Princeton and Oxford: Princeton University Press.

Dalziel, M. 2008. Immigrants as Extraordinarily Successful Entrepreneurs: A Pilot Study of the Canadian Experience. Journal of Small Business and Entrepreneurship 21:23-36.

Deloitte. 2011. Boiling Point? The Skills Gap in US Manufacturing. Washington: The Manufacturing Institute.

Drayse, M. 2010. Globalization and Innovation in a Mature Industry: Furniture 
Manufacturing in Canada. Regional Studies (First published on: 01 February 2010, iFirst).

Doeringer, P. B., and Piore, M. J. 1971. Internal labor markets and manpower analysis. Massachusetts: Heath and Company.

Dunford, M. 2005. Old Europe, new Europe and the USA: comparative economic performance, inequality and market-led models of development. European Urban and Regional Studies 12: 149-76.

Ekinsmyth, C. 1999. Professional Workers in a Risk Society. Transactions of the Institute of British Geographers 24: 353-366.

Estevez-Abe, M., Iversen, T. and Soskice, D. 2001. Social Protection and the Formation of Skills: A Reinterpretation of the Welfare State. In Varieties of Capitalism. The Institutional Foundations of Comparative Advantage, eds. Hall and Soskice, 145-183.

Florida, R. 2002. The Rise of the Creative Class. New York: Basic Books.

Freeman, C. 1987. Technology Policy and Economic Performance: Lessons from Japan. London: Frances Pinter.

Friedberg, R. M., \& Hunt, J. 1995. The impact of immigrants on host country wages, employment and growth. Journal of Economic Perspectives. 19: 23-44.

Gertler, M.S. 1995. 'Being There': Proximity, Organization, and Culture in the Development and Adoption of Advanced Manufacturing Technologies. Economic Geography 71: 1-26.

. 2001. Best practice? Geography, learning and the institutional limits to strong convergence. Journal of Economic Geography 1: 5-26.

. 2003a. A Cultural Economic Geography of Production. In Handbook of Cultural Geography, eds. Anderson et al. London: Sage, 131-146.

. 2003b. Tacit knowledge and the economic geography of context, or the undefinable tacitness of being (there). Journal of Economic Geography 3: 75-99. 2004. Manufacturing culture: The institutional geography of industrial practice. Oxford, U.K.: Oxford University Press.

-2008. Buzz without being there? Communities of practice in context. In Community, Economic Creativity, and Organization, ed. A. Amin and J. Roberts, 203-226. New York: Oxford University Press. 
. 2010. Rules of the Game: The Place of Institutions in Regional Economic Change. Regional Studies 44: 1-15.

Gertler, M. S. and Vinodrai, T. 2004. Designing the economy: Profiling Ontario's design workforce. Toronto: Design Industry Advisory Committee.

Gertler, M. S. and Vinodrai, T. 2005. Learning from America? Knowledge flows and industrial practices of German firms in North America. Economic Geography 81: 31-52.

Gertler, M. S. and D.A. Wolfe, eds. 2002. Innovation and Social Learning: Institutional Adaptation in an Era of Technological Change. Basingstoke, UK: Macmillan/Palgrave. . 2004. The Regional Innovation System in Ontario. In Regional Innovation Systems: The Role of Governances in a Globalized World. Braczyk, H-J. and Heidenreich, M. (eds.). UCL Press Limited: London, 99-135.

Gotlieb, R. 2002. New landscape: Design transforms Canadian furniture. Toronto: Design Exchange.

Grabher, G. 2002. Guest editorial: Fragile sector, robust practice: project ecologies in new media. Environment and Planning A 4:1911-1926.

Grabher, G., Ibert, O. and Flohr, S. 2008. The neglected king: The customer in the new knowledge ecology of innovation Economic Geography 84:253-280.

Guler, I., Guillén, M.F. and Macpherson, J.M. 2002. Global competition, institutions and the diffusion of organizational practices: the international spread of ISO 9000 Quality Certificates. Administrative Science Quarterly 47:207-232.

Hall, P.A., and Soskice, D. eds. 2001. Varieties of Capitalism: The Institutional Foundations of Comparative Advantage. Oxford: Oxford University Press.

Hay, I. 2000. Qualitative Research Methods in Human Geography. Toronto: Oxford University Press.

Industry Canada. 2007. Canadian Industry Statistics. Ottawa: Industry Canada (available at: www.ic.gc.ca/cis) (accessed on 2 March 2009). 2008. The Canadian Furniture Industry - An Overview. Ottawa: Industry Canada (available at http://www.ic.gc.ca/eic/site/furniture-meuble.nsf/eng/rf03598.html) (accessed on 12 February 2009)

. 2010. Industry Snapshot - Furniture Manufacturing: 2004-2008. Ottawa:

Industry Canada (available at http://www.ic.gc.ca/eic/site/furniture-

meuble.nsf/eng/rf03748.html) (accessed on 10 April 2010) 
.2011a. Performance - Office Furniture (including Fixtures) Manufacturing (NAICS 3372). Ottawa: Industry Canada (available at http://www.ic.gc.ca/cis-sic/cissic.nsf/IDE/cis-sic3372pere.html) (accessed on 20 June 2012).

. 2011b. Employment - Office Furniture (including Fixtures) Manufacturing (NAICS 3372). Ottawa: Industry Canada (available at http://www.ic.gc.ca/cis-sic/cissic.nsf/IDE/cis-sic3372empe.html) (accessed on 20 June 2012).

2012. Output per Employee Manufacturing Revenue and Manufacturing Value-added, Furniture and Related Products NAICS 3372001 - 2012. Ottawa: Industry Canada (available at http://www.ic.gc.ca/cis-sic/cis-sic.nsf/IDE/cis-sic337pere.html) (accessed on 1 Nov 2012)

Kenney, M., and Florida, R. 1993. Beyond mass production: the Japanese system and its transfer to the United States. New York: Oxford University Press.

Kloosterman, R. and Rath, J., eds. 2003. Immigrant entrepreneurs: venturing abroad in the age of globalization. New York, NY: Berg.

Kostova, T. 1999. Transnational transfer of strategic organizational practice: a contextual perspective. The Academy of Management Review 24: 308-324.

Kostova, T. and Roth, K. 2002. Adoption of an organizational practice by subsidiaries of multinational corporations: institutional and relational effects. The Academy of Management Journal 45:215-233.

Lam, A. 2000. Tacit knowledge, organizational learning and societal institutions: an integrated framework. Organizational Studies 21:487-513.

. 2002. Alternative societal methods of learning and innovation in the knowledge economy. International Social Sciences Journal 54: 67-82.

Landry, C. 2000. The Creative City: A Toolkit for Urban Innovators. London: Earthscan.

Lash, S. \& Urry, J. 1994. The Economy of Signs and Spaces. London: Sage Publications.

Lave, J. and Wenger, E. 1991. Situated Learning: Legitimate peripheral participation. Cambridge: Cambridge University Press.

Leslie, D. and S. Reimer. 2006. Situating Design in the Canadian Household Furniture Industry. Canadian Geographer 50: 319-341.

Lorenzen, M. ed. 1998. Specialisation and localised learning in the European furniture industry. Copenhagen: Copenhagen Business School Press.

Lundvall, B-A. 1985. Product Innovation and User-Producer Interaction. Industrial 
Development Research Series no. 31, Aalborg University Press.

. 1988. Innovation as an interactive process: from user-producer interaction to the national system of innovation. In G. Dosi, C. Freeman, G. Silverberg and L. Soete (eds.), Technical Change and Economic Theory. London: Pinter, 349-69.

1992. National Systems of Innovation: Towards a Theory of Innovation and Interactive Learning. London: Pinter.

Lundvall, B-A. and Johnson, B. 1994. The Learning Economy, Journal of Industrial Studies 1: 23-42.

Lundvall, B-A. and Maskell, P. 2000. Nation states and economic development - from national systems of production to national systems of knowledge creation and learning. In G.L. Clark, M.P. Feldman, and M.S. Gertler (eds), The Oxford Handbook of Economic Geography. Oxford: Oxford University Press, 353-72.

Malmberg, A. and Maskell, P. 2002. The elusive concept of localization economies: towards a knowledge-based theory of spatial clustering. Environment and Planning A 34:429-49.

Markusen, A. 2004. Targeting occupations in regional and community economic development. Journal of the American Planning Association 70: 253-68.

Maskell, P. et al. 1998. Comfort and competitiveness: the wooden furniture industry. In Competitiveness, Localised Learning and Regional Development: Specialisation and Prosperity in Small Open Economies. London: Routledge, 98-119.

Maskell, P. 1998. Localised low-tech learning in the furniture industry. In Specialisation and localised learning. Six studies on the European Furniture Industry, ed M. Lorenzen, Copenhagen: Copenhagen Business School, 33-55.

Maskell, P. and Malmberg, A. 1999. Localised learning and industrial competitiveness. Cambridge Journal of Economics 23: 167-86.

Maskell, P., Bathelt, H. and Malmberg, A. 2006. Building Global Knowledge Pipelines: The Role of Temporary Clusters. European Planning Studies 14: 997-1013.

Maurice, M., Sellier, F., Silvestre, J.-J. 1986. The Social Foundations of Industrial Power: A Comparison of France and Germany. Cambridge, MA: MIT Press.

McLafferty, S.L. 1995. Counting for women. The Professional Geographer 47:336-443.

Minichiello, V., Aroni, R. Timewell, E. and Alexander, L. 1995. In-depth interviewing: principles, techniques, analysis. Melbourne: Longman Cheshire. 
Nelson, R. R. 1988. Institutions supporting technical change in the United States. In G. Dosi, C. Freeeman, R. Nelson, G. Silverberg and L. Soete (eds) Technical Change and Economic Theory. London: Frances Pinter, 312-29.

Nelson, R. and Winter, S. 1982. An Evolutionary Theory of Economic Change. Cambridge: Belkhap Press.

OECD. 2002. International mobility of the highly skilled: policy brief. Paris: OECD.

. 2008. The global competition for talent: mobility of the highly skilled. Paris: OECD.

Patton, M. Q. 2002. Purposeful Sampling. In Qualitative research \& evaluation methods. London: Sage Publications.

Pau, W.Y., Goerzen, A., and Wu, M. 1998. The Impact of Liberalisation: Communicating with APEC Communities. Furniture Industry in Canada. Singapore: APEC Communities.

Pauly, L. and Reich, S. 1997. National structures and multinational corporate behavior: enduring differences in the age of globalization. International Organization 51: 1-30.

Peck, J. 2007. Methods Matter: transformations in Economic Geography. In Politics and Practice in Economic Geography. London: Sage, 1-23.

Penrose, E. 1995. The Theory of the Growth of the Firm. 3rd edn. Oxford: Oxford University Press.

Philip, L.J. 1997. Combining quantitative and qualitative approaches to social research in human geography - an impossible mixture? Environment and Planning A 1998 30: 261276.

Piore, M.J. and Sabel, C.F. 1984. The Second Industrial Divide. New York: Basic Books.

Piore, M.J. 1970. The dual labor market: theory and implications. In Problems in Political Economy, ed. Gordon. Lexington: Heath. . 1975. Notes for a theory of labor market stratification. In Labor Market Segmentation, eds. Edwards, Reich, and Gordon. Lexington: Heath.

Porter, M.P. 1990. The Comparative Advantage of Nations. New York: The Free Press. . 2000. Locations, clusters and company strategy. In G.L. Clark, M.P.

Feldman and M.S. Gertler (eds) The Oxford Handbook of Economic Geography. Oxford: Oxford University Press, 253-74.

Portes, A., and Sensenbrenner, J. 1993. Embeddedness and immigration: notes on the social determinants of economic action. The American Journal of Sociology 98:1320-50. 
Power, D. \& Scott, A.J. 2004. A prelude to cultural industries and the production of culture in Cultural industries and the production of culture, edited by D. Power and A.J. Scott, London and New York: Routledge, 3-16.

Putnam, R. 1993. Making Democracy Work. Princeton: Princeton University Press.

Rantisi, N. 2002. The local innovation system as a source of 'variety': openness and adaptability in New York City's garment district. Regional Studies 36: 587-602.

2004. The designer in the city and the city in the designer. Cultural

Industries and the production of culture, edited by D. Power and A.J. Scott, London and New York: Routledge, 91-109

Rosenberg, N. 1976. Perspectives on Technology. Cambridge: Cambridge University Press.

1982. Learning by using. In Inside the black box: Technology and economic, ed. N. Rosenberg, 120-140. Cambridge: Cambridge University Press.

Rusten, G. 1997. The role of geographic concentration in promoting competitive advantage: the Norwegian furniture industry Norwegian Journal of Geography 51: 173185.

Saka, A. 2004. The cross-national diffusion of work system: translation of Japanese operations in the UK. Organization Studies 25:209-228.

Saxenian, A. 1994. Regional advantage: Culture and competition in Silicon Valley and Route 128. Cambridge, Mass.: Harvard University Press.

1999. Silicon Valley's New Immigrant Entrepreneurs. San Francisco: Public Policy Institute of California.

. 2000. Networks of immigrant entrepreneurs. The Silicon Valley Edge: A Habitat for Innovation and Entrepreneurship, ed. C.M. Lee, W.F. Mill, M.G. Hancock and H.S. Rowen. Stanford: Stanford University Press, 248-68.

. 2002. Silicon Valley's New Immigrant High Growth Entrepreneurs.

Economic Development Quarterly 16: 20-31

2006. The New Argonauts: Regional Advantage in a Global Economy.

Cambridge: Harvard University Press.

Sayer, A. and Walker, R.A. 1992. The New Social Economy: Reworking the Division of Labor. Oxford: Blackwell. 
Schoenberger, E. 1991. The Corporate Interview as a Research Method in Economic Geography. Professional Geographer 43 2: 180-189.

Scott, A.J. 1988. Flexible production systems and regional development: The rise of new industrial spaces in North America and Western Europe. International Journal of Urban and Regional Research 12: 171-186

1996. The craft, fashion and cultural-products industries of LA: competitive dynamics and policy dimensions in a multisectoral image-producing complex. Annals of the Association of American Geographers 86: 306-323.

1997. The Cultural Economy of Cities. International Journal of Urban and Regional Research 21: 323-339.

.2000. The Cultural Economy of Cities. Essays on the Geography of Image-

Producing Industries London: Sage.

2001. Capitalism, cities, and the production of symbolic forms.

Transactions of the Institute of British Geographers 26: 11-23.

. 2004. Cultural-products industries and urban economic development:

prospects for growth and market contestation in global context. Urban Affairs Review 39: 461-490.

Scott, A.J. and Storper, M. 1987. High technology industry and regional development: a theoretical critique and reconstruction. International Social Science Journal, 112: 215-32.

Smith, J. P., \& Edmonston, B. 1997. The new Americans: Economic, demographic, and fiscal effects of immigration. Washington, DC: National Academy Press.

Soskice, D. 1999. Divergent Production Regimes. In Continuity and Change in Contemporary Capitalism, eds. H. Kitschelt et al. Cambridge: Cambridge University Press, 101-134.

Statistics Canada. 2008. Number of office furniture establishments (NAICS 3372) by region. Ottawa: Statistics Canada.

2011. Number of Employer Establishments in Canada by Employment Size Category and Region. Office Furniture (including Fixtures) Manufacturing (NAICS 3372). Ottawa: Statistics Canada, Canadian Business Patterns Database.

Storper, M. 1995. The resurgence of regional economies, ten years later: the region as a nexus of untraded interdependencies. European Urban and Regional Studies 2: 191-222. 1997. The Regional World: Territorial Development in a Global Economy. Guilford Press, London. 
Storper, M. and Leamer, E.E. 2001. The economic geography of the Internet age. Journal of International Business Studies 32: 641-65.

Storper, M. and Venables, A.J. 2003. Buzz: the economic force of the city 2004. Buzz: face-to-face contact and the urban economy. Journal of Economic Geography, 4: 351-70.

Stowsky, J. 1987. The weakest link: semiconductor production equipment, linkages and the limits to international trade. Working Paper 27, Berkeley Roundtable on the International Economy. Berkeley: University of California.

Streeck, W. 1996. Lean Production in the German Automobile Industry: A Test Case for Convergence Theory. In S. Berger an R. Dore (eds) National Diversity and Global Capitalism. Ithaca: Cornell University Press, 138-170.

Sturgeon, T, Van Biesebroeck, J. and Gereffi, G. 2008. Value chains, networks and clusters: reframing the global automotive industry. Journal of Economic Geography 8:297-321.

Sunley, P.; S. Pinch; S. Reimer; and J. Macmillen. 2008. Innovation in a creative production system: The case of design. Journal of Economic Geography 8:675-698.

Valentine, G. 2001. At the drawing board: developing a research design. In M. Limb and C. Dwyer (eds.) Qualitative Methodologies for Geographers: Issues and Debates. New York: Arnold, 41-54.

Valentine, G. 1997. Tell me about... : using interviews as a research methodology. Methods in human geography: a guide for students doing a research project. R. F. a. D. M. Harow. London: Longman.

Vinodrai, T. 2006. Reproducing Toronto's design ecology: career paths, intermediaries, and local labor markets. Economic Geography 82: 237-263.

von Hippel, E. 1976. The dominant role of users in the scientific instrument innovation process, Research Policy 5(3), 212-239.

1977. Transferring process equipment innovations from user-innovators to equipment manufacturing firms, $R \& D$ Management 8:13-22.

1986. Lead Users: A Source of Novel Product Concepts. Management Science 32(7):791-805.

1988. The Sources of Innovation. Cambridge: MIT Press. 
1989. New product ideas from 'lead users', Research-Technology

Management 32:24-28.

2001. Innovation by user communities: learning from open-sources software

MIT Sloan Management Review 42:82-86.

2005. Democratizing Innovation. MIT Press, Cambridge, MA.

von Hippel, E. and von Krogh, G. 2006. Free revealing and the private-collective model for innovation incentives $R \& D$ Management 36:295-306.

Waldinger, R.D., Aldrich, H., and Ward, R. 1990. Ethnic entrepreneurs: immigrant business in industrial societies. Newbury Park: Sage.

Wever, K. 1995. Negotiating Competitiveness: Employment Relations and Organizational Innovation in Germany and the United States. Cambridge, MA: Harvard Business School Press.

Winchester, H.P.M. 2000. Qualitative research and its place in human geography. In I. Hay (Ed.) Qualitative Research Methods in Human Geography. Toronto: Oxford University Press, 1-21.

Womack, J. R., Jones, D. T., and Roos, D. 1990. The machine that changed the world. New York: Rawson Associates.

Wong, W.L.P. and D.F. Radcliffe. 2000. The tacit nature of design knowledge. Technology Analysis and Strategic Management 12:493-512.

Zukin, S. 1995. The Cultures of Cities. Blackwell Publishing. 


\section{Appendix I: Survey invitation letter}

Dear --,

My name is Carolyn Hatch and I'm a PhD candidate in the Department of Geography and Planning at the University of Toronto. I'm currently conducting a study for my dissertation on the contract furniture manufacturing sector in Canada. This research is part of an overarching project that examines the strategies and practices of quality- and design-led manufacturing firms in Canada, and the factors and processes that shape and constrain competitiveness. This study is supported by the Social Sciences and Humanities Research Council of Canada (SSHRC) and the University of Toronto. Within this project, I'm examining the dynamics of innovative capacity and economic performance in Canadian firms and seek to gain insights on manufacturing competitiveness that will inform targeted policies.

If I may: I'm wondering if you would consider taking a few moments to participate in an online survey that I've developed for my research? If so, I'd be incredibly grateful. This survey is being conducted in order to collect important information about firm performance and industrial practices in this sector and your knowledge and experiences are very important.

Please note: the information you provide will not in any way be used for commercial purposes. By becoming a participant, you will also have the chance to win a Relais \& Chateau gift certificate (valued at $\$ 200$ ). This survey takes about 15 minutes and is completely voluntary. To learn more, simply click on the link below:

\section{http://manufacturingcompetitiveness.blogspot.com/}

Thank you in advance for your important contribution to this research. As well, to our understanding of profound changes that have taken place - and continue to do so - in the landscape of traditional manufacturing throughout advanced economies in recent decades.

With sincere thanks and kind regards,

Carolyn Hatch

Carolyn Hatch, $\mathrm{PhD}$ candidate

Department of Geography and Planning, University of Toronto

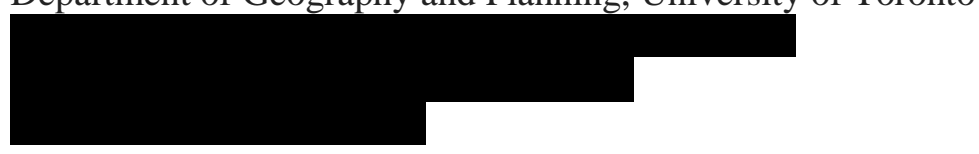




\section{Appendix I: Survey invitation letter}

Cher --,

Mon nom est Carolyn Hatch et je suis une candidate au Doctorat à la faculté de géographie et planification urbaine de l'université de Toronto. Je mène présentement pour ma mémoire une étude sur l'industrie d'ameublement commercial canadienne. Cette recherche fait partie de l'ensemble de mon projet qui examine les stratégies et pratiques de qualité et d'innovation en désign de ces entreprises manufacturiennes canadiennes, et les facteurs et processus qui forment et restreignent leur compétitivité. Cette étude est supporté par le conseil canadien de recherches en ressources humaines (CRSH) et l'université de Toronto. Par ce projet, j'examine les dynamiques qui régissent les capacités d'innovation et la performance économique de ces firmes canadiennes et je recherche à acquérir de l'information sur leur compétitivité pour pouvoir informer certaines politiques cibles.

Puis-je vous demander si possible de prendre quelque moment pour participer à ce sondage en ligne que j'ai développer pour ma recherche? J'en serais très reconnaissante. Ce sondage est mené pour recuellir de l'information sur l'innovation et les pratiques industrielles dans ce secteur et vos opinions et expériences sont primordiales pour mener à terme ma recherche.

Prendre note que l'information ne sera pas utilisé à des fins commerciales. En participant à ce sondage, vous aurez la chance de gagner un certificat cadeau de $\$ 200$ dans n'importe quel établissement de Relais et Châteaux canadiens. Ce sondage prend environ 15 minutes et est totalement volontaire.

\section{$\underline{\text { http://competitivitemanufacturiere.blogspot.com/ }}$}

Je vous remercie à l'avance de votre importante contribution à cette recherche. De plus, vos informations nous permettra de mieux comprendre les pratiques de ce secteur et de comprendre les changements profonds qui ont eu lieu dans les dernières décennies dans le paysage du secteur manufacturier traditionnel dans les économies avancées comme celle du Canada .

Salutations des plus sincères,

Carolyn Hatch

Carolyn Hatch, PhD candidate

Department of Geography and Planning, University of Toronto 


\title{
Appendix II: Survey Cover Page
}

\author{
Manufacturing Competitiveness
}

\section{SURVEY OF CANADIAN MANUFACTURING FIRMS}

This email is inviting you to participate in a study I am conducting as part of my doctoral research at the University of Toronto and under a Social Sciences and Humanities Research Council (SSHRC) Doctoral Fellowship.

This research examines the strategies and practices of competitive manufacturing firms in Canada and the factors and processes that shape and constrain competitiveness. I draw on a case study of the Canadian contract furniture sector to investigate in particular how firms organize work and deploy labour in pursuit of their competitive goals.

\section{WHY IS THIS IMPORTANT?}

- Despite the demise of traditional manufacturing industries throughout OECD countries of late, certain areas of manufacturing activity in high wage contexts have risen, and in fact flourished, in the knowledge-based economy.

- The principal goal of this study is to broaden and enrich our understanding of manufacturing competitiveness in advanced nations such as Canada in the present economic context. Specifically, it examines the dynamics of economic performance and innovative capacity in Canadian manufacturing firms.

- This project also seeks to gain insights that can inform targeted policies that shape firm practices.

- This survey is being conducted in order to collect important information about human resources practices in this sector, in particular recruitment, skills, training and talent attraction and retention. In addition, information is being collected on firm history, foundations of success, competitive strategy, innovation, sources of knowledge, and the presence of design activity, if any.

\section{CONTACT INFORMATION}

If you have any questions about this study, or would like additional information, please contact me at carolyn.hatch@utoronto.ca

\section{WOULD YOU LIKE TO HELP ANSWER THESE QUESTIONS?}


Participation in this survey is voluntary and all responses are confidential. You may stop at any time and can choose not to answer any questions. At no time will anyone but the researcher have access to your responses. I also assure that neither your name nor the details of your organization will be revealed in any presentations or publications that result from this research, without your express written permission to do so.

*After the study is completed, I would be happy to send you a summary of the research results

*Please take a moment to complete the survey by clicking on the link below. It should take 15-17 minutes and is completely confidential:

\section{SURVEY}

\section{Click here to take survey}

AS A FURTHER INCENTIVE, BY PARTICIPATING IN THIS SURVEY YOU HAVE THE CHANCE TO WIN A RELAIS \& CHATEAU GIFT CERTIFICATE VALUED AT $\$ 200$. Relais \& Chateau is a collection of luxury hotels and gourmet restaurants in Canada and around the world: www.relaischateaux.com/. This is valid for 2 years and can be used like cash at member establishments.

\section{THIS RESEARCH IS SUPPORTED BY:}

This research is funded by the University of Toronto and the Social Sciences and Humanities Research Council of Canada Doctoral Fellowship Program. 


\title{
Appendix II: Survey Cover Page
}

\author{
Compétitivité industrie manufacturière
}

\section{SONDAGE SUR LES ENTREPRISES MANUFACTURIÈRES CANADIENNES}

Ce courriel est une invitation pour participer à une étude que je dirige dans le cadre de ma recherche pour mon doctorat à I'université de Toronto et subventionné par le Conseil de Recherche de Sciences Humaines du Canada (CRSH).

Cette recherche examine les stratégies et pratiques d'entreprises manufacturières compétitives canadiennes et les facteurs et processus leur permettant d'être compétitives. J'ai dirigé cette recherche vers le secteur de l'ameublement commercial pour étudier comment les entreprises organisent leur travail et leur main-d'œuvre dans la poursuite de leurs objectifs de compétitivité.

\section{QU'EST-CE QUI EST IMPORTANT?}

- Malgré la disparition du secteur manufacturier traditionnel dans les pays de I'OCDE, certains secteurs d'activités à salaires plus élevés ont émergé dans un contexte d'une économie base sur la connaissance.

- Le but principal de cette étude est d'élargir et enrichir notre compréhension de la compétitivité manufacturière dans des sociétés avancées comme le Canada dans le contexte économique actuel. Plus spécifiquement, nous examinons la dynamique de la performance économique et la capacité d'innovation des entreprises manufacturières canadiennes.

- Ce projet recherche également des idées qui pourrait mener la création de politiques qui régissent les pratiques de la firme.

- Ce sondage a pour but de compiler l'information importante sur les pratiques en ressources humaines dans ce secteur et plus particulièrement le recrutement, les habilités techniques, la formation et la capacité d'attirer et garder la main-d'œuvre qualifiée. De plus, de l'information sera recueilli sur I'histoire de la firme, les raisons de leur succès, la stratégie de compétitivité, l'innovation, les sources de connaissances et de la présence de l'activité de design s'il y en a.

\section{COORDONNÉES DU CONTACT}

Si vous avez des questions sur cette recherche ou si vous avez besoin de plus amples informations, vous pouvez me contacter àcarolvn.hatch@utoronto.ca.

\section{VOULEZ-VOUS AIDER À RÉPONDRE À CES QUESTIONS?}

La participation à ce sondage est volontaire et toutes les réponses reçues demeureront confidentielles. Vous pouvez décider d'arrêter en tout temps et/ou choisir de ne pas répondre à certaines questions. Aucune personne en tout temps 
outre la personne en charge de cette recherche aura accès à ces réponses. Je peux également assurer que votre nom ou les détails de votre organisation ne seront révélés dans quelques présentations ou publications résultants de cette recherche sans une permission écrite de votre part.

*Je serai en mesure de vous envoyer un sommaire des résultats de la recherche après que cette dernière soit complétée.

*Prenez un moment pour compléter ce sondage en cliquant sur le lien cidessous. Ça ne devrait prendre pas plus que 15-17 minutes et demeurera confidentiel.

\section{SONDAGE}

\section{- cliquez ici pour débuter le sondage}

\section{EN GUISE D'INCITATIF EN PARTICIPANT À CE SONDAGE, VOUS} COURREZ LA CHANCE DE GAGNER UN CERTIFICATE CADEAU DE $\$ 200$ DANS UN RELAIS \& CHÂTEAU CANADIEN. Relais \& Château est un regroupement d'hôtel de luxe et de restaurants haut-de-gamme au Canada et partout dans le monde. www.relaischateaux. $\operatorname{com} /$. Ce certificat sera valide pour 2 ans et peut-être utilisé comme argent comptant dans un de leurs établissements.

\section{CETTE RECHERCHE EST SUPPORTÉ PAR:}

L'université de Toronto et par le Conseil en Recherche de Sciences Humaines du Canada (CRSH). 


\section{Appendix III: Survey Consent Form}

\section{Consent Form (required)}

*I have read the information presented above about a study being conducted by Carolyn Hatch from the Department of Geography and Planning at the University of Toronto.

I am also aware that information from this survey may be included in the thesis and/or publications to come from this research. I understand that my responses are confidential and that neither my name nor the details of my organization will be revealed in any presentations or publications that result from this research, without my express written permission to do so. I am aware that I can stop answering the survey at any time with no penalty and that I may choose not to answer any questions. I am aware that at no time will anyone but the researcher have access to my responses.

With full knowledge of all foregoing, I agree, of my own free will, to participate in this study.

\section{Lettre de consentement (à signer)}

*J'ai lu l'information présentée ci-dessous pour une étude de marché préparée et dirigée par Carolyn Hatch de la faculté de géographie et planification de l'université de Toronto.

Je suis également conscient que l'information mentionné dans ce questionnaire pourrait se retrouver dans sa thèse ou publications qui découleront de celle-ci. Je comprends que toutes mes réponses sont confidentielles et que mon nom et détails de mon organisation ne peuvent être révélées dans toutes présentations ou publications que ce soit sans une permission écrite de ma part. Je suis conscient que je peux arrêter de répondre à ce questionnaire en tout temps sans pénalité ou que je puisse décider de ne pas répondre à certaines questions. Je suis au courant qu'aucune personne autre que Carolyn Hatch aura accès à mes réponses.

En connaissance de cause, j'accepte de mon propre chef de participer à cette étude. 


\section{Appendix IV: Survey Questionnaire}

\section{I: BACKGROUND INFORMATION}

These questions are in the interest of gathering basic information about the background and organization of your firm.

In this questionnaire, we refer both to your "plant" and to your "firm". By "plant", we mean your local operations. By "firm", we mean all plants and operations in Canada or in other countries that comprise your company (if applicable).

1. In what year was your plant established:

2. In what year was your firm established:

3. Are the operations of your plant part of a larger firm?

$$
\text { Yes }
$$

4. If yes, please indicate the geographical location(s) and number of other plants and operations in your firm:

in region

elsewhere in province

elsewhere in Canada

in US

in other country(ies). Please specify:

5. Please estimate (as best you can) the total number of employees in your firm:

6. Please estimate (as best you can) the total number of employees in your plant:

7. Please estimate (as best you can) the percentage of your full-time employees in your plant in 2009 who had:

A university degree

A college/technical institute diploma

\section{II: FOUNDER AND OWNERSHIP}

These questions deal with firm ownership and background of the firm founder which may be fundamental factors in shaping competitive strategies and practices

1: Is your firm Canadian owned?

$$
\begin{aligned}
& \text { Yes } \\
& \text { No }
\end{aligned}
$$

2: If no, what is the country of ownership of your firm?

Please specify:

3: Has the ownership of this firm remained the same since its establishment?

Yes

No (Please explain:

$$
\text { Don't know }
$$

4: Is your firm public or private?

$$
\text { Publicly traded }
$$

$$
\text { Privately held }
$$

5: If private, is it family-owned?

$$
\text { Yes }
$$

No

6: Was the founder(s) of this firm born outside Canada?

$$
\text { Yes }
$$

No

Don't know 
7: If yes, please indicate the geographical location(s) where the firm founder(s) was born:

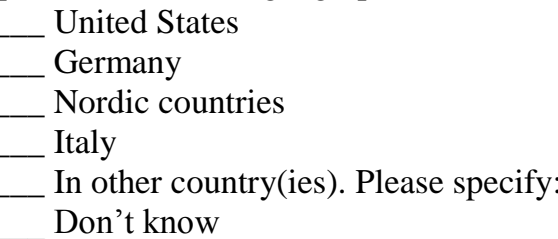

8: Was the founder(s) of this firm educated or trained outside Canada?

$$
\text { Yes }
$$

No

Don't know

9: If yes, please indicate the geographical location(s) where the firm founder(s) was educated or trained outside Canada (check all that apply):

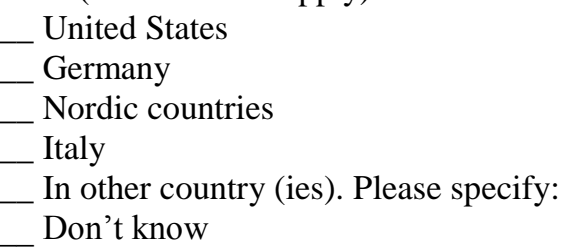

III: FOUNDATIONS OF SUCCESS AND COMPETITIVE STRATEGY

This section collects information on the topic of success factors and competitive strategy. There is no right or wrong answer.

1: Please rate the importance of the following factors for the success of your firm or plant (whichever is applicable):

1. Value of Canadian dollar

\section{Low Medium High Not relevant}

2. Lower production costs relative to competitors

3. Supply of workers with particular skills

4. Quality of design

5. Appealing workplace and good employee benefits

6. Close relationship with lead customers

7. Close relationship with key suppliers

8. Knowledge of strategies and practices of key competitors

9. Close relationship with research organizations

10. Close relationship with educational and training institutions

11. Co-location with other firms in the same industry

12. Quality of physical, transportation and communications infrastructure

13. Availability of financing

14. Supportive public policies or programs 
2: On a scale of 1-7, please describe your firm's competitive strategy based upon the following dimensions:

\begin{tabular}{|c|c|c|c|c|c|c|}
\hline \begin{tabular}{|c|}
1 \\
High volume \\
production for mass \\
markets
\end{tabular} & 2 & 3 & 4 & 5 & 6 & $\begin{array}{c}7 \\
\text { Small batch } \\
\text { production for niche } \\
\text { markets }\end{array}$ \\
\hline $\begin{array}{c}1 \\
\text { Low cost/pricing }\end{array}$ & 2 & 3 & 4 & 5 & 6 & $\begin{array}{c}7 \\
\text { High cost/pricing }\end{array}$ \\
\hline $\begin{array}{c}1 \\
\text { Low quality }\end{array}$ & 2 & 3 & 4 & 5 & 6 & $\begin{array}{c}7 \\
\text { High quality }\end{array}$ \\
\hline 1 & 2 & 3 & 4 & 5 & 6 & $\begin{array}{c}7 \\
\text { Design-driven }\end{array}$ \\
\hline \begin{tabular}{|c|}
1 \\
Infrequent changes to \\
product line
\end{tabular} & 2 & 3 & 4 & 5 & 6 & $\begin{array}{c}7 \\
\text { Highly flexible, } \\
\text { responsive to } \\
\text { markets }\end{array}$ \\
\hline $\begin{array}{c}1 \\
\text { Productivity achieved } \\
\text { through more } \\
\text { intensive use of } \\
\text { labour }\end{array}$ & 2 & 3 & 4 & 5 & 6 & $\begin{array}{c}7 \\
\text { Productivity achieved } \\
\text { through adopting } \\
\text { higher levels of } \\
\text { automation }\end{array}$ \\
\hline
\end{tabular}

\section{IV: INNOVATION AND KNOWLEDGE}

Innovation is vital for economic growth and development. Responses to these questions will allow us to explore and understand the innovativeness of your firm.

A PRODUCT INNOVATION is the market introduction of a new good or a significantly improved good. The innovation (new or improved) must be new to your plant.

1: During the last three years, did your plant introduce:

$$
\text { New or significantly improved goods Yes No }
$$

2: If yes, during the last three years (2007-2009), how many new or significantly improved PRODUCTS did your plant introduce onto the market?

Number of new goods:

3: During the three years, 2007 to 2009, were ANY of your new or significantly improved PRODUCTS introduced by your plant:

$$
\text { Yes No Do not know }
$$



a. A first in your province/territory?
b. A first in Canada?
c. A first in North America?
d. A world first?

These questions seek information on the process of innovation including identifying the important sources of your firm's information and knowledge. There is no right or wrong answer.

A PROCESS INNOVATION is the implementation of a new or significantly improved production process, distribution method, or support activity for your goods or services. The innovation (new or improved) must be new to your plant.

During the last three years (2007-2009), did your plant introduce:

4: New or significantly improved methods of manufacturing or producing goods or services Yes No

5: New or significantly improved logistics, delivery or distribution methods for your inputs, goods or services

Yes No

6: New or significantly improved supporting activities for your processes, such as maintenance systems or operations for purchasing, accounting, or computing

Yes No

7: During the three years, 2007 to 2009, were ANY of your new or significantly improved PROCESSES introduced by your plant:
a. A first in your province/territory?
b. A first in Canada?
c. A first in North America?
d. A world first?

8: During the last three years (2007-2009), how important to your innovation activities were each of the following sources of information

Information sources

Internal

a. Product development and engineering staff

b. Design staff

b. Sales and marketing staff

c. Production staff

d. Management staff: firm founder

e. Management staff: other

f. Other plants in your firm

\section{Market Sources}

g. Suppliers

h. Clients or customers

i. Competitors or other firms in your sector

j. Consultants

k. Commercial labs/R\&D firms

Institutional Sources

1. Universities or other higher education institutions

m. Colleges/technical institutes

n. Federal government research laboratories

o. Provincial/territorial government research laboratories

p. Private non-profit research laboratories
Degree of Importance Medium High Not Relevant 


\section{Other Sources}

q. Trade fairs, conferences, exhibitions

r. Trade/technical publications

s. Investors (banks, venture capitalists, etc.)

t. Industry associations

u. Internet

v. Experienced risk-takers or entrepreneurs

w. Other, please specify:

\section{V: HUMAN RESOURCE PRACTICES}

These questions seek information about HR practices that underpin firm performance, namely work organization, skills, training, and tenure. The emphasis in this section is on production workers (both skilled and semi-skilled).

1: Below is a list of job categories/occupations. Please indicate (as best you can) the approximate number of employees your firm has in each category (at this location, if more than one). Indicate the number in all that apply.

\begin{tabular}{|l|l|}
\hline \multicolumn{1}{|c|}{ Occupation/job category } & $\begin{array}{l}\text { Number of } \\
\text { employees }\end{array}$ \\
\hline Management & \\
\hline $\begin{array}{l}\text { Technical, Engineering, Product } \\
\text { Development }\end{array}$ & \\
\hline Design & \\
\hline Marketing/Sales & \\
\hline Supervisory Production & \\
\hline "Highly-skilled" Production & \\
\hline "Semi- and Un-skilled" Production & \\
\hline Clerical/office/customer support & \\
\hline Other (Specify) & \\
\hline
\end{tabular}

2: Please estimate (as best you can) the percentage of your workforce that is unionized: $\%$

3: Please rate the importance of the following sources for employees for each production occupational category.

Degree of importance

Low Hedium Hot relevant

Supervisory and skilled production workers

Internally (promotion)

Secondary education (high school)

College/university

Specialized vocational training institutions

Trades and apprenticeship system

Other firms in the sector or furniture industry

Other firms outside the sector or furniture industry

Immigration

Other (specify) 
Semi- and un-skilled production workers

Secondary education (high school)

College/university

Other firms in the sector or furniture industry

Other firms outside the sector or furniture industry

Immigration

Other (specify)

4: Please rate the most important criteria used in your decisions to hire SKILLED production workers.

Degree of importance

$$
\text { Low Hedium Hot relevant }
$$

Strong work ethic and positive attitude

Ability to work with others

Problem solving skills

Ability to comprehend and follow instructions

Technical skills (i.e. computer literacy)

Other (please specify

5: Please rate the most important criteria used in your decision to hire SEMI- and UN-SKILLED production workers.

Degree of importance
Low
Medium
High
Not relevant

Strong work ethic and positive attitude

Ability to work with others

Problem solving skills

Ability to comprehend and follow instructions

Technical skills (i.e. computer literacy)

Other (please specify

6: Please rate the following METHODS OF RECRUITMENT for your SKILLED production workers.

Degree of importance
Low $\quad$ Medium High Not relevant

Word of mouth

Walk-ins off street

Advertising

Use of public/private sector agencies

Headhunters

Raiding/poaching workers from other firms

Collaboration/sharing employees with other firms 
Other (please specify)

7: Please rate the following METHODS OF RECRUITMENT for your SEMI- and UN-SKILLED production workers

\section{Degree of importance}

Low Medium High Not relevant

Walk-ins off street

Advertising

Use of public/private sector agencies

Collaboration/sharing employees with other firms

Other (please specify)

8: Has your firm gone outside of the country to hire expertise in certain areas? Yes No

9: If yes, for what skills?

10: Why? (Check all that apply)

_ Absence of suitable postsecondary (i.e. university) education program in Canada

Absence of suitable specialized technical (i.e. vocational) training program in

Canada

Difficult to provide on-the-job training for these skills

Absence of qualified individuals in the labour market

Other (Please specify)

11: Does your firm offer any programs or incentives for employees to take additional training?

Yes $\quad$ No

12: If No, why not? Please check all that apply:

Too costly

Investment in labour force training not deemed important for competitive strategy

Fear that skilled workers will be poached/raided by competitive firms

Other (Specify)

13: If Yes, which of the following does your firm use? Please check all that apply.

\begin{tabular}{|l|l|l|l|l|}
\cline { 2 - 5 } & $\begin{array}{c}\text { on-the-job } \\
\text { training, in- } \\
\text { house }\end{array}$ & $\begin{array}{c}\text { classroom } \\
\text { education in- } \\
\text { house }\end{array}$ & $\begin{array}{c}\text { online } \\
\text { training }\end{array}$ & $\begin{array}{c}\text { education/training } \\
\text { off-site }\end{array}$ \\
\cline { 2 - 5 } & & & & \\
$\begin{array}{l}\text { Supervisory and skilled } \\
\text { production workers }\end{array}$ & & & & \\
\cline { 2 - 5 } $\begin{array}{l}\text { Semi- and un-skilled } \\
\text { production workers }\end{array}$ & & & & \\
\hline
\end{tabular}

Other (Please specify) 
14: What is the average total number of training hours per year per employee for each of the following job categories?

\begin{tabular}{|c|c|}
\cline { 2 - 2 } & $\begin{array}{c}\text { Average number of } \\
\text { annual training hours per } \\
\text { year per employee }\end{array}$ \\
\cline { 2 - 2 } Skilled production workers & \\
\cline { 2 - 2 } $\begin{array}{c}\text { Semi- and un-skilled } \\
\text { production workers }\end{array}$ & \\
\hline
\end{tabular}

15: Please rate the importance of the following factors and incentives for attracting and retaining workers to your firm.

Competitive salaries/wages

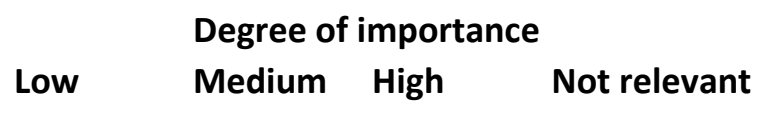

Benefits (i.e. paid leave, pension etc.)

Performance-based pay (i.e. bonuses, profit-sharing, stock options/ownership)

Strong corporate brand

Positive public image

Opportunities for career advancement and growth in company

Investment in skills and training

Investment in culture of motivation (i.e. programs to recognize employees etc.)

Positive working conditions

Cooperative management-labour relations

16: How difficult is it to attract and retain suitable employees for the following job categories?

Skilled production workers

Semi- and un-skilled production

\begin{tabular}{|c|c|c|c|c|c|c|c|}
\hline \multicolumn{4}{|c|}{ Attracting } & \multicolumn{4}{|c|}{ Retaining } \\
\hline $\begin{array}{c}\text { Extremely } \\
\text { difficult }\end{array}$ & Difficult & $\begin{array}{c}\text { Somewhat } \\
\text { difficult }\end{array}$ & $\begin{array}{c}\text { Not at } \\
\text { all }\end{array}$ & $\begin{array}{l}\text { Extremely } \\
\text { difficult }\end{array}$ & Difficult & $\begin{array}{c}\text { Somewhat } \\
\text { difficult }\end{array}$ & $\begin{array}{l}\text { Not at } \\
\text { all }\end{array}$ \\
\hline & & & & & & & \\
\hline & & & & & & & \\
\hline & & & & & & & \\
\hline
\end{tabular}


17: During the last 3 years (2007-2009), how would you describe the rate of turnover in your workforce relative to (a) - other firms in the same industry in Canada and (b) employers in other manufacturing sectors?

Skilled production workers

Semi- and un-skilled production workers

\begin{tabular}{|c|c|c|c|c|c|c|c|}
\hline \multicolumn{2}{|c|}{ Other firms in the same industry in Canada } & \multicolumn{4}{|c|}{ Employers in other manufacturing sectors } \\
\hline lower & equal to & higher & $\begin{array}{c}\text { don't } \\
\text { know }\end{array}$ & lower & equal to & higher & $\begin{array}{c}\text { don't } \\
\text { know }\end{array}$ \\
\hline & & & & & & & \\
\hline & & & & & & & \\
\hline
\end{tabular}

18: If your rate of workforce turnover was above-average for your industry during the last 3 years (20072009), what were the most important reasons for this? Please check all that apply:

_ Lower wage rates relative to other employers

_ Benefits

_ Working conditions

_ Other (Specify)

_ Not relevant

19: Have you lost any of your workforce to other firms during the last 3 years (2007-2009)?

Yes No

20: If yes, how many?

\section{VI: DOWNTURNS}

1: When your firm encounters downturns in business, how does it manage its labour force: Please check all that apply.

_ Cut overtime

Encourage voluntary leave

_ Lay-off workers

Cut wage rates

Increase worker productivity

Short work week/shorter shifts

Share core workers/collaborate with other firms

Long-term reallocation of core skilled workers (i.e. craftsmen) to new tasks

Government work share programs

Other (Please specify: 


\section{VII: DESIGN PRACTICES}

These questions are intended to gather information on design activity in your firm, if there is such activity.

Design activities may include creative problem solving techniques in the development, engineering, testing and/or communication of designs for products, structures, and/or systems.

1: Do you carry out design activities in your firm or plant (whichever is applicable)?

Yes No

2: If so, what percentage of your firm's total expenditures (dollar value) in 2009, were on design activities?

Please provide your best estimate.

\% $\%$

3: What proportion of these expenditures was in-house? $\%$

4: What proportion of these expenditures was for externally acquired design services? $\%$

\section{VIII: CONCLUSION AND BACKGROUND INFORMATION}

The following section asks questions about your firm, your job type and you. All answers are for statistical purposes only and are completely confidential.

1. Please indicate if I can contact you for a follow-up:

Yes

No

2. Do you have any comments or suggestions that you would like to share?

3. What is your name and contact information? This is important so we

know who to contact should we have questions about this survey.

\section{VII: CONTEST TO WIN RELAIS \& CHATEAU GIFT CERTIFICATE}

THANK YOU FOR YOUR TIME. THE SURVEY IS NOW COMPLETE.

>If you would like to be entered into the contest to win a Relais \& Chateau gift certificate (valued at \$200), please click "Contest" below.

>If you would ALSO like to receive a summary of the results of the study, please click "Contest AND Results".

>If you only want the results of the study, please click "Results only."

>If you are NOT interested in being entered into the draw or receiving a summary of the results of this study, choose "No, Thanks" and you will be directed to the final page of the survey containing contact information for the researcher.

- Contest

- Contest AND Results

- Results only

- No thanks. Just take me to the last page of the survey.

*Please enter your name, email address and phone number. Winners will be randomly selected and notified by email. The contest deadline is July 1 st, 2010.

YES -I want to be sent results of the study

*To be sent a short summary of the results of this study, please enter your contact information below.

Results will be sent out in the late summer of 2010.

Please enter your name, email address and phone number below.

Thank you for your time. 
If you have any questions about this study, or would like additional information, please use the contact information

below:

Carolyn Hatch, Ph.D. candidate

Department of Geography and Planning

University of Toronto Cultural Economy Lab

Rm 6027A, Sidney Smith Hall

100 St. George Street, Toronto, ON., M5S 3G3

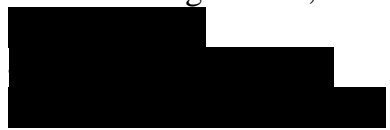

You can also contact my supervisor Professor Meric S. Gertler at the address below.

Meric S. Gertler

Dean, Faculty of Arts and Science

2005 Sidney Smith Hall,

100 St. George Street, Toronto, ON, M5S 3G3

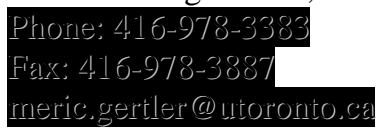

Should you have any questions about this research project or your rights as a research participant, you may also contact

the Office of Research Ethics:

Director, Office of Research Ethics

University of Toronto

McMurrich Building, 3rd floor

12 Queen's Park Crescent West

Toronto, ON M5S 1S8

Phone: 416-946-3273

Fax: 416-946-5763

ethics.review@utoronto.ca 


\section{Appendix V: Interview Letter of Introduction}

Dear --,

My name is Carolyn Hatch and I am a PhD candidate in the Department of Geography and Planning at the University of Toronto. I am currently conducting a study for my dissertation on the contract furniture manufacturing sector in Canada and am contacting you to request your participation in an interview. This research is part of an overarching project that examines the strategies and practices of quality- and design-led manufacturing firms in Canada, and the factors and processes that shape and constrain competitiveness. This study is supported by the Social Sciences and Humanities Research Council of Canada (SSHRC) and the University of Toronto. Within this project, I am examining the dynamics of innovative capacity and economic performance in Canadian firms and seek to gain insights on manufacturing competitiveness that will inform targeted policies.

For this reason, I would greatly appreciate the opportunity to learn about your insights on the most important factors that contribute to (or inhibit) the growth and innovativeness of ---, particularly those that relate to some of the important manufacturing processes and practices in place.

Your opinions and experiences would provide valuable insight for this research and I would be grateful to have the opportunity to discuss the above themes with you. I expect the interview would take about 45 minutes of your time, and it is completely confidential. Please let me know if you would be willing to participate and what your availability is like in the next two weeks. I can meet at your office or any location in the city, at your convenience.

Sincerely,

Carolyn Hatch, PhD candidate

Department of Geography and Planning, University of Toronto 


\section{Appendix VI: Interview Consent Form}

\section{Understanding globally competitive manufacturing strategies in Canada: a case study in furniture design and production}

This research investigates the strategies and practices of globally competitive manufacturing firms, and the factors and processes that shape and constrain competitiveness. It is widely acknowledged by scholars and policy makers alike that in the present knowledge-based economy, high quality, design-led strategies are increasingly integral to the competitiveness of manufacturing firms in high-wage countries such as Canada. I examine these questions in depth by drawing on a case study of the Canadian contract furniture manufacturing sector to investigate in particular how firms make use of quality and designintensity, and how they organize work and deploy labour in the pursuit of their competitive goals.

Your experiences and insights are very valuable for this research. While there may be no immediate benefit to you for participating, the principal goal of this study is to broaden and enrich our understanding of manufacturing competitiveness in advanced nations such as Canada in the knowledgebased economy. Specifically, this research examines the dynamics of economic performance and innovative capacity in Canadian manufacturing establishments, and seeks to gain insights that can inform targeted policies.

The interview will, with your permission, be recorded with a digital voice recorder, and typically lasts 45 minutes. Participation is voluntary and all responses are confidential. You may stop at any time and can choose not to answer any questions. At no time will anybody but the researcher have access to your responses. I also assure that neither your name nor the details of your organization will be revealed in any presentations or publications that result from this research, without your express written permission to do so.

If you have any questions or would like to speak to someone aware of but not directly involved with the study, you may contact the University of Toronto Ethics Review Office at ethics.review@ utoronto.ca or (416) 978 3273. You may also contact my faculty supervisor Prof. Meric S. Gertler at the University of Toronto If you would be interested in receiving a copy of the research results or if you have any questions regarding the study and your participation in it, please do not hesitate to contact me.

Carolyn Hatch, $\mathrm{PhD}$ candidate

Department of Geography and Planning, University of Toronto

100 St. George Street, Room 5047, Toronto, Ontario, Canada, M5S 3G3

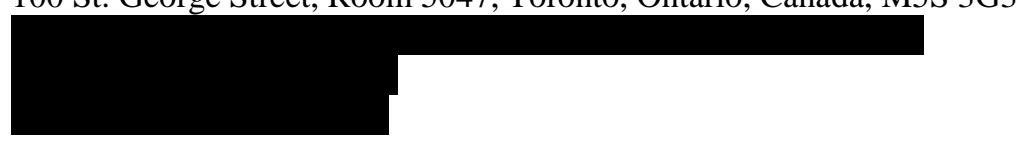

I agree to participate in the study as outlined above. My participation in this study is voluntary and I understand that I may withdraw at any time.

(Name/Title/Organization PLEASE PRINT CLEARLY)

May we contact you in future to seek your permission to identify you and/or your organization by name in any presentations or papers resulting from this research? Yes $\square$ No

Participant's Signature

Date

Researcher

Date 


\section{Appendix VII: Interview Guide (Generic Senior Manager / Designer)}

Interviewee Name and Position:

Firm Name:

Date and Time:

Location:

Personal background and career history

- Where were you born?

○ If outside the city/locality/region, when did you first move here?

○ How would you describe your ethnic identity?

- Educational history and credentials

- Employment history

- Have you ever been trained or worked in manufacturing operations outside Canada?

- What is your job? Who do you work with, where do you work, what are your primary responsibilities?

Background, Culture, Market

Are you familiar with the events that stimulated the founding of ? Who

were the individuals and/or organizations inside and outside this company that played a key role in its development?

- What are your primary products and services?

- How would you describe 's core strengths and competencies?

- How would you describe the corporate culture?

- Why are you located here? What are the advantages/disadvantages?

- How do you define the market you serve? Has it changed?

Design and production practices

I'm trying to get a sense of the way in which design work is organized for this sector: Can you talk about the practices?

- Do you employ designers? If so, do you have an in-house design team, do you employ freelance designers, or do you have a combination of the two? Why or why not?

- Do you use local design talent, international, or both? Why or why not?

- Do you employ advanced business practices in:

(a) Product design and development process: i.e. $x$-functional design teams, concurrent design/ stagegate process? Virtual product development? Rapid prototyping? E-based (online) design/engineering?

(b) Manufacturing process: continuous improvement, JIT/lean manufacturing? ISO certified?

- If not, how would you describe your product design and development process?

- IF APPLICABLE: Who is involved? Is it a project/temporary process? Who are the members of the project team? Who coordinates this process? How long do teams stay together?

- How important to your innovation activities is design/ engineering/manufacturing expertise? To what extent are these skills in-house or to you outsource? 
- How important to your innovation activities is the use of technology, machinery, and automation on the shop floor? Why? What kind of advanced machinery and technology do you employ?

\section{HR Practices}

- Does the labour force in your locality or region possess any distinct or unique sets of skills, knowledge or capabilities that are an asset to your company?

- How is shop floor work organized? (i.e. cellular manufacturing?)

- To what degree is the division of production labour categorized as high versus semi-skilled?

- How difficult is it to ATTRACT and RETAIN semi-skilled and skilled production workers?

- What challenges, if any, do you currently face with respect to the attraction and retention of your shop floor workers, (supervisory, skilled, semi-skilled)?

- Are your production workers unionized?

- Do you provide training or financial support for the development of your production workers? If so, what form does this training take (i.e. how long?) For which occupations?

- IF APPLICABLE: To what degree do in-house training and job rotation schemes promote continuous skills formation and systematic career progression for your shop floor workforce?

- Are there opportunities for advancement for your production workers?

- What is the role of education and training institutions? (local/non local)

- To what extent are workers encouraged to (or have the opportunity to) share their knowledge of improvements in product and process? What are some examples that you can think of?

$\circ$ Who are the important people/occupations? (i.e. team leaders/lead hands, supervisors, managers, shop floor)

\section{Competitors, Suppliers and Customers/ Users}

- To what extent are you aware of what your competitors are doing? Is it important for you to be located close to them, and why?

- Where are your most important suppliers located - locally and non-locally?

$\circ$ How important is it for you to be located close to them, and why?

- How would you describe the relationship you have with your suppliers?

$\circ \quad$ What is the duration and nature of this relationship? (i.e. co-schedule)

- Where are your most important customers located - locally and non-locally? How important is it for you to be located close to them, and why?

- Is the end user an important source of knowledge for your innovation? If so, how do you tap into this?

- Who are the important players here?

\section{$\underline{\text { Associative Interaction }}$}

- Do you or the company belong to (membership with) any associations at the local, provincial, national level (i.e. Bifma, CME)? If yes, which are the most valuable and why? If no, why not?

\section{Factors of competitiveness}

- What are the most important factors that have enabled to emerge and thrive in a high quality, design-intensive competitive niche since NA trade liberalization during the 1980s?

- What are the most important factors, locally and non-locally, that inhibit the growth and innovativeness of 
Future

- What are the key trends (challenges or opportunities) that will most influence the growth of __ in the next five years (as we enter a new phase of intensified globalization)?

- What are the most important challenges or obstacles facing the company?

- What factors, external supports or policies would be most helpful to growing your company?

- Is there anything else that you feel is important to discuss? 


\section{Appendix VIII: Interview Guide (Contract Designer)}

Interviewee Name and Position:

Firm Name:

Date and Time:

Location:

Personal, educational background and career history

- Where were you born? If outside the city, when did you first move here? Why?

- How would you describe your ethnic identity?

- Do you mind disclosing your age and family status?

- Describe your educational background (institution, geographic location, specialization)

- Have you completed any additional training? (i.e. workshops, courses).

- How did you become interested in design?

- Describe your previous work experience (employer(s), location, length of time, major roles and responsibilities, nature of work)

- In the cases where there was a succession of jobs, why? Were such changes voluntary or not?

- To what extent have you moved between different disciplinary boundaries, kinds of occupations, firms, sectors, industries, places?

- Describe your current employment situation

- Why have you chosen to work in this manufacturing sector?

- What motivates you in your work? What do you strive for?

Organization of design work/geography of design activity in this sector

The purpose of this section is to understand how design work is organized for this sector

- How is design work organized in this sector?

- Who do you work with? Are they similar to you or do they have different skills and areas of expertise? (production, engineering, in-house design, management, product development, suppliers, customers, competitors)

- Where do you work? (At the firm? At home? Local? travel?)

- Where do the people you work with work?

- Who else do you need to interact with outside your immediate workgroup?

- Do you participate in team-based or project-based work for this sector? What is the composition of the team (other firm members, clients, occupational mix)?

- What are the advantages/disadvantages of working like this for this sector? How long do these projects last/teams stay together? Do you often work with the same people again?

- Who coordinates this process? Where are team members located (geography)? How important is face-to-fact contact?

- What kind of interaction do you have with project team members?

- How is knowledge created and shared between these communities or individuals?

- Do you have knowledge of engineering and manufacturing criteria when you design?

- To what extent do you incorporate these criteria into the design process?

- What is your role in tapping into end user knowledge for this sector, if any?

- How important is design expertise to driving innovation in this sector? 
Practice, skills, knowledge and innovation

- To what extent have you applied knowledge gained from working in other jobs/occupations /industries/places to your work in this manufacturing sector?

- Can you identify and describe instances where you have taken a process/design/idea from one project/job and applied it in a different context within this sector?

- Have the things that you have learned in the sector been helpful in approaching other project/jobs? How easy is it to recombine old project/job ideas into new work?

- Where do you find inspirations for new designs/ideas? How do you implement these?

- What are the barriers to your own ability to be creative in this sector? What limits are placed on the design process?

- What are the factors that enhance your own ability to be creative?

- What are your most important sources of information, knowledge, ideas, creativity (local and non-local)?

- How do you maintain your skill levels and learn about new tools/practices?

Future

- What are your future career plans/aspirations? What would you like to e doing and where?

- What strategies are you undertaking in pursuit of these goals? Challenges? 


\section{Appendix IX: Interview Guide (Production)}

Name:

Position:

Number years at company:

Where were you born? If outside the city/region, when did you come here?

How would you describe your ethnic identity?

What is your family status?

Describe your educational background

(Have you completed an apprenticeship?)

Describe your employment history

(In the case of succession of jobs, why? Was this voluntary?)

Have you moved around at ---?

How did you become interested in this field? Why did you take this job? Do you like the job?

How did you find this employment? Are there challenges to finding work in this field? If so, what are they?

What is your job? What are your daily tasks, roles and responsibilities?

How did you get the training to do your job?

Have you trained on the job? Have you learned on the job? If so, what?

How many supervisors and/or managers do you report to? Who coordinates the work you do?

How would you describe your job in terms of: diversity, variety and complexity of tasks and responsibilities? Would you describe your job as diverse (on one hand), repetitive (on the other) or somewhere in between?

Would you say that you have a certain amount of flexibility and autonomy in your job, or not?

Would you describe management/employee relations as cooperative (on the one hand),

adversarial (on the other) or somewhere in between?

To what extent do you 'have a say' in what gets done or the ways things get done, in your job and other areas of the shop floor related to your area of expertise? To what extent do you play a role in strategic decision making in the organization?

Is teamwork and collaborative relations with your coworkers an important element in your job, or not?

Have you ever been poached by another firm, or has anyone you know been poached? Does it happen in the industry?

What are your future career plans?

Can I contact you for a follow-up if necessary?

Email address:

Phone number: 